RECOVERY OF STRAWBERRY AROMA COMPOUNDS BY

PERVAPORATION

\author{
A THESIS SUBMITTED TO \\ THE GRADUATE SCHOOL OF NATURAL AND APPLIED SCIENCES \\ $\mathrm{OF}$ \\ MIDDLE EAST TECHNICAL UNIVERSITY
}

BY

\begin{abstract}
ASLI İŞÇİ
IN PARTIAL FULFILLMENT OF THE REQUIREMENTS

FOR

THE DEGREE OF MASTER OF SCIENCE

IN

FOOD ENGINEERING
\end{abstract}

JUNE 2004 
Approval of the Graduate School of Natural and Applied Sciences

Prof. Dr. Canan Özgen

Director

I certify that this thesis satisfies all the requirements as a thesis for the degree of Master of Science.

Prof Dr. Levent Bayındırlı

Head of Department

This is to certify that we have read this thesis and that in our opinion it is fully adequate, in scope and quality, as a thesis for the degree of Master of Science.

Assoc. Prof. Dr. Gülüm Şumnu Co-Supervisor

Examining Committee Members
Assoc. Prof. Dr. Serpil Şahin

Supervisor
Prof. Dr. Levent Yilmaz

Assoc. Prof. Dr. Serpil Şahin

Assoc. Prof. Dr. Gülüm Şumnu (METU, FDE)

Assoc. Prof. Dr. Esra Yener

(METU, FDE)

Assoc. Prof. Dr. Nihal Aydoğan (HU, CHE) 
I hereby declare that all information in this document has been obtained and presented in accordance with academic rules and ethical conduct. I also declare that, as required by these rules and conduct, I have fully cited and referenced all material and results that are not original to this work.

ASLI İŞÇİ

iii 


\title{
ABSTRACT \\ RECOVERY OF STRAWBERRY AROMA COMPOUNDS BY PERVAPORATION
}

\author{
İşçi, Aslı \\ M.Sc., Department of Food Engineering \\ Supervisor: Assoc. Prof. Serpil Şahin \\ Co-Supervisor: Assoc. Prof. S. Gülüm Şumnu
}

June 2004, 99 pages

Pervaporation is a selective membrane technique in which a liquid feed mixture is separated by means of partial vaporization through a non-porous perm-selective membrane. This method can be used for the recovery of heat sensitive aroma compounds to avoid them from thermal damage in beverage industries. 
The main objective of this study was to determine the effects of feed temperature $\left(30,40,50^{\circ} \mathrm{C}\right)$, composition (different model solutions, strawberry essence), concentration $(50,100,150 \mathrm{ppm})$ and permeate pressure $(4,8 \mathrm{mbar})$ on the recovery of aroma compounds of strawberry by pervaporation in terms of mass flux and selectivity.

In addition, it was aimed to optimize the extraction conditions (extraction time, temperature, agitation speed, strawberry matrix) of Solidphase microextraction (SPME), which is used for the analysis of strawberry aroma compounds. Optimum results for SPME were obtained at $40^{\circ} \mathrm{C}, 700 \mathrm{rpm}$ for $30 \mathrm{~min}$ and no matrix effect was observed.

Pervaporation experiments were performed using a hydrophobic membrane, PERVAP 1070 (PDMS). As the feed temperature increased, the mass flux and selectivity increased and the total mass flux followed an Arrhenius type relation. Decreasing downstream pressure increased both total flux and selectivity, while increase in feed concentration led to higher organic fluxes but lower selectivities.

In general, PERVAP 1070 showed a higher selectivity towards Methyl butyrate (MTB) than Ethyl butyrate (ETB) and MTB flux was affected negatively by the presence of ETB in the feed solution. Pervaporation experiments were also performed with a strawberry essence and strawberry model solution. The selectivities of MTB and ETB were negatively affected by the presence of other aroma compounds.

Keywords: Ethyl Butyrate, Methyl Butyrate, Pervaporation, Solid-phase microextraction, Strawberry aroma. 
öz

\title{
ÇILEK AROMASININ PERVAPORASYON YÖNTEMIYLE GERİ KAZANIMI
}

\author{
İşçi, Aslı \\ Yüksek Lisans, Gıda Mühendisliği \\ Tez Yöneticisi: Doç. Dr. Serpil Şahin \\ Yardımcı Tez Yöneticisi: Doç. Dr. S. Gülüm Şumnu
}

Haziran 2004, 99 pages

Pervaporasyon, seçici geçirgen bir membran kullanılarak bir karışımdan istenilen bileşenlerin vakum ile ayrılması işlemidir. Bu teknikle içeceklerdeki, ısıya hassas aroma bileşiklerinin zarar görmeden geri kazanımı sağlanabilmektedir.

Çalışmanın ana amacı, besleme çözeltisi sıcaklığının $\left(30,40,50^{\circ} \mathrm{C}\right)$, çözeltinin komposizyonunun (değişik model çözeltiler, çilek esansı), 
konsantrasyonunun $(50,100,150 \mathrm{ppm})$ ve basıncın $(4,8$ mbar) etkisinin çilek aroma bileşiklerinin pervaporasyon yöntemiyle geri kazanımına etkilerinin akı ve seçicilik açısından incelenmesidir.

Ek olarak bu çalışmada aroma bileşiklerinin analizinde kullanılan katı faz mikroekstraksiyonunun çilek aroması için optimizasyonu da çalışılmıştır. Optimizasyon sırasında, ekstraksiyonu etkileyen en temel üç parametre dikkate alınmıştır. Bunlar ekstraksiyon sıcaklığı, süresi, karıştırma hızı ve çilek matrisidir. Optimum koşul $40^{\circ} \mathrm{C}, 700 \mathrm{rpm}$ 'de 30 dakika olarak bulunmuş ve matris etkisi görülmemiştir.

Pervaporasyon sirasında hidrofobik bir membran olan PERVAP 1070 (PDMS) kullanılmıştır. Besleme çözeltisinin sıcaklığı arttıkça madde akısının ve seçiciliğin de arttığı ve toplam madde akısının Arrhenius tipi bir eğilim gösterdiği gözlenmiştir. Basıncın düşmesi hem toplam akıyı hem de seçiciliği arttırmış, besleme çözeltisi konsantrasyonunun artması ise aroma bileşiklerinin akısını arttırırken seçiciliği azaltmıştır.

Genel olarak, PERVAP 1070 membranının metil bütirata (MTB), etil bütirattan (ETB) daha seçici olduğu bulunmuştur ve MTB akısının, besleme çözeltisine ETB' in eklenmesiyle olumsuz yönde etkilendiği gözlenmiştir. Son olarak pervaporasyon deneyleri çilek esansı ve çilek model çözeltisi ile de yapılmıştır. MTB ve ETB'ın seçicilikleri, diğer aroma bileşiklerinin besleme çözeltisine eklenmesiyle olumsuz yönde etkilenmiştir.

Anahtar Sözcükler: Çilek aroması, Etil Bütirat, Katı-faz mikroekstraksiyon, Metil Bütirat, Pervaporasyon 
Dedicated to my family and to the memory of my beloved mother, Gülay İşçi 


\section{ACKNOWLEDGMENTS}

I would like to express my deepest gratitude to my supervisor Assoc. Prof. Dr. Serpil Şahin for her guidance and encouragement. Her continuous support and solutions in every stage of this study are greatly acknowledged.

I extent my sincere appreciation to my co-supervisor Assoc. Prof. Dr. Gülüm Şumnu for her time, kind advices and useful suggestions.

I wish to express my appreciation to Prof. Dr. Ayhan S. Demir who have kindly permitted the use of GC-MS at The Department of Chemistry and I would also like to thank to Research Assistants Çiğdem İğdir and Ömer Reis for their help during the analysis of strawberry essence by GC-MS.

I would like to thank to my dear friends Firdevs Doğan, Emel Iraz Göksu, Pınar Demirekler, Senem Taşkın, Zeynep Kollu and everyone in our research group for the times we have spent together, and for their valuable support and love.

I extend my warmest thanks to Serap Hanc1 for her moral support, patience, encouragement and practical assistance during my entire study and thanks to Erkan Karacabey and B. Gökçen Mazı for their physical support while carrying liquid nitrogen.

Sincere thanks are extended to my brother Evren İşçi and his wife for their love, concern and encouragement during these years.

My special thanks go to my parents, Nursel \& Osman İşçi, for their love, support and encouragement. I am grateful forever to them for their endless love and patience. They were always with me whenever I needed them. Without them this thesis would not be completed and more than that life would be meaningless. 


\section{TABLE OF CONTENTS}

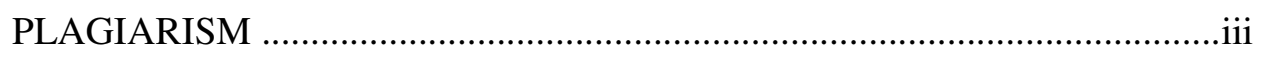

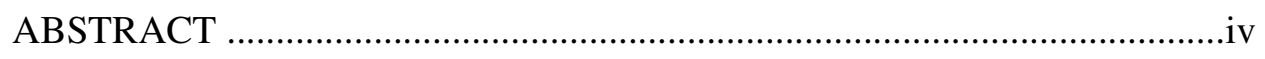

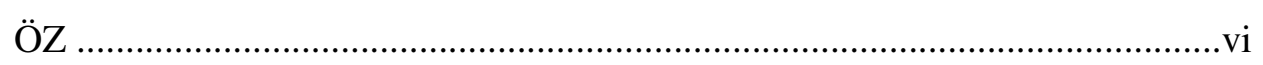

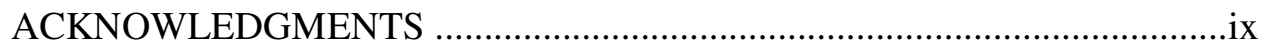

LIST OF TABLES …...............................................................................

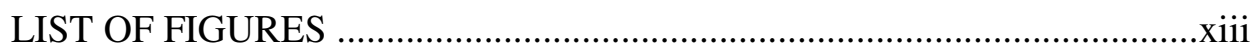

\section{CHAPTER}

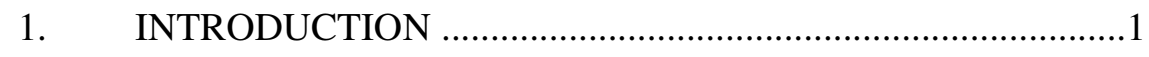

1.1 Strawberry Aroma …......................................................... 1

1.2 Analysis of Aroma Compounds by Solid-phase Micro-

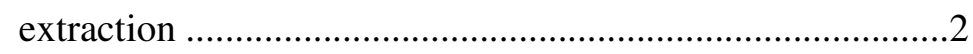

1.3 Recovery of Aroma compounds ...................................... 8

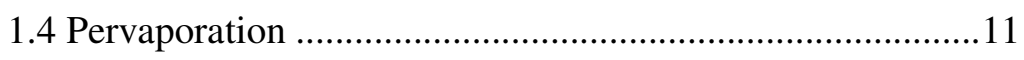

1.5 Types of Membranes ......................................................21

1.6 Applications of Pervaporation in Food Industry ................26

1.7 Objectives of the Study ......................................................30

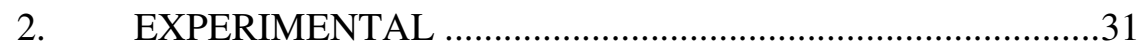

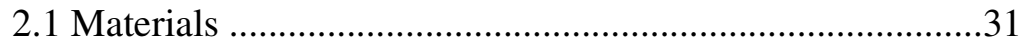

2.2 Optimization of Extraction Conditions of SPME ................34

2.3 Pervaporation Experimental Set-up ....................................35 
2.4 Pervaporation Procedure …............................................40

2.5 Chromatographic Analysis ....................................................42

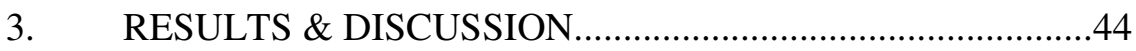

3.1 Optimization of SPME for strawberry aroma ...................44

3.1.1 Effect of Extraction Temperature .......................45

3.1.2 Effect of Agitation Speed ...................................46

3.1.3 Effect of Extraction Time ...................................48

3.1.4 Effect of Strawberry Matrix ................................50

3.2 Pervaporation of Model Strawberry Juice Aroma

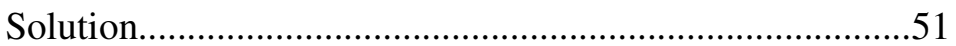

3.2.1 Effect of Feed Temperature and Pressure ...........54

3.2.2 Effect of Feed Concentration in Binary

Mixtures.........................................................62

3.2.3 Pervaporation Performance in MTB-ETB-

Water Ternary Mixture .......................................67

3.2.4 Pervaporation Performance in Strawberry

Essence and Model Strawberry Solution..............69

4. CONCLUSION \& RECOMMENDATIONS ...........................73

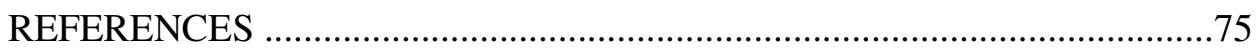

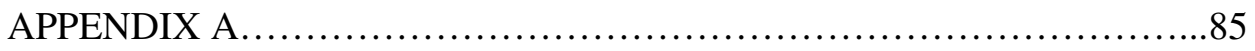

APPENDIX B...................................................... 99 


\section{LIST OF TABLES}

\section{TABLE}

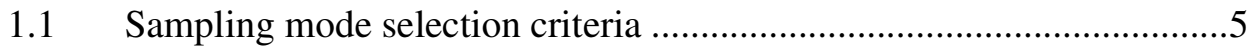

2.1 Physical properties of strawberry aroma compounds .........................32

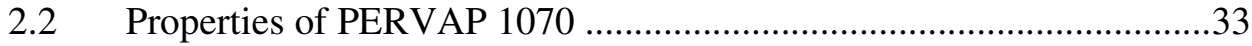

3.1 Average retention times of strawberry aroma compounds ..................45

3.2 Activation energies that are calculated from Arrhenius plots ..............59

3.3 Solubility parameters and diffusivities of some compounds..............67

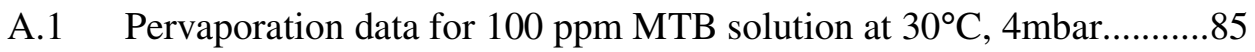

A.2 Pervaporation data for $100 \mathrm{ppm} \mathrm{MTB}$ solution at $30^{\circ} \mathrm{C}, 8 \mathrm{mbar} . \ldots \ldots \ldots . . . .86$

A.3 Pervaporation data for $100 \mathrm{ppm}$ MTB solution at $40^{\circ} \mathrm{C}, 4 \mathrm{mbar}$...........87

A.4 Pervaporation data for $100 \mathrm{ppm}$ MTB solution at $40^{\circ} \mathrm{C}, 8 \mathrm{mbar}$..........88

A.5 Pervaporation data for $100 \mathrm{ppm} \mathrm{MTB}$ solution at $50^{\circ} \mathrm{C}, 4 \mathrm{mbar} . . . . . . . . .89$

A.6 Pervaporation data for $100 \mathrm{ppm}$ MTB solution at $50^{\circ} \mathrm{C}, 8 \mathrm{mbar}$..........90

A.7 Pervaporation data for $50 \mathrm{ppm} \mathrm{MTB}$ solution at $50^{\circ} \mathrm{C}, 4$ mbar............91

A.8 Pervaporation data for $150 \mathrm{ppm}$ MTB solution at $50^{\circ} \mathrm{C}, 4$ mbar..........92

A.9 Pervaporation data for $50 \mathrm{ppm}$ ETB solution at $50^{\circ} \mathrm{C}, 4$ mbar.......... 93

A.10 Pervaporation data for $100 \mathrm{ppm}$ ETB solution at $50^{\circ} \mathrm{C}, 4$ mbar...........94

A.11 Pervaporation data for $150 \mathrm{ppm}$ ETB solution at $50^{\circ} \mathrm{C}, 4$ mbar...........95

A.12 Pervaporation data for $100 \mathrm{ppm}$ MTB and $100 \mathrm{ppm}$ ETB solution at

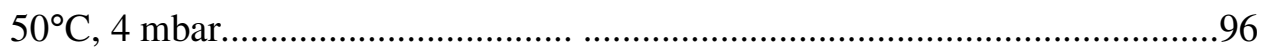

A.13 Pervaporation data for strawberry essence at $50^{\circ} \mathrm{C}, 4$ mbar.................97

A.14 Pervaporation data for strawberry model strawberry solution at $50^{\circ} \mathrm{C}, 4$

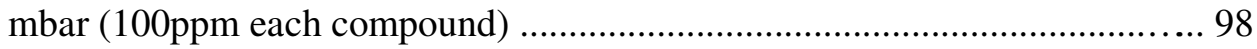




\section{LIST OF FIGURES}

\section{FIGURE}

1.1 Design of the first commercial SPME device made by Supelco..............3

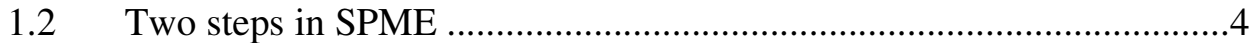

1.3 The principle of solute transport across the membrane in

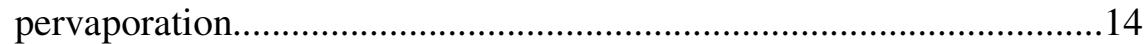

1.4 The ideal profile of the concentration and chemical potential of a solute $\mathrm{i}$ in the membrane polymer .............................................................16

1.5 Areas of pervaporation: membranes and applications.........................24

1.6 Cross-section of a composite membrane.........................................25

2.1 Schematic diagram of pervaporation experimental set-up...................37

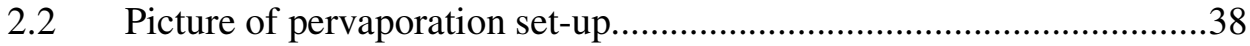

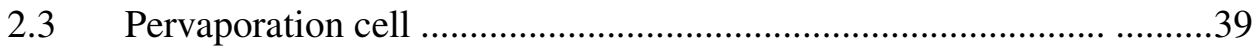

$2.4 \quad$ Schematic diagram of pervaporation cell ..........................................40

3.1 Effect of extraction temperature on peak areas of aroma compounds at $700 \mathrm{rpm}$ for 30 minutes extraction....................................................46

3.2 Effect of agitation speed on peak areas of aroma compounds at $40^{\circ} \mathrm{C}$

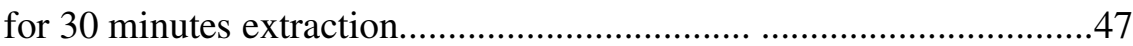

3.3 Effect of extraction time on peak areas of aroma compounds at $40^{\circ} \mathrm{C}$ and $700 \mathrm{rpm}$ 49

3.4 Matrix effect on peak areas of aroma compounds at $40^{\circ} \mathrm{C}$ and $700 \mathrm{rpm}$ for 30 minutes extraction.

3.5 Change of total mass flux with time for 100ppm Methyl Butyrate solution at $50{ }^{\circ} \mathrm{C}, 8$ mbar .53 
3.6 Change of selectivity with time for 100ppm Methyl Butyrate solution at $50^{\circ} \mathrm{C}, 8 \mathrm{mbar}$

3.7 Effect of feed temperature on total mass flux at different downstream pressures for 100 ppm Methyl Butyrate solution.

3.8 Effect of feed temperature on Methyl Butyrate flux at different downstream pressures for $100 \mathrm{ppm}$ Methyl Butyrate solution .56

3.9 Effect of feed temperature on water flux at different downstream pressures for 100 ppm Methyl Butyrate.

3.10 Arrhenius type relation on total mass flux....

3.11 Effect of feed temperature on selectivity of 100 ppm Methyl Butyrate solution at different downstream pressures.........................................61

3.12 Effect of feed concentration on total mass flux at $50^{\circ} \mathrm{C}, 4$ mbar. 62

3.13 Effect of feed concentration on organic mass fluxes at $50^{\circ} \mathrm{C}, 4$ mbar..63

3.14 Effect of feed concentration on water fluxes of binary solutions at $50^{\circ} \mathrm{C}, 4$ mbar. .64

3.15 Effect of feed concentration on selectivities of binary solutions at $50^{\circ} \mathrm{C}$, 4 mbar. .65

3.16 Comparison of enrichment factors in binary and ternary systems at 50 ${ }^{\circ} \mathrm{C}, 4$ mbar. .68

3.17 Comparison of partial organic fluxes in binary and ternary solutions at $50^{\circ} \mathrm{C}, 4$ mbar. .69

3.18 Enrichment factors of organic compounds for strawberry essence at $50^{\circ} \mathrm{C}, 4$ mbar. .70

3.19 Enrichment factors of organic compounds for model strawberry solution at $50^{\circ} \mathrm{C}, 4$ mbar.

B.1 Chromatogram of strawberry aroma compounds .99 


\section{CHAPTER 1}

\section{INTRODUCTION}

\subsection{Strawberry Aroma}

Flavor or aroma is described as the sensation produced by a material taken in the mouth, perceived principally by the senses of taste and smell and also by the general pain, tactile and temperature receptors in the mouth (Hall, 1968). Flavor also denotes the sum of the characteristics of the material, which

produce that sensation. Aroma compounds can be classified as volatile organic compounds such as; aldehydes, alcohols, ketons, esters, lactones and terpenes. They are typically present in ppm levels in natural sources. Due to their dissimilar molecular characteristics and concentrations, every single aroma compound has different contributions on the final aroma of a fruit.

Strawberry belongs to genus Fragaria (family Rosaceae) and it has one of the most complicated fruit flavors. The typical aroma of strawberries comes from not just one or a few impact aroma compounds but from numerous volatiles present at certain concentrations and in a particular balance among them. Thus, strawberry aroma is the result of the combined perception of many aromatic notes, such as caramel, jam, floral, fruity, buttery, sour and grassy (Schieberle and Hofmann, 1997). Although approximately 360 compounds have been identified in the aroma of strawberries only 15-25 volatiles (methyl and ethyl esters, furanones, C6 aldehydes and other C6 derivative compounds, 
diacetyl, acetic acid and other aliphatic acids, linalool, g-dodecalactone, benzaldehyde and some sulfur compounds) appear to be the most important contributors to strawberry aroma (Zabetakis and Holden, 1997). Methyl esters give a floral and sweet-apricot fruit flavor, ethyl esters give sour-cheese and banana flavor. C6 aldehydes and linalool contributes to foliage, grass-fruit, unripe fruit aroma and rose, floral, lemon-wooded aroma, respectively.

\subsection{Analysis of Aroma Compounds by Solid-phase Microextraction}

There are several analytical methods for the extraction and determination of flavor compounds, such as headspace techniques (Macku and Jennings, 1987), purge and trap (Miszczak et al., 1995), liquid-liquid extraction (Kok et al., 1987) and simultaneous distillation and extraction (Blanch et al., 1991). Each sample preparation method is subject to its drawbacks. The disadvantages of these methods are; high cost, excessive time consumption and requirement of a solvent.

Among the newest technologies to extract aroma compounds, solidphase microextraction (SPME), which was introduced by Pawliszyn in 1990 (Pawliszyn, 1997), has received the greatest attention. As can be seen in Figure 1.1, SPME device is a sort of needle that is mainly composed of a plunger, barrel, an adjustable needle guide and coated fused silica fiber. SPME is an inexpensive, rapid, simple and solvent-free extraction method for the isolation of organic compounds from gaseous and liquid samples (Louch et al., 1992). SPME process has two steps: partitioning of analytes between the coating and the sample matrix, followed by desorption of concentrated extracts into an analytical instrument. In the first step, the coated fiber is exposed to the sample or its headspace, which causes the analytes to partition from the sample matrix 
into the coating. The fiber bearing concentrated analytes is then transferred to an instrument for desorption, where upon separation and quantitation of extracts can take place. Figure 1.2 illustrates an SPME laboratory setup for direct extraction and GC analysis (Pawliszyn, 1997).

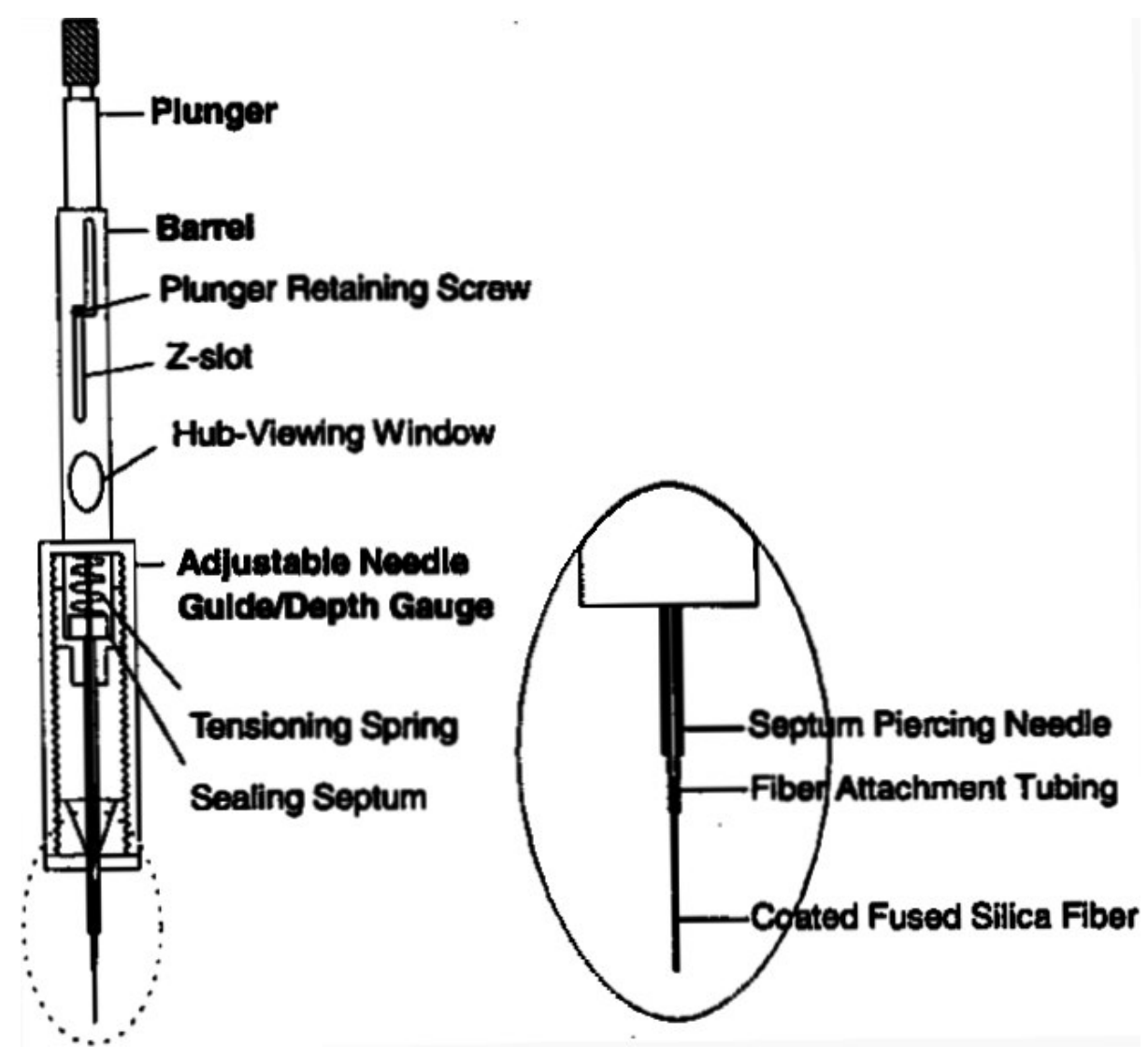

Figure 1.1 Design of the first commercial SPME device made by Supelco (Pawliszyn, 1997). 


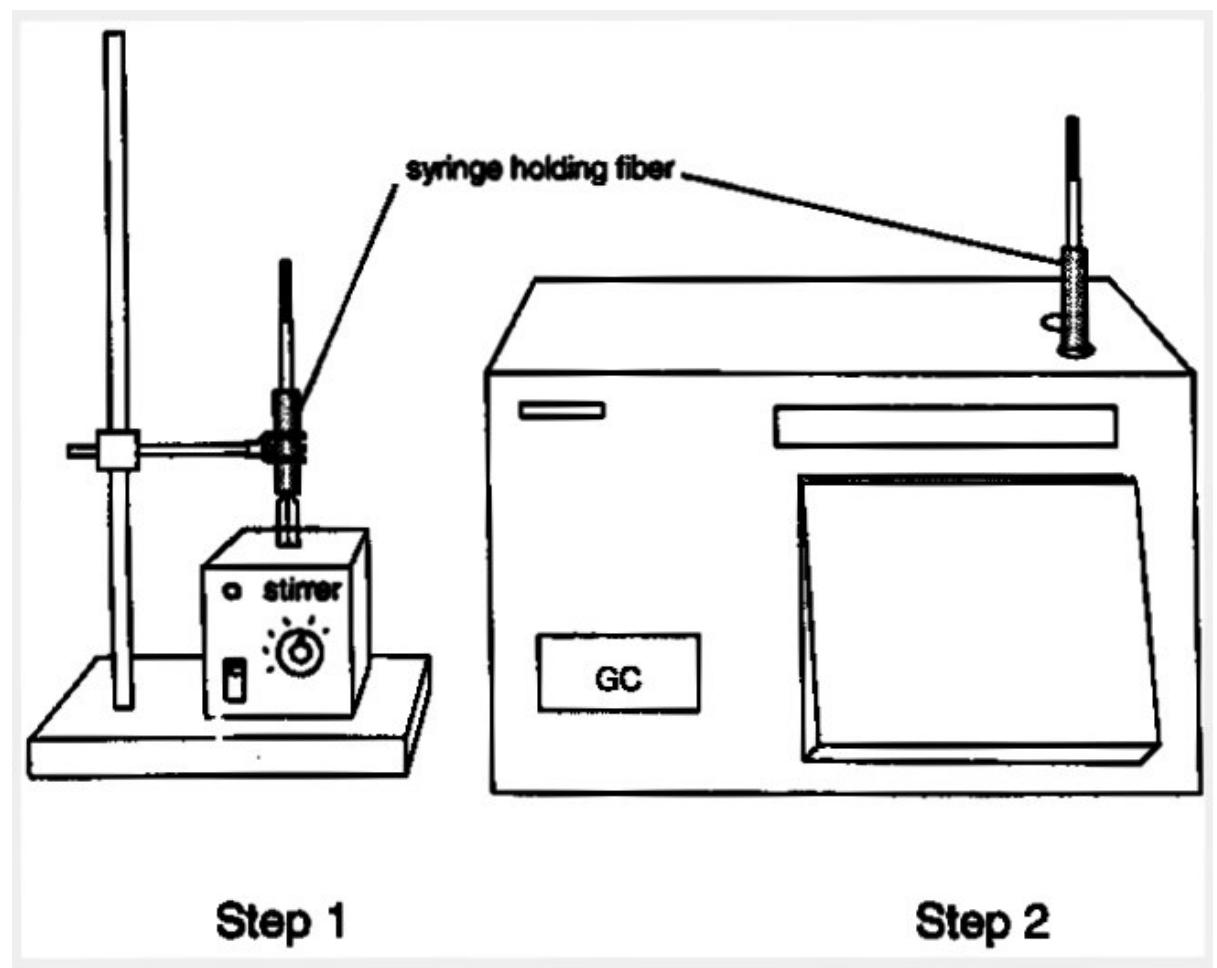

Figure 1.2 Two steps in SPME (1) equilibration of the analyte between the fiber coating and a sample matrix; (2) transfer of the fiber to an analytical instrument (Pawliszyn, 1997).

There are several factors, that must be considered during extraction, affecting the equilibrium of analytes between the sample and fiber such as, extraction mode (headspace and direct immersion or liquid SPME), type of fiber coating, the extraction temperature and time, the ratio of liquid to headspace volume in the case of headspace sampling, stirring type and intensity, the presence of salt, $\mathrm{pH}$ of the sample solution and composition of the aqueous matrix. 
Extraction mode selection is made by considering the sample matrix, analyte volatility and its affinity to the matrix (Table 1.1). For the samples that contain substances, which can cause damage to fiber, the headspace mode should be selected. For clean samples direct sampling can be considered. Moreover, headspace mode is also a good choice for volatile compounds due to faster equilibration times. Headspace SPME can generally be applied for analytes of medium to high volatility.

Table 1.1 Sampling Mode Selection Criteria (Pawliszyn, 1997).

\begin{tabular}{ccc}
\hline Sampling Mode & Analyte Properties & Matrices \\
\hline Direct & medium to low volatility & gaseous samples, liquid \\
& (preferably simple) \\
headspace & volatility & liquid (including complex), \\
& solids \\
\hline
\end{tabular}

There are several coating types commercially available in different thicknesses for different purposes. Typically the chemical nature of the analytes determines the type of coating used. A simple general selection rule, "similar extracts similar" applies here. In general, the selectivity which can be obtained is based on polarity and volatility (molecular weight) differences among molecules.

Poly (dimethyl siloxane) (PDMS) fibers are the most useful ones. PDMS coatings are very rugged liquid coatings which have high thermal resistance, up to about $300{ }^{\circ} \mathrm{C}$. Although PDMS is a nonpolar phase and it 
extracts nonpolar analytes very well, it may also be used for the extraction of more polar compounds, after optimization of extraction conditions.

Poly (acrylate) (PA) phase, on the other hand, is suitable for more polar compounds such as phenols. It is a low density solid polymer at room temperature, which allows analytes to diffuse into the coating, but the diffusion coefficients are lower as compared to PDMS, resulting in longer extraction times for volatile analytes in the headspace.

Mixed phase coatings have complementary properties compared to PDMS and PA. Mixed phase coatings such as Poly (dimethyl siloxane) / poly/divinylbenzene) (PDMS/DVB), poly (ethylene glycol)/poly (divinylbenzene) (Carbowax/DVB) are more suitable for more volatile species, and the resulting distribution constants are typically higher compared to PDMS (Pawliszyn, 1997).

As can be predicted, temperature has an important effect on the extraction of compounds by SPME, in terms of extraction time. An increase in extraction temperature causes an increase in extraction rate, but simultaneously a decrease in the distribution constant. In general, if the extraction rate is of major concern, the highest temperature which still provides satisfactory sensitivity should be used.

The main idea during SPME experiments is to reach distribution equilibrium in the system. At this condition, the system reaches to steady conditions, and hence a variation of mass transfer does not affect the final results. The equilibration time is defined as the time after which the amount of extracted analyte remains constant and corresponds within experimental error to the amount extracted at infinite extraction time (Pawliszyn, 1997).

The ratio of liquid to headspace volume is also an important parameter during headspace SPME. Very volatile compounds will prefer to accumulate in the headspace, resulting in a very substantial loss in sensitivity when the 
headspace is large. Thus, sample volume should be optimized during extraction.

Generally for most of the liquid samples, agitation is required to facilitate mass transport between the bulk of the aqueous sample and the fiber. Equilibration times of aqueous samples are affected by the effectiveness of the agitation techniques. Magnetic stirring, intrusive stirring, vortex, fiber movement, flow through and sonication are the agitation techniques used for SPME analysis. Among these techniques, magnetic stirring is most commonly used in SPME experiments since it is available in the majority of analytical laboratories and can be conveniently used with SPME sampling modes (Pawliszyn, 1997).

The addition of an inorganic salt is also used in order to enhance the activity coefficients of volatile components in aqueous solutions, by increasing the concentration in the headspace vapor due to salting-out effect. In most cases, an increase in salt concentration results in higher concentration of analytes in the headspace. The following salts can be used for this purpose: $\mathrm{NH}_{4} \mathrm{Cl}, \mathrm{MgCl}_{2}, \mathrm{KCl}, \mathrm{NaCl}, \mathrm{K}_{2} \mathrm{CO}_{3}, \mathrm{Na}_{2} \mathrm{CO}_{3}, \mathrm{NH}_{4} \mathrm{NO}_{3}, \mathrm{KNO}_{3}, \mathrm{NaNO}_{3}$, $\left(\mathrm{NH}_{4}\right)_{2} \mathrm{SO}_{4}, \mathrm{MgSO}_{4}, \mathrm{~K}_{2} \mathrm{SO}_{4}, \mathrm{Na}_{2} \mathrm{SO}_{4}$ (Pawliszyn, 1997).

Since sample $\mathrm{pH}$ influences the dissociation equilibrium in aqueous media, $\mathrm{pH}$ adjustments can improve sensitivity for basic and acidic analytes. Consequently, different sample matrixes may have positive or negative effects on the extracted amounts.

SPME can be used successfully in different areas of science. Some of the areas can be listed as:

- Environment (e.g. determination of pesticides in drinking/ground water)

- Food and Pharmaceuticals (e.g. flavor analysis in food)

- Clinical and Forensic (e.g. analysis of alcohol and drugs in body fluids) 
Applications of SPME in food analysis have been reviewed previously (Kataoka et al., 2000). Although SPME method was found to be suitable for rapid and quantitative analysis of volatile aroma compounds in strawberry (Verheoeven et al., 1997; Song et al., 1998; Holt et al., 2001), optimization of sorption conditions of SPME in analysis of strawberry volatiles is lacking in literature.

\subsection{Recovery of Aroma Compounds}

Processing, especially high temperature treatments can cause considerable physical and/or chemical changes in the aroma compounds of foods. Chemical changes of aroma compounds may occur due to heat-induced oxidation or Maillard reactions and physical losses may occur during evaporation steps. For example, in fruit juice industry, changes in aroma compounds are inevitable, since pasteurization of fruit juice is required in order to increase the shelf life of the product. Moreover, evaporation is the main step for fruit juice concentrates and fruit aroma concentrates are extensively used as ingredients in food industry. As mentioned above, aroma compounds are volatile and removal of water by evaporation also results in losses of aromas. If this loss includes an important aroma compound, the effect will be perceived in the final product. Therefore, aroma can be considered as one of the most important characteristics of food that is directly related to the quality of the product and consumer's acceptance. Hence, to recover and put back these lost aromas in the final product, draws a great attention in order to improve the quality of the final product.

There are several methods for the extraction which minimize chemical changes and physical losses of aroma compounds. These methods can be 
categorized as; vapor-liquid separations based on distillation/evaporation or partial condensation, gas injection based separations, adsorption and supercritical fluid extraction. Each method is subject to its drawbacks, although offering specific advantages under certain circumstances.

In 1944, Milleville and Eskew, working at USDA, presented the first process for aroma recovery and separation of apple aroma (Colombo, 1983). The fundamental principle of separation in distillation and evaporation is based on the fact that a liquid will form equilibrium with the surrounding gas or vapor and those different liquids exhibit differences in this equilibrium. If the aroma recovery occurs at atmospheric pressure, high temperatures are required, and this can cause thermal damage. This application is normally used for products that are not heat sensitive. For products with heat sensitive aroma compounds a reduced pressure is preferred but this reduced pressure also affects the separation efficiency.

The use of partial condensation for aroma recovery has been described by Hasting (1978). The water vapors containing aromas were first partially condensed in order to recover heat but also to increase the fraction of aromas in the vapors. This liquid-vapor system was then fed to the system. One of the disadvantages of this system, a 2 or 3 stage condensations is required to recover aromas, which results in excessive time consumption.

The formation of an aroma rich vapor/gas can also be established by the injection of an inert gas, such as nitrogen or air, into loss stream. This methodology is often used in preparative and analytical chemistry (Poll, 1983) but it can also be used for aroma recovery plants (Bomben et al., 1973). The injection of an inert gas into a liquid with the objective of removing aroma from it, is called gas stripping, and the technique exhibits similarities to evaporation and distillation. This process has been described by Ghodsizadeh (1986) for recovery of aromas from ground coffee. Nitrogen is passed through ground coffee in order to strip the aroma. The resulting aroma rich gas is 
contacted with liquid nitrogen, in order to condense aroma compounds. In practice, it is very difficult to operate condensers at very low temperatures such as $-196^{\circ} \mathrm{C}$, especially if the partial pressures of the aromas in the gas strip are low. In addition to this, since air is used mostly for this kind of systems due to high cost of other inert gases, sensitive aroma compounds can be affected during extraction because of oxidation.

Another process type for the recovery of aromas is adsorption. Adsorption is a process based on the phenomenon that a solid has the ability to bind components from a liquid or gas surrounding it to its surface. Adsorption can be physical or chemical, according to the type of binding. The technique is to feed the process stream, which contains aroma compounds to be recovered, to an adsorption tower filled with a solid that can selectively adsorb the aroma. The use of adsorption for aroma recovery during food processing is not a common process, since a strong solvent is required in order to desorb the aroma compounds afterwards.

An interesting extraction method is supercritical fluid extraction (SFE), in which a component is removed, or separated, from a system by contact with another material or phase having a higher affinity for that particular component. In SFE the solvent, a gas under normal conditions, is converted to supercritical fluid (SF) by increasing the temperature and pressure. Supercritical fluids are characterized by high densities, low viscosities and diffusivities intermediate gases and liquids. These properties make them potentially very good solvents. After the extraction of the aroma compound dissolved in SF can be recovered by decreasing the pressure and/or increasing the temperature. There are many examples where SFE is used for the recovery of aromas (Schultz and Randall, 1970; Bundschuh et al., 1986; Temelli, et al., 1988; Raasch and Knorr, 1990; Palmer and Ting, 1995; Sonsuzer et al., 2004). Although SFE seems a good choice for the extraction of aroma compounds, there is still a limited knowledge of how multi-component systems, such as 
food systems, behave during SFE and this combination with the expense and practical problems associated with the process, pose a problem for technology to reach commercial applications (Palmer and Ting, 1995).

As it can be concluded, the most important disadvantages of conventional separation techniques can be stated as follows:

- the requirement of a solvent or adsorbent, which must be separated from the aroma compounds in a purification/desorption step to avoid contamination of the product,

- deterioration of the aroma due to high temperatures and oxidation,

- high energy and time consumption

- high cost, and

- limited range of applicability.

In order to overcome these limitations of the conventional processes, instead of recovering the aroma compounds from the loss stream, the membrane process pervaporation has been widely considered as an alternative method for aroma recovery. It can be performed on the juice prior to evaporation or pasteurization step and the heat treatment of the sensitive aroma compounds can thus be avoided.

\subsection{Pervaporation}

In 1917, Kober stated in his paper that "a liquid in a collodion (cellulose nitrate) bag, which was suspended in the air, evaporated, although the bag was tightly closed". Kober was not the first researcher to observe this phenomenon that a liquid can evaporate through a tightly closed "membrane", 
but the first to realize its potential for the separation of the liquid mixture. He first introduced the term "pervaporation" and today pervaporation is known as a membrane technique in which a liquid mixture is separated by means of partial vaporization through a non-porous perm-selective membrane (Néel, 1991).

Pervaporation is a complex process involving simultaneous heat and mass transfer; latent heat is required to pervaporate the liquid. The principle of separation is not similar to that of distillation where separation is largely dependent upon vapor/liquid equilibrium; rather it is dependent on the solubility and the diffusivities of the constituents in the membrane. Transport, across the membrane, is generally explained by the solution-diffusion model, in a sequence of three steps (Howell et al., 1993):

-Absorption of the component from the liquid phase at the membranefeed solution interphase

-Diffusion of the absorbed species through the polymer matrix to the gas membrane interphase

-Release of the species into the gas phase by desorption and evaporation.

The principle of pervaporation is illustrated in Figure 1.3. A nonporous membrane separates a liquid feed which is usually close to atmospheric pressure, from downstream compartment where a vacuum is applied. The solutes (denoted by i) are first absorbed by the membrane surface when they contact with the membrane due to the interactions between the solutes and polymer (Figure 1.3.I). When the chemical potential of the component $i$ is equal in the feed that is adjacent to the membrane and in the selective layer of the membrane, a thermodynamic equilibrium will be reached. These solutes that are absorbed by the membrane surface create a chemical potential difference across the membrane, which causes a diffusive net flux of solute through the membrane polymer (Figure 1.3.II). Ideally all the solute particles 
that have diffused through the membrane desorbed suddenly and removed by vacuum applied on the downstream side of the membrane. As a result, the solute concentration on the membrane downstream surface remains practically zero, and a maximum concentration gradient between the two membrane surfaces is maintained. If the vacuum is not sufficiently low enough to desorb all the solutes reaching the membrane downstream surface, the concentration of the solute at the bottom of the membrane will not be zero and consequently the concentration gradient will decrease, so will the net flux across the membrane. The driving force in pervaporation is thus the gradient of chemical potential of a solute across the selective membrane (Schafer and Crespo, 2002). Thus the mass transport in a pervaporation membrane can be described as a function of the chemical potential gradient only:

$$
J_{i}=f\left(\Delta \mu_{i}\right)
$$

where $\mathrm{J}_{\mathrm{i}}$ and $\mu_{\mathrm{i}}$ are the mass flux and chemical potential of solute $\mathrm{i}$, respectively. The chemical potential can be stated as a function of the state variables; pressure, composition and temperature:

$$
\mu=f(P, C, T)
$$

Accordingly, differences in the permeate pressure, feed composition and temperature causes differences in chemical potential. For this reason, there are three methods in pervaporation to establish a suitable chemical potential gradient in the membrane as driving force for the mass transport. A hydrostatic pressure difference between feed and permeate mixture is established by introducing a vacuum on the permeate side. In this case the process is referred to as vacuum pervaporation. An inert gas stream on the permeate side of the membrane can be used to remove the component and thus establish a concentration gradient driving force. This mode of operation is referred to as 
sweep gas pervaporation. Finally, if a temperature difference between the feed and the permeate mixture is used to establish a chemical potential gradient in the membrane, the process is called thermo-pervaporation (Howell et al., 1993).
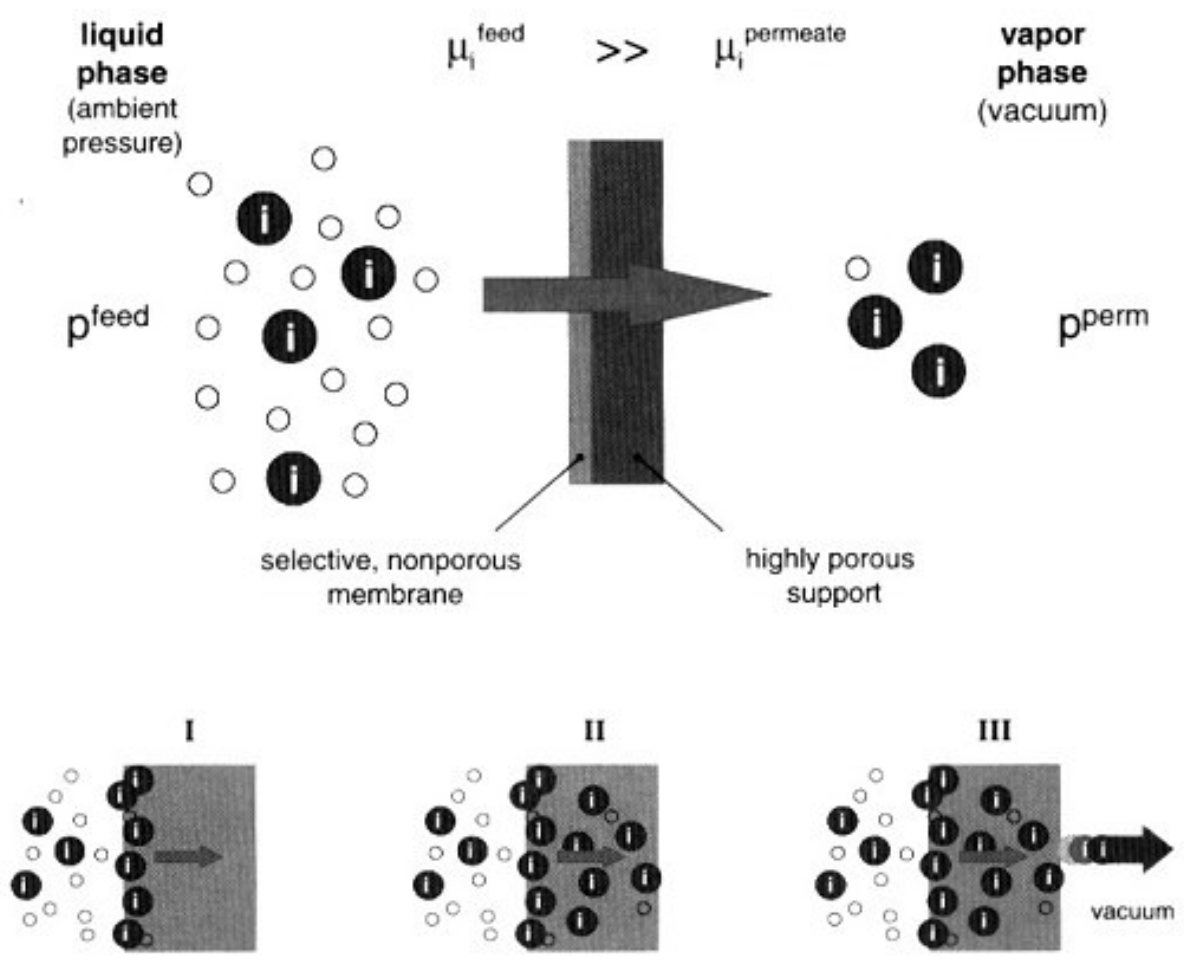

Figure 1.3 The principle of solute transport across the membrane in pervaporation (Schafer and Crespo, 2002) 
A set of parameters is used to describe the performance of the pervaporation process. The widely accepted parameters are flux, separation factor and enrichment factor. For the ideal diffusion of solute $\mathrm{i}$ across the membrane polymer toward the membrane downstream surface, Fick's First law apply:

$$
J_{i}=D_{i}\left[\frac{d C_{i}}{d z}\right]
$$

where, $J_{i}$ is the flux of the permeant $i, C_{i}$ is the concentration of the permeant $i$ in the polymer membrane, $\mathrm{z}$ is the position in the membrane, measured from the feed side of the membrane and $D_{i}$ is the diffusion coefficient of the permeant $\mathrm{i}$ in the polymer membrane. The studies on the pervaporation of dilute organic-water mixtures have shown that the diffusion coefficient of a specific component through a polymer can be assumed independent of the solute concentration. Integration across a membrane, with a thickness $\mathrm{Z}$, yields:

$$
J=D_{i} \frac{\left(C_{i}^{\text {mem, }}-C_{i}^{\text {mem, }, p}\right)}{Z}
$$

where, $\mathrm{C}_{\mathrm{i}}^{\text {mem, } \mathrm{f}}$ and $\mathrm{C}_{\mathrm{i}}^{\text {mem,p }}$ are the concentrations of the permeant $\mathrm{i}$ inside the membrane at the feed side and at the permeate side of the membrane, respectively. If we assume there is such a strong vacuum on the permeate side of the membrane, such that all of the solute particles that diffuses through the membrane is removed instantaneously, then $\mathrm{C}_{\mathrm{i}}^{\text {mem,p }}$ can be taken as zero and Equation (4) reduces to:

$$
J_{i}=D_{i} \frac{\left(C_{i}^{\text {mem, } f}\right)}{Z}
$$


Assuming constant solute feed concentration and rapid removal of solute on the membrane downstream, the selective transport of the solute i from the bulk feed to the downstream compartment can ideally be described by successive steps as:

1. An equilibrium partitioning (sorption) of the solute $i$ between the liquid bulk feed and the membrane upstream surface

2. A diffusion of solute $\mathrm{i}$ across the membrane polymer toward the membrane downstream surface

3. An equilibrium partitioning (desorption) of the solute $\mathrm{i}$ between the membrane downstream surface and the permeate vapor as shown in Figure 1.4.
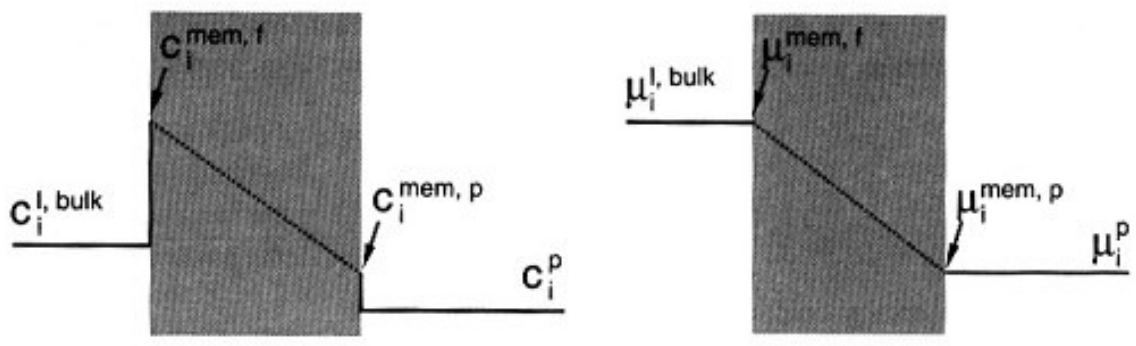

Figure 1.4 The ideal profile of the concentration and chemical potential of a solute $\mathrm{i}$ in the membrane polymer. (Schafer and Crespo, 2002) 
For the equilibrium partitioning in steps 1 and 3, it follows that:

$$
S_{i}=\frac{C_{i}^{m e m, f}}{C_{i}^{l, b u l k}}
$$

where, $\mathrm{C}_{\mathrm{i}}^{1}$, bulk is the concentration of component $\mathrm{i}$ in the bulk liquid, whereas $\mathrm{S}_{\mathrm{i}}$, is the sorption (partitioning) coefficient of $\mathrm{i}$ in the homogeneous membrane polymer. Combination of equations (5) and (6) yields the transport model commonly applied in pervaporation, the so-called solution-diffusion model. This model gives the overall solute flux across the membrane $\mathrm{J}_{\mathrm{i}}\left(\mathrm{kg} / \mathrm{m}^{2} \mathrm{sec}\right)$ as;

$$
J_{i}=S_{i} D_{i} \frac{\left(C_{i}^{l, b u l k}\right)}{Z}=P_{i} \frac{\left(C_{i}^{l, b u l k}\right)}{Z}
$$

$\mathrm{P}_{\mathrm{i}}\left(\mathrm{m}^{2} / \mathrm{sec}\right)$ is the so-called permeability of $\mathrm{i}$ in the membrane which is the product of the solubility and diffusivity of the solute $\mathrm{i}$ in the membrane. As it can be concluded from the equation above, for an ideal case the flux of a specific component is directly related to the concentration of the component in the bulk feed. In addition, one can calculate the permeability of the solute from the slope of flux versus feed concentration graph, if the thickness of the membrane is known. Furthermore, the solute concentration is related to the solute partial pressure, the driving force can also be expressed as a partial pressure gradient of the solute i across the membrane yielding;

$$
J_{i}=S_{i} D_{i}\left[\frac{\Delta P_{i}}{Z}\right]=P_{i}^{\prime}\left[\frac{P_{i}^{f}-P_{i}^{p}}{Z}\right]
$$


where, $\mathrm{P}_{\mathrm{i}}{ }^{\prime}$ is the permeability coefficient $(\mathrm{kg} / \mathrm{m} \cdot \mathrm{sec}$. $\mathrm{Pa})$, and $\mathrm{P}_{\mathrm{i}}{ }^{\mathrm{f}}$ and $\mathrm{P}_{\mathrm{i}}{ }^{\mathrm{p}}$ denotes for partial pressure of compound $\mathrm{i}$ in the feed and permeate sides, respectively.

The selectivity, together with the flux, determines the performance of the pervaporation process. The separation factor, $\alpha_{\mathrm{i} / \mathrm{j}}$, is a measure of the selectivity and it is calculated from the concentrations of the compounds to be separated $\mathrm{i}$ and $\mathrm{j}$ in the feed and the permeate, respectively, as the relation between the partial fluxes of the compounds according to:

$$
\alpha_{i / j}=\frac{\left(C_{i}^{p} / C_{i}^{l, b u l k}\right)}{\left(C_{j}^{p} / C_{j}^{l, b u l k}\right)}
$$

In the case of very dilute solutions, the feed and the permeate concentration of the solvent is close to unity and the separation factor can be assumed to be equal to the enrichment factor, $\beta_{\mathrm{i}}$, defined according to:

$$
\beta_{i}=\frac{C_{i}^{p}}{C_{i}^{l, b u l k}}
$$

The theory, explained above, does not include the effects of flow coupling and influence of external mass transfer resistance, such as concentration polarization in the feed boundary layer and limitation of mass transfer due to the presence of a porous support layer. In actual case non-ideal transport phenomena can occur in the feed liquid phase adjacent to the membrane upstream surface, within the membrane polymer, and in the vapor phase adjacent to the membrane downstream face. 
In the equations above, perfect mixing of the feed and sudden removal of the solutes leaving the membrane downstream face were assumed. If these assumptions are not valid, boundary layers will develop on both sides of the membrane, affecting the solute transport to and away from the respective membrane surface. If the flux of a solute i through the membrane is higher than that of through the liquid phase toward the membrane, then the solute $\mathrm{i}$ will be depleted in the liquid phase over the membrane upstream surface, resulting in a liquid solute concentration lower than that in the bulk feed. Since the solute concentration in the liquid at the membrane upstream surface determines the partitioning of the solute into the membrane, the concentration of $i$ in the membrane upstream surface will be lower with respect to bulk concentration. Hence, the concentration gradient across the membrane will decrease so as the overall flux. This phenomenon is known as concentration polarization and affects the fluxes of compounds of high sorption coefficient, even under turbulent hydrodynamic conditions over the membrane. A similar phenomenon can also be found on the membrane downstream face (Schafer and Crespo, 2002). The concentration polarization strongly depends on the feed flow velocity and on the hydraulic diameter. An increase in the feed flow velocity and a decrease in the hydraulic diameter, decrease the effect of concentration polarization (Borjesson et al., 1996).

As a result, if we consider the mass transfer limitations and resistances in the overall flux equation, overall mass transfer coefficient, $\mathrm{k}_{\mathrm{ov}, \mathrm{i}}$, can be expressed as the sum of mass transfer resistances:

$$
\left(\frac{1}{k_{o v, i}}\right)=\left(\frac{1}{k_{b l, i}}\right)+\left(\frac{1}{k_{m, i}}\right)+\left(\frac{1}{k_{p, i}}\right)
$$


where, $\mathrm{k}_{\mathrm{bl}, \mathrm{i}}$ is the mass transfer coefficient for the boundary layer, $\mathrm{k}_{\mathrm{m}, \mathrm{i}}$, is the mass transfer coefficient for the membrane and $\mathrm{k}_{\mathrm{p}, \mathrm{i}}$ is the mass transfer coefficient for the permeate side.

Although in most of the cases it is hard to achieve an ideal case, if the feed flow velocity is maintained high enough during pervaporation, i.e. turbulent flow regime, the mass transfer resistance in the feed boundary layer can be neglected in comparison with overall mass transfer resistance system (Karlsson and Tragardh, 1993). Moreover if a good vacuum is applied on the permeate side of the membrane, i.e. everything that diffuses through the membrane is instantaneously pumped away, then mass transfer effects in permeate can also be neglected. Consequently, equation (11) simplifies to;

$$
\left(\frac{1}{k_{o v, i}}\right)=\left(\frac{1}{k_{m, i}}\right)
$$

Therefore, overall mass transfer of component i from the bulk of the feed to the bulk of permeate can be described by:

$$
J_{i}=k_{o v, i}\left(C_{i}^{l, b u l k}-C_{i}^{p}\right)=k_{m, i}\left(C_{i}^{l, b u l k}-C_{i}^{p}\right)
$$

As mentioned before, there are generally three process parameters that affect the chemical potential gradient across a specific membrane; feed temperature, feed composition and downstream pressure.

Since solubility and diffusivity of the feed mixture component in polymeric membranes are generally dependent on the operating temperature, pervaporation flux is also dependent on the temperature. When the temperature of the feed increases the permeation rate follows an Arrhenius-type law: 


$$
J=J^{\prime} e^{\left(\frac{-E_{a}}{R T}\right)}
$$

where, $\mathrm{E}_{\mathrm{a}}$ stands for the overall activation energy of pervaporation, $\mathrm{T}$ is the feed temperature in Kelvin and $\mathrm{R}$ is the universal gas constant (8314.34 $\mathrm{J} / \mathrm{kgmol} \cdot \mathrm{K})$.

According to the solution-diffusion model, both sorption and diffusion of the components in the membrane characterize the membrane properties. A change in feed composition directly affects the sorption phenomena at the liquid-membrane interface. Since the diffusion of the components in the membrane is dependent on the concentration of the components (or the solubility of the components), the permeation characteristics are obviously dependent on the feed concentration (Huang, 1991).

The permeate pressure is directly related to the activity of the components at the downstream side of the membrane. Therefore, the permeate pressure strongly influences the pervaporation characteristics. The maximum driving force can be attained at zero pressure of the permeate side. An increase in the vapor pressure in the downstream side of the membrane leads to a decrease of the driving force for transport. As a result, the pervaporation flux decreases. In addition the downstream pressure may also affect the selectivity, depending on the relative volatility of the permeating components (Huang, 1991).

\subsection{Types of Membranes}

The membrane type used in the pervaporation experiments determines the selectivity towards the molecules, hence the application type. Therefore, membrane selection is one of the most important issues in pervaporation. In 
general, two main points are taken into account during selection of a membrane. Firstly, it needs to have high selectivity and flux for the components to be separated and secondly it must maintain its integrity for a long period of time under operating conditions, i.e. it must have chemical, mechanical and thermal stability (Schafer and Crespo, 1997).

A membrane can be simply defined as a permselective barrier, made-up of polymers, between the feed and permeate. Polymers are synthetic macromolecular materials that gain their properties during the steps of their design. Polymers are very large molecules, i.e. about 1000 to 100000 times larger than water molecule, which are manufactured by the help of the chemical processes. Polymers gain different characteristics during their design. Generally there are two types of polymers: glassy polymers and rubbery polymers or elastomers. Their ground state at room temperature determines their distinction (Koops and Smolders, 1991).

Glassy polymers have a glass transition temperature above the room temperature and can be subdivided into three groups: crystalline, semicrystalline and amorphous polymers. The presence of crystallites has an important affect on all kinds of polymers in terms of tensile strength, elasticity, impact strength, solubility, diffusivity in the polymer, etc. Generally, glassy polymers preferentially permeate water (Böddeker and Bengtson, 1991). Some examples of glassy polymers are cellulose acetate, polysulfone, polypropylene, polystyrene and polyvinylchloride.

Polymers with a glass transition temperature below room temperature are classified as rubbers or elastomers. The polymer chains of the elastomers contain rather small side groups, which are non-polar. Due to the absence of strong intermolecular forces, such as H-bonding or dipole-dipole interactions, elastomers are flexible and mostly hydrophobic polymers. Since they absorb organic molecules with relatively high fluxes, elastomers are the most suitable 
polymers for the separation of organic molecules from aqueous solutions (Koops and Smolders, 1991).

Glassy and rubbery membranes differ strongly in terms of flexibility of their polymeric structure. Within the rigid polymeric structure of a glassy membrane, the diffusivity of components are strongly related to their molecular volume, whereas in the flexible region of a rubbery membrane, solute- polymer interactions are much more important than the diffusivities of components. This is why the selectivity of glassy membranes is more diffusion controlled, while the selectivity of rubbery membranes is more sorption controlled (Schafer and Crespo, 2002).

As mentioned before, the types of polymers used in pervaporation process determines the selectivity, and hence the application. Depending on the permeating component two main membranes of pervaporation can be identified (1) hydrophilic membranes, and (2) organophilic membranes. Figure 1.5, gives an overview of the areas of PV, membranes applied and their applications.

Hydrophilic polymers show a great affinity to water molecules, due to the presence of groups in the polymer chain that are able to interact with water molecules. Hydrophilic polymers are the best candidate materials for dehydration membranes. Polymers that are water repellent are called hydrophobic polymers. They preferentially permit the permeations of organic substances, due to lack of strong interaction forces as in the case of hydrophilic polymers (Koops and Smolders, 1991). Some of these hydrophobic polymers are also used for the preparation of target-organophilic pervaporation membranes in order to separate the target organic compounds from organicorganic mixtures by being preferentially permeated through the membrane. 


\section{PERVAPORATION}

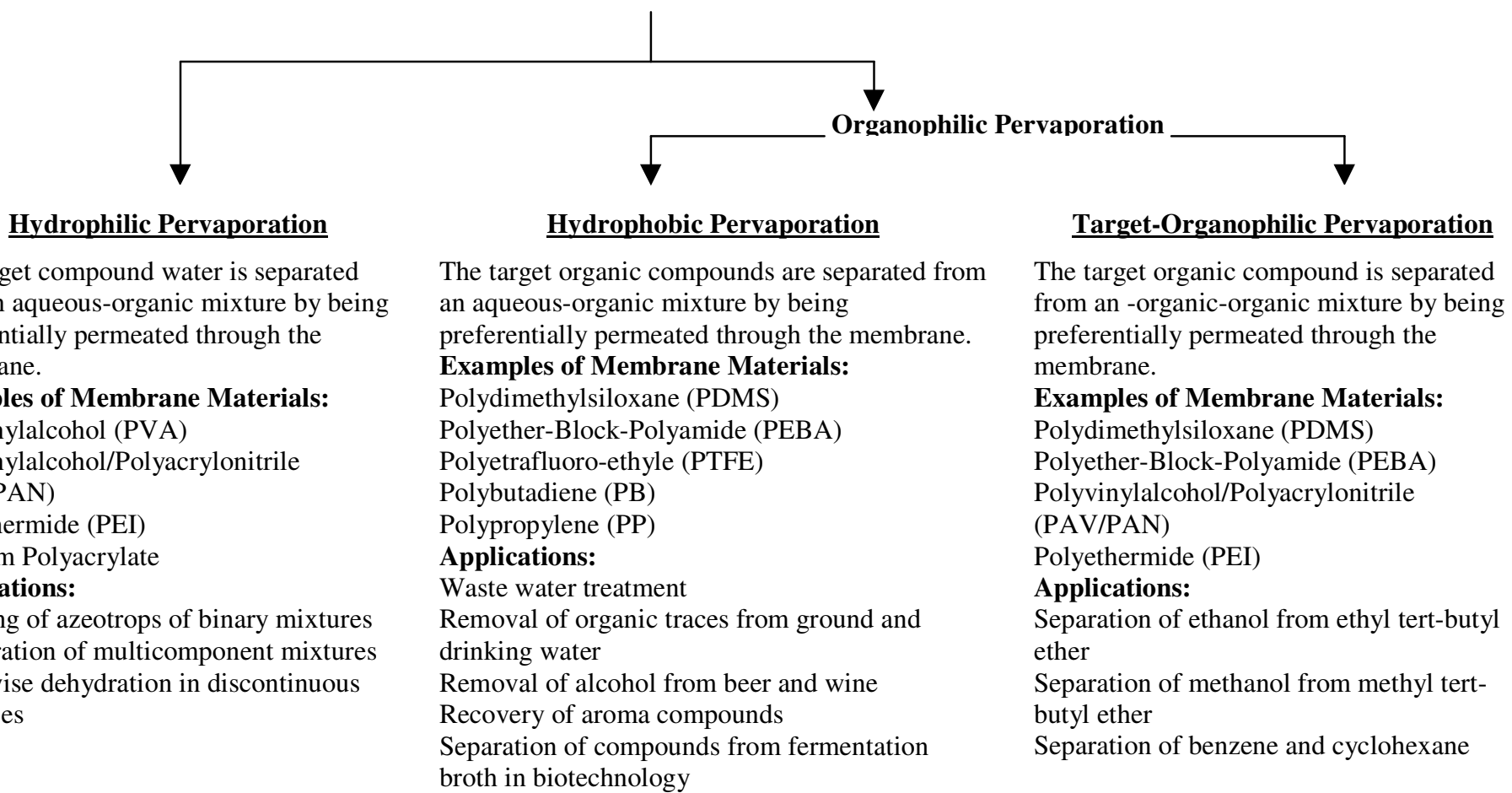

Figure 1.5 Areas of pervaporation: membranes and applications (Lipnizki et al., 1999) 
Generally in membrane production for pervaporation processes composite membrane structure is preferred which offers the possibility of making membrane with a thin effective separation layer. This leads to an increase in flux and the mechanical strength can be maintained. Composite membranes are composed of three layers. As can be seen in Figure 1.6, the first layer is the thin dense layer, which has a very good separation capability. The second layer is the porous support layer that has an asymmetric pore structure. The top layer is made out of a different material as the support layer, and the last layer is a woven or non-woven textile fabric. Polyester, polyethylene, polyphenylene sulfide and similar fibers are used for the textile carrier layer. Structural polymers with high resistance against chemical attack and food thermal and mechanical properties like polyacrylonitrile, polyethermide, polysulfone etc. form the porous support.

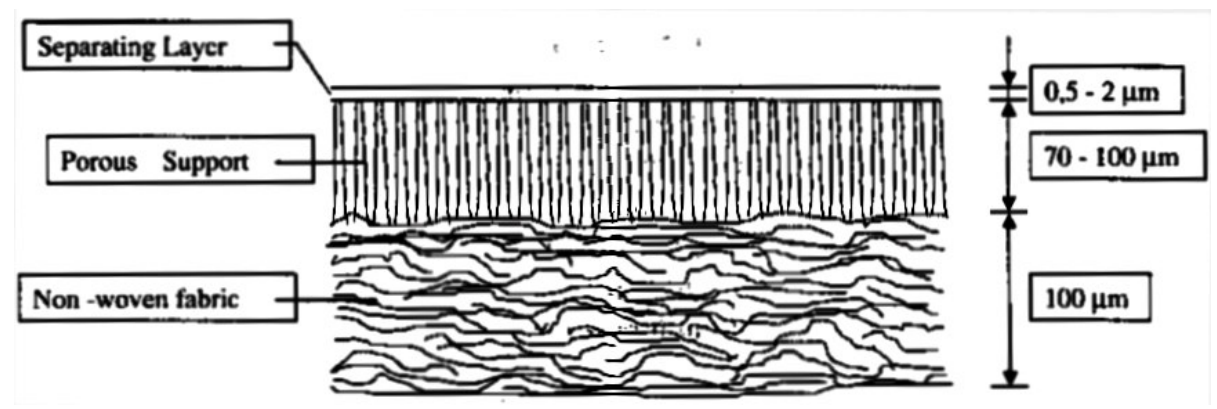

Figure 1.6 Cross-section of a composite membrane (Brüschke, 2001) 
One of the most commonly used organophilic membranes is poly (dimethyl siloxane) (PDMS). The dense separating layer is formed by crosslinked silicones. The monomer of PDMS is:

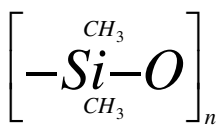

Although PDMS membranes have high organic fluxes, the water fluxes are also quite high which results in high overall fluxes and reasonable selectivities. Hennepe et al. (1987) developed a PDMS membrane, which has zeolite support layer, in order to improve the organic selectivity of PDMS membranes. The zeolite, silicate, was hydrophobic and its addition to PDMS resulted in membranes with higher fluxes and higher selectivities than ordinary PDMS. Nowadays, PDMS membranes with different porous support layers are commercially available.

\subsection{Applications of Pervaporation in Food Industry}

As an emerging membrane-based separation technique, pervaporation has promising applications in food processing. One of the most promising applications of pervaporation is the recovery of aroma compounds from aqueous mixtures. Since aroma compounds are highly heat sensitive and loss of aroma compounds during heat treatments is inevitable, they should be separated from food systems so that they can be feed back to the final product. This can be accomplished either by recovering the lost aromas from the loss stream or by stripping the aromas from the ingoing raw material stream before 
processing. This will eventually increase the quality and the acceptance of the final product.

In aroma recovery the key advantages of pervaporation over conventional processes are (Lipnizki et al., 2002a):

- high selectivity,

- low energy consumption,

- physical separation mechanism,

- moderate operating temperature, and

- no additive requirement.

There are a large number of researches that have been carried out in this area. Some of the examples are as follows:

Rajagopalan and Cheryan (1995) studied pervaporation of model flavor compound of grapes (methyl anthranilate) with several membranes (PDMSPC, PEBA, PERVAP-1070). Flux and selectivity decreased linearly with increase in downstream pressure, but increased with temperature. The presence of ethanol in the feed solution lowered separation factors but increased total flux. Experiments with commercial grape essence confirmed the excellent potential of pervaporation for the production of highly enriched flavors.

Baudot and Marin (1996), performed their experiments for the recovery of two dairy aroma compounds (methylthiobutyrate, diacetyl) diluted in model aqueous solutions through two different membranes (GFT, GKSS PEBA). The tested membranes showed a good selectivity for the extraction of methylthiobutyrate at high dilution rate. However, for the recovery of diacetyl, two-stage condensation coupled with pervaporation improved the selectivity of the whole process significantly.

Recovery of aroma compounds from a wine-must fermentation by organophilic pervaporation had been studied by Schafer et al. (1999). It was shown that ogranophilic pervaporation can be highly suitable for the 
continuous recovery of very complex and delicate aromatic profiles produced during microbial fermentation.

Borjesson et al. (1996) had investigated the performance of six different pervaporation membranes for the recovery of apple juice aromas. Two polyoctylmethyl siloxane membranes with different support layers and a polydimethyl siloxane membrane were shown to have very good performance. Moreover, the influence of feed flow velocity (Olsson and Tragardh, 1999) and the influence of permeant and membrane properties (Olsson et al., 2002) on recovery of aroma compounds by pervaporation had also been examined. A novel process simulation of pervaporation had been developed for multicomponent mixtures (Lipnizki et al., 2002a) and this study is continued with the integration and optimization of hydrophobic pervaporation for the recovery of natural aroma compounds in the food industry (Lipnizki et al., 2002b).

Pervaporation separation was also used to recover aroma compounds from ethyl butyrate and ethyl caproate mixtures, which are most important aroma components of pineapple and banana juice, by using POMS and PDMS membranes (Sampranpiboon et al., 2000). The effect of operating conditions on the separation performance was investigated and in general the POMS membrane was found to be more selective to aroma compounds than PDMS membranes. Moreover, a strong interaction is observed between the two permeating components and permeation of one aroma compound was affected by the presence of other aroma compound.

Shepherd et al. (2002) studied the use of poly (dimethyl siloxane) (PDMS) hollow fibers in orange juice aroma recovery. Modules for pervaporation were designed and built, scrutinized with binary ester-water feeds and compared to other module geometries using experimental enrichment factors and mass transfer coefficient values. The results show a good potential of the modules for dilute aroma recovery. 
Membrane processing was investigated in order to clarify and to recover aroma from tropical fruit juices (Pereira et al., 2002). Pineapple and passion fruit juices were selected and the results indicated that olefin pervaporation membranes presented a good performance due to their low permeability and high enrichment factor to the components of aroma.

Peng and Liu (2003), evaluated separation factor of six constituent aroma compounds, representing some typical flavoring ingredients from blueberry juice with a PDMS membrane. The results showed that separation factor was in the range of 70 to 430 , depending on molecule size and polarity of compounds. All compounds, except 1-heptanol, showed no significant coupling effect in the mixture system. The effect of temperature was also examined for a given feed-flow rate.

The possibility of using pervaporation to recover the tea aroma compounds from tea aroma condensate generated in the manufacturing of tea or instant tea as well as directly from tea extract had been studied by Kanani et al. (2003). Two different membrane types (POMS and PDMS) had been used to recover eight aroma compounds that make a significant contribution to tea aroma. Mainly the effect of feed concentration on the organic flux and selectivity had been studied and the results indicated that pervaporation is an attractive technology for the recovery of tea aroma compounds from tea aroma condensates as it yields good separation and operates under mild conditions.

Dealcoholization of alcoholic beverages including beer and wine is another application of pervaporation. The idea behind this process is the separation of ethanol through hydrophobic membranes much more readily than water. There are many publications in this area (Escoudier et al., 1988; Bruschke, 1990; Kimmerle and Gudernatsch, 1991)

Another interesting application of pervaporation in the processing of edible oils had been described by Koseoglu et al. (1995). In the extraction of oils from various raw materials, isopropanol can be used. The water in the 
isopropanol-water mixture must be separated for the extraction of oil. The use of pervaporation was suggested for the separation.

\subsection{Objectives of the Study}

Loss of aroma compounds due to high temperature treatments is an important problem, since absence of aroma compounds causes considerable decrease in the quality of beverages especially fruit juices. Because of the limitations of conventional aroma recovery processes, pervaporation which is a membrane process, had been widely considered as an alternative method.

Although pervaporation is applied for the recovery of many aroma compounds, the effect of process parameters on the recovery of strawberry aroma compounds are lacking in literature. For this reason, the main objective of this study was to determine the effects of feed temperature, concentration and composition and permeate pressure on the recovery of aroma compounds of strawberry by pervaporation in terms of mass flux and selectivity.

In this study, among the instrumental analysis techniques, solid-phase microextraction (SPME) was used for the extraction of aroma compounds. The optimum extraction conditions for strawberry aroma were also missing in

literature. Therefore, it was aimed to optimize the extraction conditions of SPME for the most important aroma compounds (methyl butyrate, ethyl butyrate, butyl butyrate, methyl caproate, ethyl caproate, linalool) of strawberry. Extraction time, temperature and agitation speed have been taken into account during optimization. In addition, matrix effect of strawberry was also studied. 


\section{CHAPTER 2}

\section{EXPERIMENTAL}

\subsection{Materials}

The aroma compounds (methyl butyrate, ethyl butyrate, butyl butyrate, methyl caproate, ethyl caproate and linalool) that are used for the preparation of the model strawberry solutions were purchased from Aldrich with a purity above $99 \%$. Table 2.1 shows some of the properties of strawberry aroma compounds.

Pervaporation experiments were also performed with a strawberry essence (On Target A. D. C., IL., USA).

The hydrophobic membrane, PERVAP 1070, was obtained from Sulzer Chemtech (Switzerland). The properties of PERVAP 1070 membrane is shown in Table 2.2. PERVAP 1070 comprises a separating layer filled with an organophilic zeolite.

Solid-phase microextraction (SPME) apparatus was used for the extraction of aroma compounds. The SPME fiber holder, for manual use, the silica fiber, polydimethylsiloxane (PDMS $100 \mu \mathrm{m}$ ), the $4 \mathrm{ml}$ screw-cap vials were purchased from Supelco (Bellefonte, PA, USA). The fiber was conditioned at $250^{\circ} \mathrm{C}$ for 3 hours prior to use according to supplier's instructions. 
Table 2.1 Physical properties of strawberry aroma compounds from Fenaroli's Handbook of Food Flavor Ingredients (Giovanni, 1995), " Molar volumes were estimated with Tyn and Calus method (Reid et al., 1987).

\begin{tabular}{|c|c|c|c|c|c|c|}
\hline $\begin{array}{l}\text { Name of } \\
\text { compound }\end{array}$ & $\begin{array}{c}\text { Methyl } \\
\text { Butyrate }\end{array}$ & $\begin{array}{c}\text { Ethyl } \\
\text { Butyrate }\end{array}$ & $\begin{array}{l}\text { Methyl } \\
\text { Caproate }\end{array}$ & $\begin{array}{c}\text { Butyl } \\
\text { Butyrate }\end{array}$ & $\begin{array}{c}\text { Ethyl } \\
\text { Caproate }\end{array}$ & Linalool \\
\hline $\begin{array}{c}\text { Empirical } \\
\text { formula }\end{array}$ & $\mathrm{C}_{5} \mathrm{H}_{10} \mathrm{O}_{2}$ & $\mathrm{C}_{6} \mathrm{H}_{12} \mathrm{O}_{2}$ & $\mathrm{C}_{7} \mathrm{H}_{14} \mathrm{O}_{2}$ & $\mathrm{C}_{8} \mathrm{H}_{16} \mathrm{O}_{2}$ & $\mathrm{C}_{8} \mathrm{H}_{16} \mathrm{O}_{2}$ & $\mathrm{C}_{10} \mathrm{H}_{18} \mathrm{O}$ \\
\hline $\begin{array}{l}\text { Density } \\
\left(\mathrm{g} / \mathrm{cm}^{3}\right)\end{array}$ & 0.898 & 0.878 & 0.885 & 0.887 & 0.873 & 0.868 \\
\hline $\begin{array}{c}\text { Molecular } \\
\text { weight }\end{array}$ & 102.13 & 116.16 & 130.18 & 144.21 & 144.21 & 154.25 \\
\hline $\begin{array}{c}{ }^{*} \text { Molar } \\
\text { volume } \\
\left(\mathbf{c m}^{3} / \mathbf{m o l}\right)\end{array}$ & 128 & 151 & 129.4 & 122 & 196 & 179 \\
\hline $\begin{array}{c}\text { Boiling point } \\
\left({ }^{\circ} \mathbf{C}\right)\end{array}$ & $102-103$ & $121-122$ & 151 & 165 & 168 & 198 \\
\hline Solubility & $1: 60$ in water & $\begin{array}{l}1: 3 \text { in } 60 \% \\
\text { alcohol }\end{array}$ & $\begin{array}{l}\text { Insoluble in } \\
\text { water, soluble } \\
\text { in alcohol }\end{array}$ & $\begin{array}{c}\text { Insoluble in } \\
\text { water, soluble } \\
\text { in alcohol }\end{array}$ & $\begin{array}{c}\text { Insoluble in } \\
\text { water }\end{array}$ & $\begin{array}{c}1: 4 \text { in } 60 \% \\
\text { alcohol }\end{array}$ \\
\hline $\begin{array}{l}\text { Organoleptic } \\
\text { characteristics }\end{array}$ & $\begin{array}{l}\text { Apple-banana } \\
\text { pineapple } \\
\text { flavor }\end{array}$ & $\begin{array}{l}\text { Fruity odor, } \\
\text { sweet taste }\end{array}$ & $\begin{array}{c}\text { Ether-like } \\
\text { odor }\end{array}$ & $\begin{array}{c}\text { Fruity (pear- } \\
\text { pineapple- } \\
\text { like) odor }\end{array}$ & $\begin{array}{l}\text { Powerful, } \\
\text { fruity odor in } \\
\text { pineapple }\end{array}$ & Floral odor \\
\hline
\end{tabular}


Table 2.2 Properties of PERVAP 1070 (supplied by Sulzer Chemtech Membrane System)

New Code

Old Code (equivalent)

Main Application

Max. Temperature, continuous

Max. Temperature, short term

Max. Organic in Feed

Excluded Components

Selective layer thickness

Total Flux at $50^{\circ} \mathrm{C}, 8 \mathrm{mbar}$ $\left(95 \% \mathrm{H}_{2} \mathrm{O}, 5 \% \mathrm{EtOH}\right)$

Selectivity at $50^{\circ} \mathrm{C}, 8 \mathrm{mbar}$ $\left(95 \% \mathrm{H}_{2} \mathrm{O}, 5 \% \mathrm{EtOH}\right)$
PERVAP $^{\circledR} 1070$

$$
\text { PERVAP }^{\circledR} 1170
$$

Removal of volatile organics from aqueous and gaseous streams

$90^{\circ} \mathrm{C}$

Water miscible organics: $50 \%$ Max. Organic phase for systems with miscibility gap

Aprotic solvents (DMF, DMSO), Alkali, Strong Amines

$80 \mu \mathrm{m}$

$0.075 \mathrm{~kg} / \mathrm{m}^{2} \mathrm{~h}$

4.21 


\subsection{Optimization of Extraction Conditions of SPME}

Analyses of aroma compounds were done using gas chromatography (GC) after SPME. First, the extraction conditions of SPME were optimized for this purpose.

Mixtures of standard solutions containing $100 \mathrm{ppm}$ of each aroma compound were prepared using double distilled water for optimization of extraction conditions of SPME. For headspace solid-phase microextraction, 2 $\mathrm{ml}$ of mixture was placed into the $4 \mathrm{ml}$ vials containing magnetic stirring bar for agitation. The vial was placed in a thermostated block on a stirrer (MR 3001K, Heidolph Instruments GmbH \& Co. KG, Schwabach, Germany). After 10 minutes of equilibration time at the desired temperature and agitation speed, the fiber was immersed into the headspace of the mixture and waited for a definite time. Subsequent to extraction of aroma compounds, thermal desorption took place in the injection port of GC for 10 minutes.

In order to observe the effect of sample matrix on the extraction of aroma compounds, a strawberry juice matrix, including pectin $(0.4 \mathrm{~g})$, glucose $(2.3 \mathrm{~g})$, fructose $(2.3 \mathrm{~g})$, sucrose $(1 \mathrm{~g})$, citric acid $(0.7 \mathrm{~g})$, and malic acid $(0.1 \mathrm{~g})$ in $100 \mathrm{ml}$ double distilled water, had been prepared (Scherz and Senser, 1994). Pure aroma compounds were added to the matrix to make the concentration of each aroma compound $100 \mathrm{ppm}$.

Three different parameters, extraction temperature, agitation speed and extraction time were considered for the optimization of solid-phase microextraction of aroma compounds of strawberry. First, the effects of extraction temperatures $\left(30,40\right.$ and $\left.50{ }^{\circ} \mathrm{C}\right)$ were studied. The following experiments were carried out at the optimum extraction temperature. In the second part of optimization experiments, the effect of agitation speed (500, $700,1000 \mathrm{rpm})$ was studied. Next, at the optimum temperature and agitation 
speed, the effect of extraction time $(5,15,30,45 \mathrm{~min})$ was evaluated. Finally, the effect of strawberry matrix had been studied at the optimum condition. All the extractions were carried out in triplicate.

\subsection{Pervaporation Experimental Set-up}

A schematic diagram and the picture of experimental set-up constructed are shown in Figure 2.1 and 2.2.

The pervaporation cell (Figure 2.3 and 2.4) was manufactured by Tekson Drilling and Mechanical Shop Company (Ankara, Turkey). It is composed of two compartments, made up of stainless steel. The membrane is placed between these compartments and is supported by filter papers and perforated metal disc to prevent mechanical deformation. The active area of the membrane is $35.26 \mathrm{~cm}^{2}$. A gasket is placed between the top and bottom compartments and they are connected and tightened with four screws in order to maintain constant vacuum during the experiments. The upper part of the cell has one entrance for the feed and an exit for the retentate to circulate. The lower compartment has one exit at the bottom for the permeate to be collected in traps.

The pervaporation experiments were conducted continuously. The reservoir which is a $4000 \mathrm{ml}$ glass flask containing $2000 \mathrm{ml}$ feed solution was kept inside the temperature controlled water bath (Nüve, BA101, Nüve Sanayi Malzemeleri İmalat ve Ticaret A.Ş., Turkey) during the experiments. The feed reservoir was connected to a variable-speed peristaltic pump (Watson-Marlow 505U, Watson-Marlow Limited, Cornwall, UK) to pump the feed to the upper part of the pervaporation cell. The feed flow rate was $780 \mathrm{ml} / \mathrm{min}$ which was in turbulent region. The retentate coming out of the cell was recycled back to the 
feed reservoir. The temperature of the retentate coming back to the feed reservoir was measured using copper-constantan thermocouple in order to be sure about the temperature of the feed inside the pervaporation cell. The temperature of the feed was kept constant by the help of the controller of the water bath $\left( \pm 0.2^{\circ} \mathrm{C}\right)$. The vacuum was applied to the lower compartment of the cell by the help of a vacuum pump (Büchi, Vac V-1000, BUCHI Labortechnik AG, Switzerland) in order to provide a pressure gradient across the membrane. The vacuum pressure in the system was controlled $( \pm 1$ mbar $)$ by a vacuum controller (Büchi, Vacuum Controller V-805, BUCHI Labortechnik AG, Switzerland) which was connected to the vacuum pump. The permeate was collected in cold traps by condensation, with liquid nitrogen at $-196{ }^{\circ} \mathrm{C}$. There were three traps present in the set-up; the first two were connected in parallel in order to maintain the steady state condition during data collection. The third one was connected in series to parallel traps as a safety trap in order to ensure that practically no permeate reached to vacuum pump. 


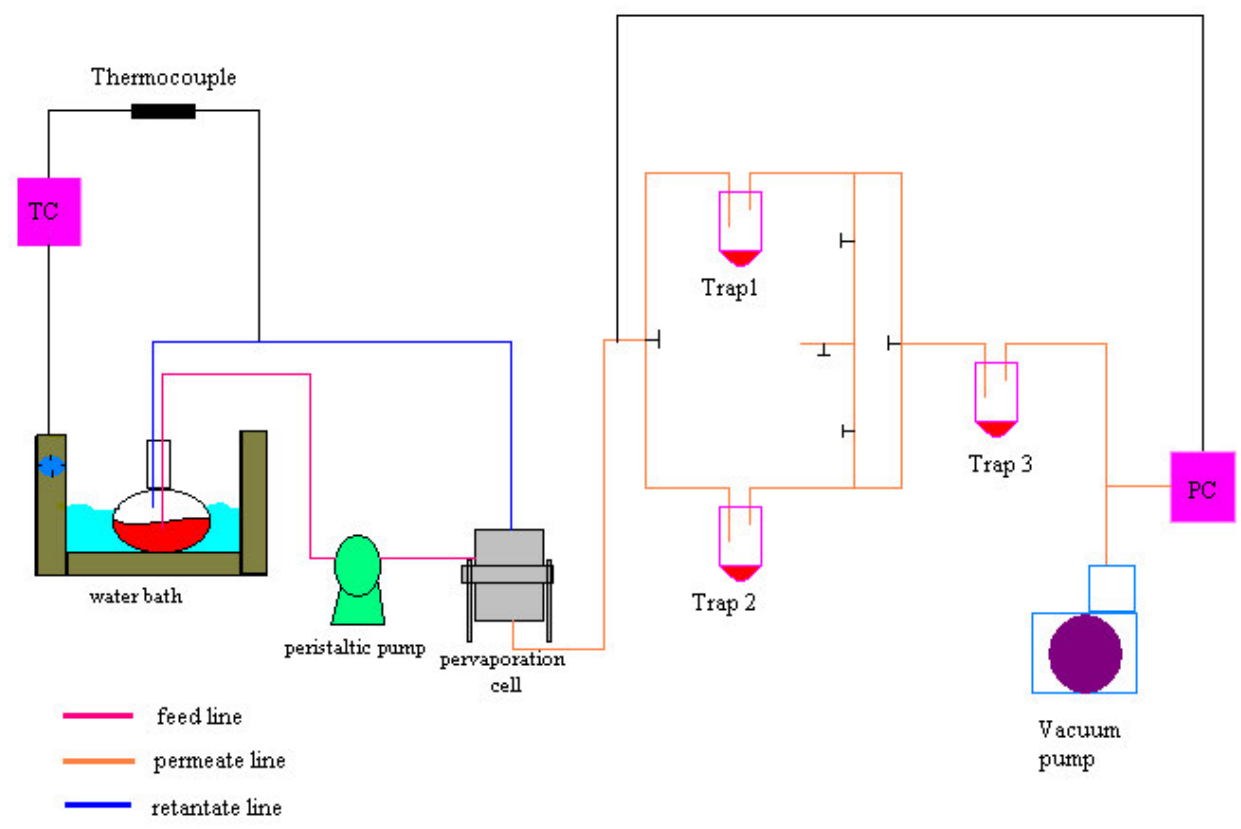

Figure 2.1 Schematic diagram of pervaporation experimental set-up 


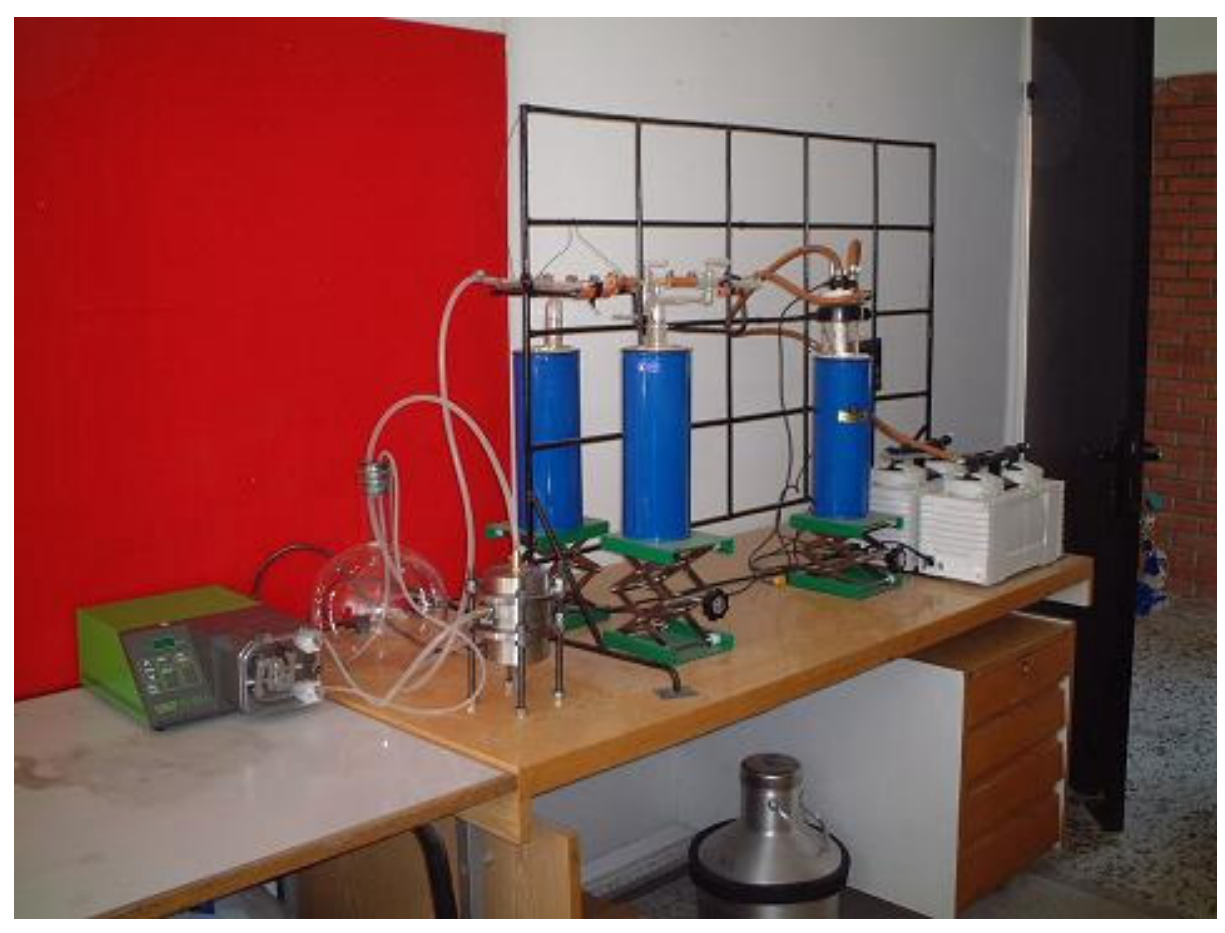

Figure 2.2 Picture of pervaporation set-up 


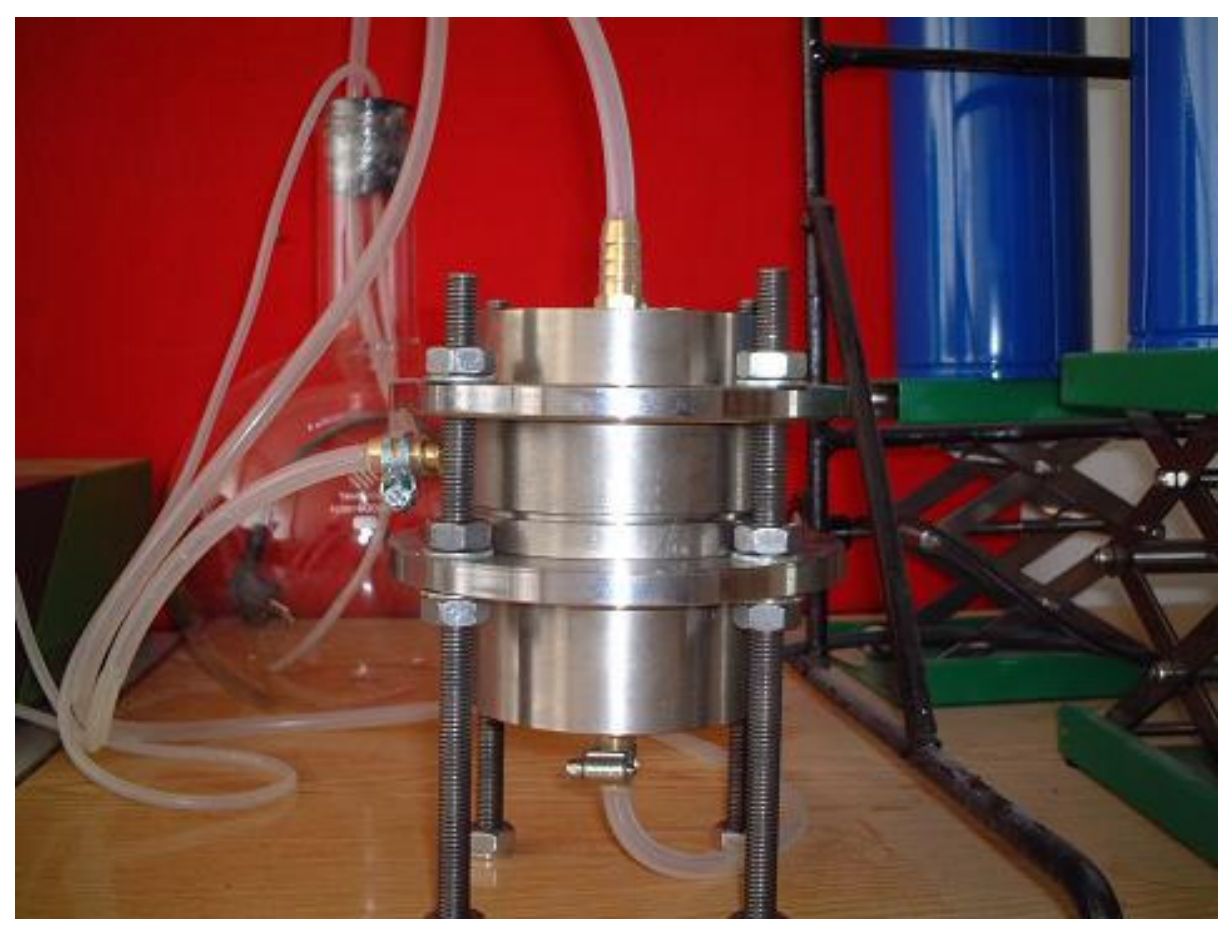

Figure 2.3 Pervaporation cell 


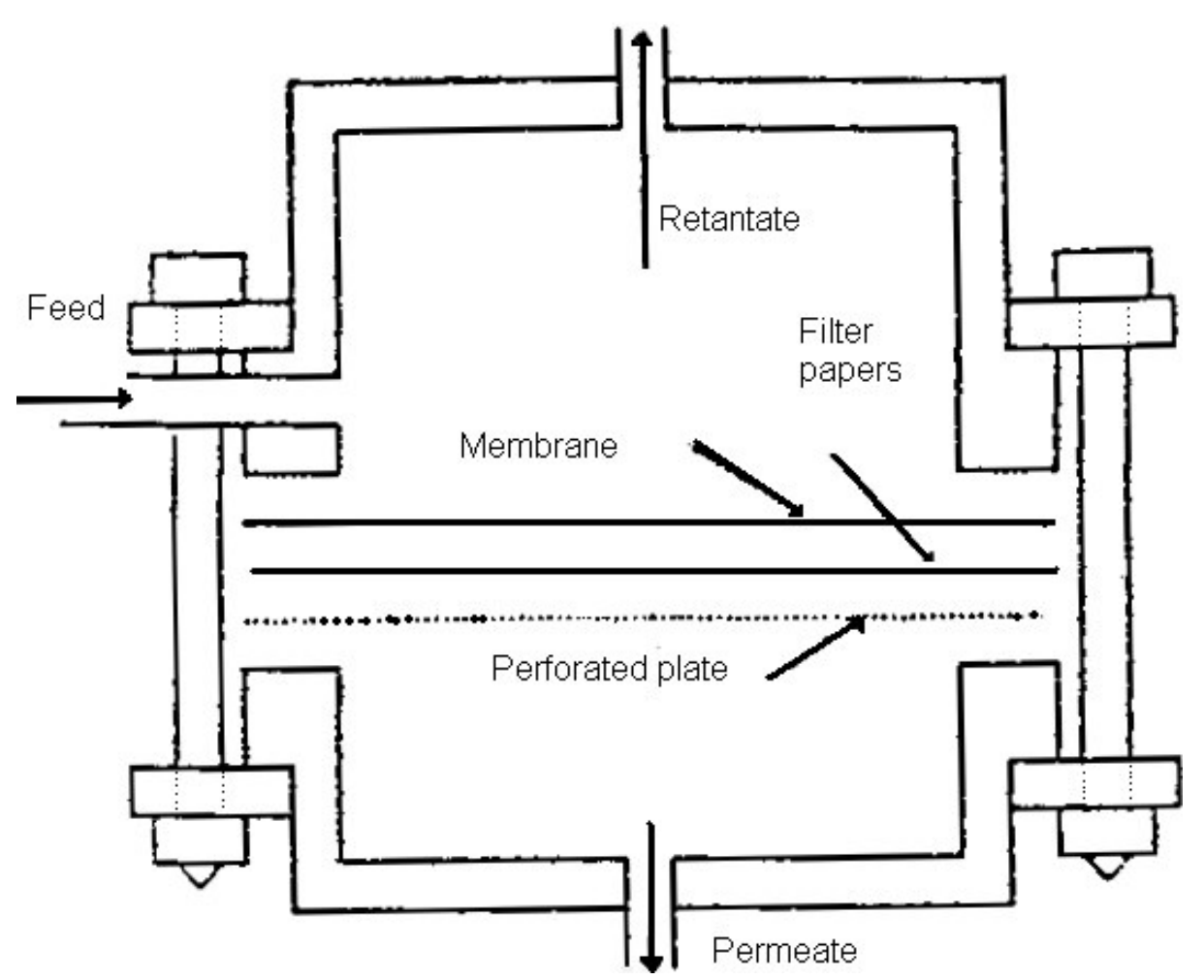

Figure 2.4 Schematic diagram of pervaporation cell (Korkut, 2001)

\subsection{Pervaporation Procedure}

The most important aroma compounds that are positively correlated with quality and odor of strawberry were searched and 3 different model solutions were established for the experiments. These are:

$\checkmark \quad$ Methyl butyrate (50, 100, $150 \mathrm{ppm})$ and water

$\checkmark \quad$ Ethyl butyrate (50, 100, $150 \mathrm{ppm})$ and water

$\checkmark \quad$ Methyl butyrate, ethyl butyrate (100 ppm each) and water. 
Before the pervaporation experiments, the membranes were always conditioned in the feed solution for two days. The membranes, which were 6.7 $\mathrm{cm}$ in diameter, were always kept in the solution in order to avoid it from drying. The heater of the water bath was set to the desired temperature and the feed tank was placed into the water bath about half an hour earlier than the start of the experiment, in order to heat the feed to the desired equilibrium temperature before the experiment started. Then, the metal disc, filter papers, the membrane and the gasket were placed into the pervaporation cell in this order on top of each other. The upper compartment was placed on the gasket and the cell was mounted and tightened by screws. Then, the tared empty trap was connected to the line and placed into the liquid nitrogen container. Afterwards, the vacuum was applied step by step to the pervaporation set-up, in order to check the system if there was any leakage during the experiment. When the vacuum was maintained constant at the desired pressure, the feed solution was started to circulate. The feed solution was changed in every two hours so that its concentration was kept constant. The pervaporation line was also changed and the collected permeate was weighed in every two hours. The collected permeate was placed into the $4 \mathrm{ml}$ screw-cap vials and kept at $-35^{\circ} \mathrm{C}$ until further analysis. The flux was calculated by using the weight of collected permeate in a period of time (around 2 hours) per unit membrane surface area. Selectivity was calculated from the chromatographic analysis.

In this study, the effect of feed temperature, the permeate pressure and the effect of feed concentration on flux and selectivity was determined for aroma compounds of strawberry. First, three different temperatures (30, 40, $\left.50^{\circ} \mathrm{C}\right)$ were studied at two different downstream pressures $(4,8 \mathrm{mbar})$ for methyl butyrate (100 ppm) solution. Then, the temperature and pressure giving maximum flux and selectivity were determined and the following experiments were carried out at this condition. Subsequently, the effect of feed concentration $(50,100,150 \mathrm{ppm})$ was examined for methyl butyrate-water and 
ethyl butyrate-water binary mixtures. Next, in order to observe whether there was any coupling effect or not, pervaporation experiment was performed with a ternary mixture of methyl butyrate-ethyl butyrate-water. Finally, an experiment with a strawberry essence and with a model solution containing strawberry juice matrix were performed. The feed flow rate was kept constant during the experiments for all runs, as $780 \mathrm{ml} / \mathrm{min}$ to prevent concentration polarization. Pervaporation experiments were repeated twice at each experimental condition.

\subsection{Chromatographic Analysis}

The calculation of selectivity requires the knowledge of feed and permeate concentrations. Compositions of permeate was determined by using a Gas Chromatography (Shimadzu GC-14A, Japan) equipped with a CP-SIL 5CB (100\% dimethyl siloxane) Varian chrompack capillary column (25m X $0.25 \mathrm{~mm}$ ID $\mathrm{X} 0.2 \mu \mathrm{m}$ film thickness). Helium at $1 \mathrm{ml} / \mathrm{min}$ constant flow rate was used as the carrier gas. The GC oven temperature was kept at $60^{\circ} \mathrm{C}$ for 10 min and raised up to $260^{\circ} \mathrm{C}$ at a rate of $5^{\circ} \mathrm{C} /$ minute and kept constant at that temperature for 10 minutes. The injection and detector (FID) temperatures were both $250{ }^{\circ} \mathrm{C}$. Splitless injection mode was used during sampling and the split valve being opened after 10 minutes. The peak area versus concentration (ppm) of standard solutions was plotted for each chemical and calibration curves were obtained. By the help of these calibration curves the concentration of aroma compounds in permeate, and consequently the selectivities were calculated.

The analysis of strawberry essence was performed by using a Gas Chromatography-Mass Spectroscopy (ThermoQuest (TSP), Trace GC-2000 Series) equipped with Phenomenex Zebran ZB-5 capillary column ( 5\% 
phenylmethylsiloxane, $30 \mathrm{~m}, 250 \mu \mathrm{m} ; \mathrm{T}_{\mathrm{GC}}$ injector $=250{ }^{\circ} \mathrm{C}, \mathrm{T}_{\mathrm{MS}}$ (ion source) $=200$ ${ }^{\circ} \mathrm{C}$, MS: ThermoQuest Finnigon multi Mass (EI, 70ev)). The oven temperature was first kept at $60{ }^{\circ} \mathrm{C}$ for $10 \mathrm{~min}$ and raised up to $150{ }^{\circ} \mathrm{C}$ at a rate of 20 ${ }^{\circ} \mathrm{C} / \mathrm{min}$, then after 5 minutes of holding time, the oven temperature was raised up to $240{ }^{\circ} \mathrm{C}$ at the same rate and kept constant at that temperature for 5 minutes. The splitless injection mode was used during sampling. 


\section{CHAPTER 3}

\section{RESULTS \& DISCUSSION}

\subsection{Optimization of SPME for strawberry aroma}

The optimization experiments have been performed with a model solution containing 6 aroma compounds (methyl butyrate, ethyl butyrate, butyl butyrate, methyl caproate, ethyl caproate and linalool), which are the most important contributors to strawberry aroma. The pure aroma compounds were first given into the GC individually in order to determine their retention times. Table 3.1 summarizes the retention times of relevant aroma compounds.

The extraction mode selection depends on the nature of the sample matrix. Among the two-extraction mode (direct injection and headspace), headspace is the best for the extraction of volatile aroma compounds as they can be easily extracted from the gas phase. 
Table 3.1 Average retention times of strawberry aroma compounds (Fig.B1)

\begin{tabular}{cc}
\hline Compound name & Retention time (min) \\
\hline Methyl butyrate & 6.46 \\
Ethyl butyrate & 11.23 \\
Methyl caproate & 23.42 \\
Butyl butyrate & 28.02 \\
Ethyl caproate & 28.21 \\
Linalool & 33.36 \\
\hline
\end{tabular}

\subsubsection{Effect of Extraction Temperature}

The effect of extraction temperature was investigated at $700 \mathrm{rpm}$ for 30 min. Three different extraction temperatures were selected $\left(30,40,50^{\circ} \mathrm{C}\right)$. The effect of temperature on the area counts of the model solution is shown in Figure 3.1. It was found that the temperature increase had a little effect on the extraction of ethyl butyrate and methyl butyrate, however a noticeable increase in the amount absorbed was observed for the rest of the compounds as the temperature increased. At $50^{\circ} \mathrm{C}$ the amount absorbed started to decrease significantly for butyl butyrate and ethyl caproate. At temperatures lower than $40^{\circ} \mathrm{C}$ due to decrease in diffusion, equilibrium has not reached and less of the analytes are absorbed. At temperature above $40^{\circ} \mathrm{C}$, although equilibrium is reached, partition coefficient decreases, because absorption is an exothermic process (Arthur et al., 1992). From Figure 3.1 the optimum extraction temperature was determined as $40^{\circ} \mathrm{C}$ and the following experiments were performed at this temperature. 


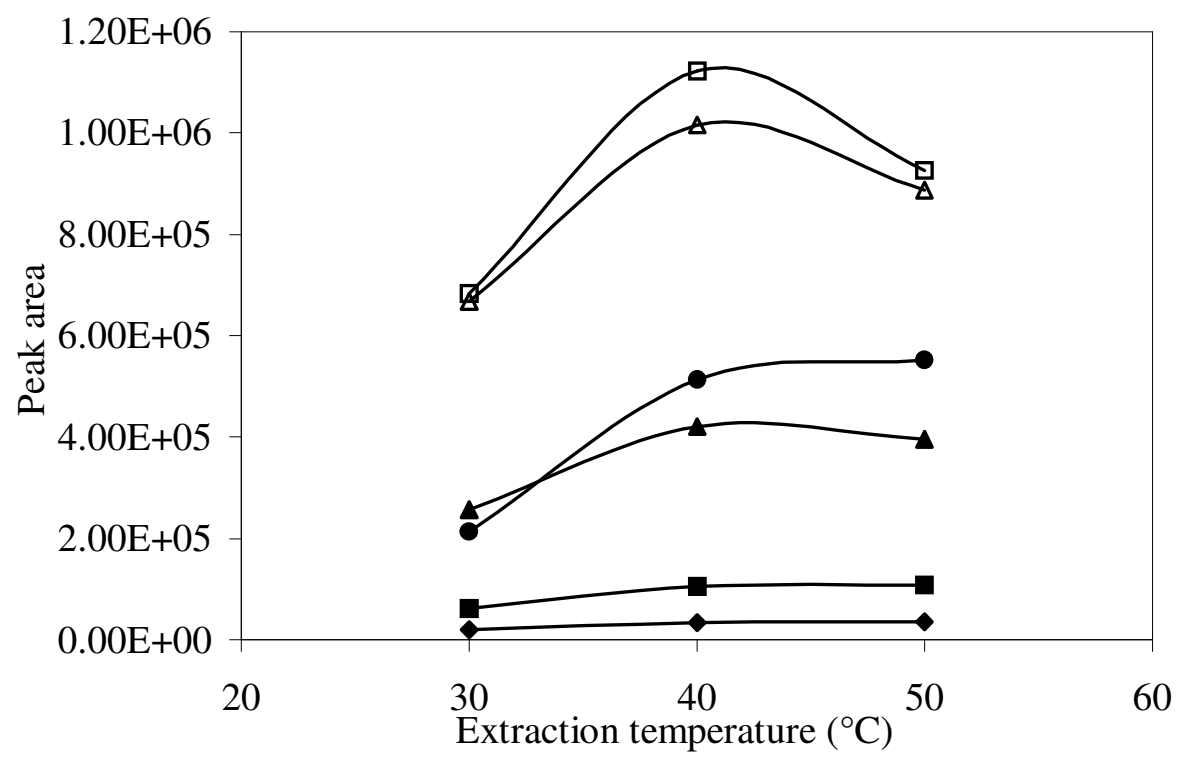

Figure 3.1 Effect of extraction temperature on peak areas of aroma compounds at $700 \mathrm{rpm}$ for 30 minutes extraction

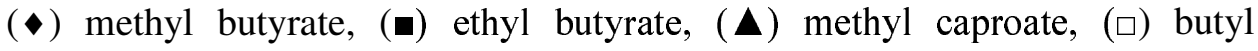
butyrate, $(\Delta)$ ethyl caproate, $(\bullet)$ linalool

\subsubsection{Effect of Agitation Speed}

Agitation accelerates the transfer of analytes from the sample matrix to the coating fiber. Although the equilibration time progressively decrease with increasing agitation rate, faster agitation tends to be uncontrollable and the rotational speed might cause a change in the equilibration time and poor measurement precision (Kataoka et al., 2000). Figure 3.2 shows that the peak areas reach their maximum at $700 \mathrm{rpm}$. This agitation speed is the $50 \%$ of the 
maximum stirring speed. As the stirring rate approaches to $50 \%$, the stir bar rotates more quickly and mixing is progressively better. After $50 \%$ the mixing efficiency decreases, because the stir bar no longer rotates completely but it vibrates instead. Therefore, the optimum stirring speed was selected as 700 rpm. The similar result was also observed by Arthur et al (1992). This effect was explained by poor coupling between the magnetic field of the stirrer and stir bar because of the geometry of the equipment.

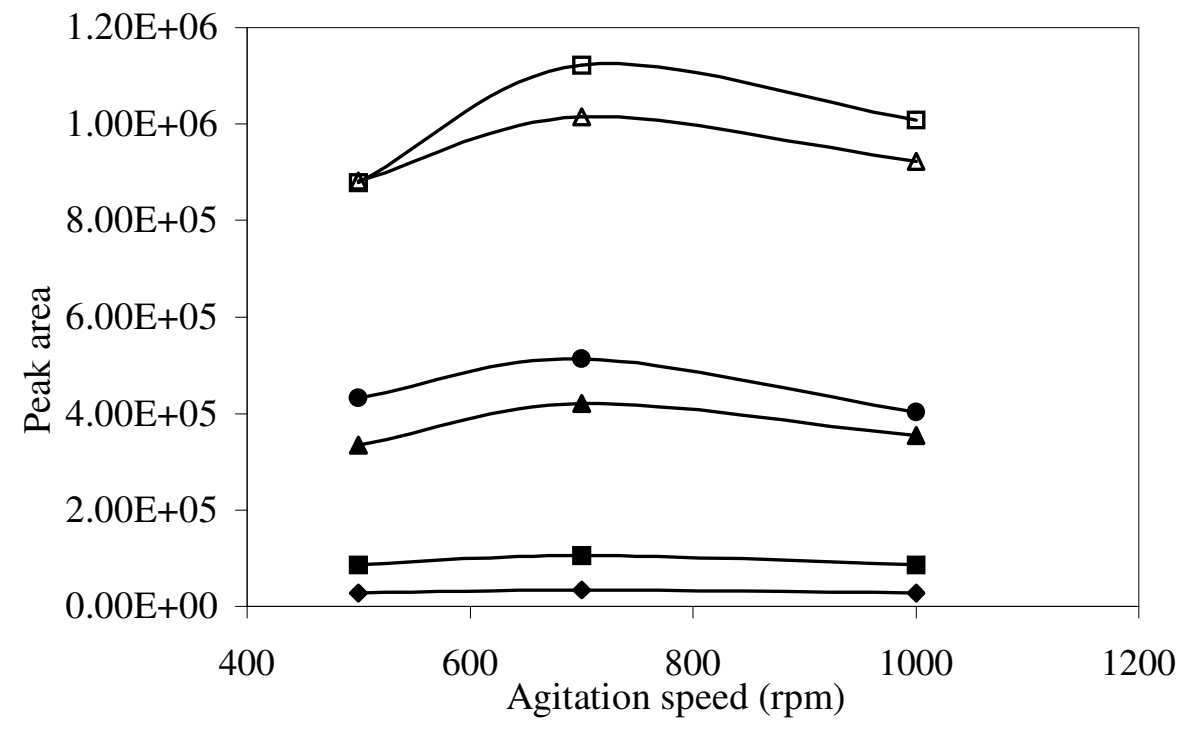

Figure 3.2 Effect of agitation speed on peak areas of aroma compounds at $40^{\circ} \mathrm{C}$ for 30 minutes extraction

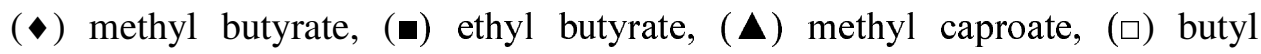
butyrate, $(\Delta)$ ethyl caproate, $(\bullet)$ linalool 


\subsubsection{Effect of Extraction Time}

SPME mechanism depends on the equilibrium of analyte between the aqueous phase and solid fiber; therefore time of equilibrium should be taken as the optimum time for extraction. Components of a multicomponent mixture reach the equilibrium at different times (Bartelt, 1997) and the analytes having various sizes and boiling points may display each other (Furton et al., 1995).

Different times were examined at optimum temperature $\left(40^{\circ} \mathrm{C}\right)$ and agitation speed $(700 \mathrm{rpm})$. As can be seen in Figure 3.3, all of the aroma compounds have achieved their equilibrium at 30 minute. In addition, some of the compounds start to desorb after 30 min such as ethyl caproate and linalool. Desorption of the aroma compounds after 40 minutes of extraction by SPME have been also observed by other researchers (Rodriguez-Bencomo et al., 2002). Since all of the compounds reached their equilibrium at 30 minute, optimum extraction time can be taken as 30 minutes. 


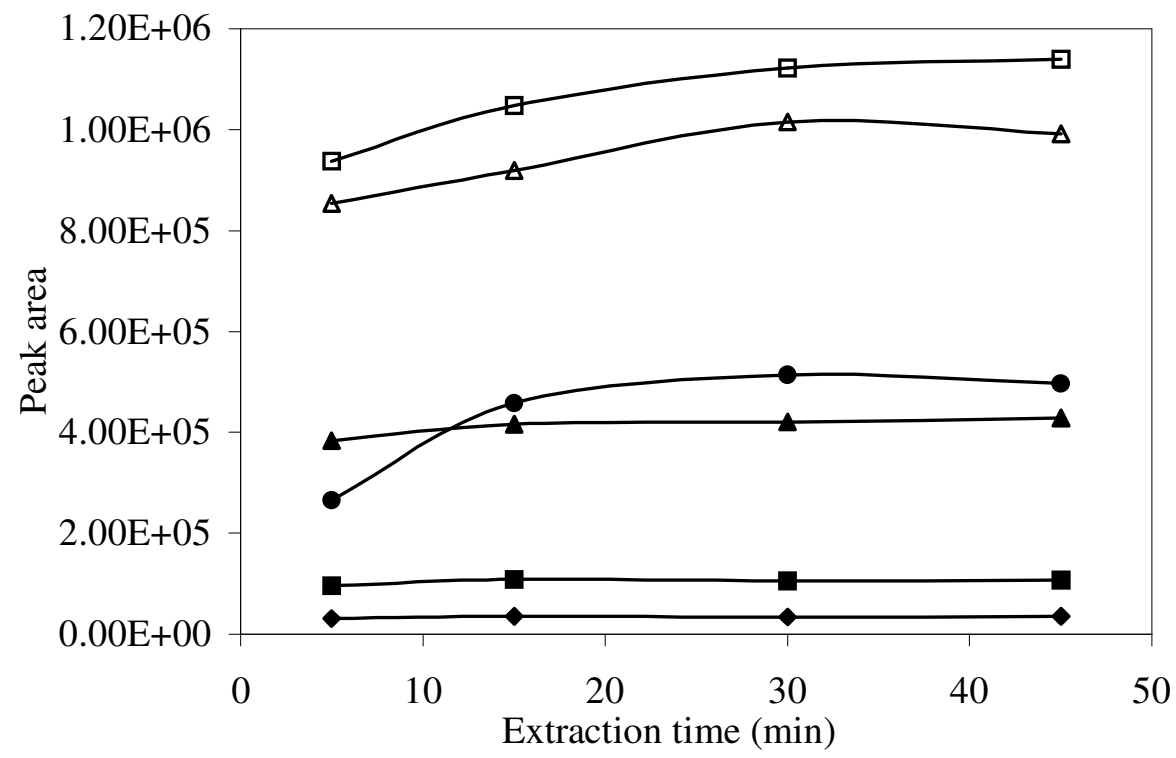

Figure 3.3 Effect of extraction time on peak areas of aroma compounds at $40^{\circ} \mathrm{C}$ and $700 \mathrm{rpm}$

(•) methyl butyrate, ( $\square$ ) ethyl butyrate, ( $\mathbf{\Delta})$ methyl caproate, ( $\square$ ) butyl butyrate, $(\Delta)$ ethyl caproate, $(\bullet)$ linalool 


\subsubsection{Effect of Strawberry Matrix}

The final parameter, studied, was the effect of sample media. It is known that the partition coefficients of the analytes are affected by the composition of the aqueous matrix. As can be concluded from Figure 3.4, there was no matrix effect and the model solution that was used to determine the optimum point for the extraction can be applicable for the real strawberry juice. Lack of matrix effect was also observed previously (Rodriguez-Bencomo et al., 2002). 


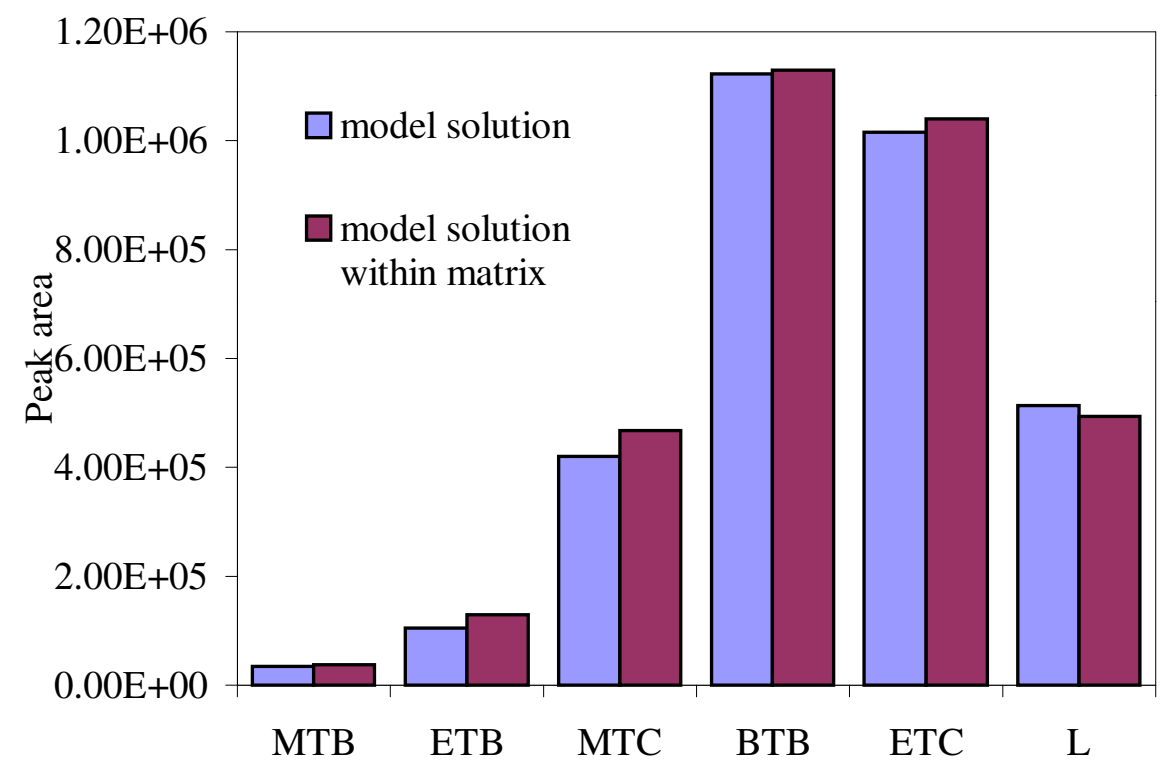

Figure 3.4 Matrix effect on peak areas of aroma compounds at $40^{\circ} \mathrm{C}$ and 700rpm for 30 minutes extraction

MTB: methyl butyrate, ETB: ethyl butyrate, MTC: methyl caproate, BTB: butyl butyrate, ETC: ethyl caproate, L: linalool

\subsection{Pervaporation of Model Strawberry Juice Aroma Solution}

Pervaporation experiments have been performed using model solutions containing the most important aroma compounds in strawberry juice. First, the effect of temperature and pressure on pervaporation performance was studied with methyl butyrate-water solution. Then, the effects of feed concentration for binary methyl butyrate-water and ethyl butyrate-water solutions were determined. Next, pervaporation experiments were performed for methyl 
butyrate-ethyl butyrate-water ternary system, strawberry essence and strawberry model solution containing six aroma compounds (methyl butyrate, ethyl butyrate, butyl butyrate, methyl caproate, ethyl caproate, linalool).

The performance of the pervaporation was evaluated by using steady state fluxes and selectivities. It was observed that, the time required for steady state condition to be reached varied between 4 to 6 hours. Figure 3.5 and 3.6 were given as sample graphs to observe the variation of flux and selectivity with time, respectively.

All the experiments were replicated twice and the flux and selectivity values were compared each other. The experiments that were repeated by using different cuts of the membrane gave almost the same flux and selectivity under the same conditions. The average percent deviations from the mean were calculated and the maximum percent deviations from the mean were found to be $7.2 \%$ for fluxes and $4.1 \%$ for the selectivities. In the literature, it was mentioned that the average deviations up to $40 \%$ was allowable (Huang, 1991). Therefore, the pervaporation experiments were performed in a reproducible manner. Standard errors in the data varied from $\pm 6.78 * 10^{-4}$ to $\pm 4.39 * 10^{-3}$ $\mathrm{kg} / \mathrm{m}^{2} \mathrm{~h}$ for fluxes and \pm 0.03 to \pm 4.13 for selectivities after steady-state condition was reached.

As mentioned before, the membranes were kept in feed solutions for at least two days before the experiments. During this time the membrane absorbs the feed and swallows, therefore, results in initially high fluxes. As can be seen in Figure 3.5, at the beginning the flux was relatively high and fell to a constant level when the steady state was achieved.

Similarly, as the concentration profile across the membrane develops during pervaporation, the concentration profile of the more permeating species increases at the vacuum side of the membrane. Figure 3.6 shows the change of selectivity with elapsed time. It can be seen that, selectivity increased with time until the fully developed concentration profile was attained. 


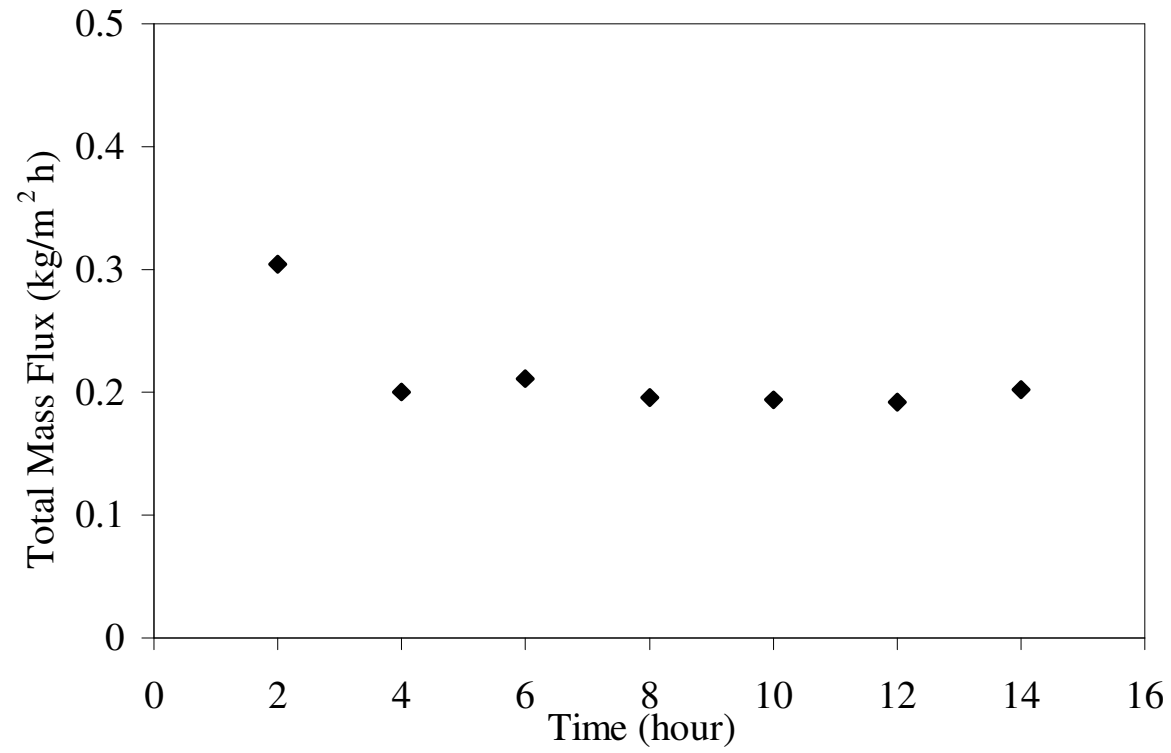

Figure 3.5 Change of total mass flux with time for 100ppm methyl butyrate solution at $50{ }^{\circ} \mathrm{C}, 8 \mathrm{mbar}$ 


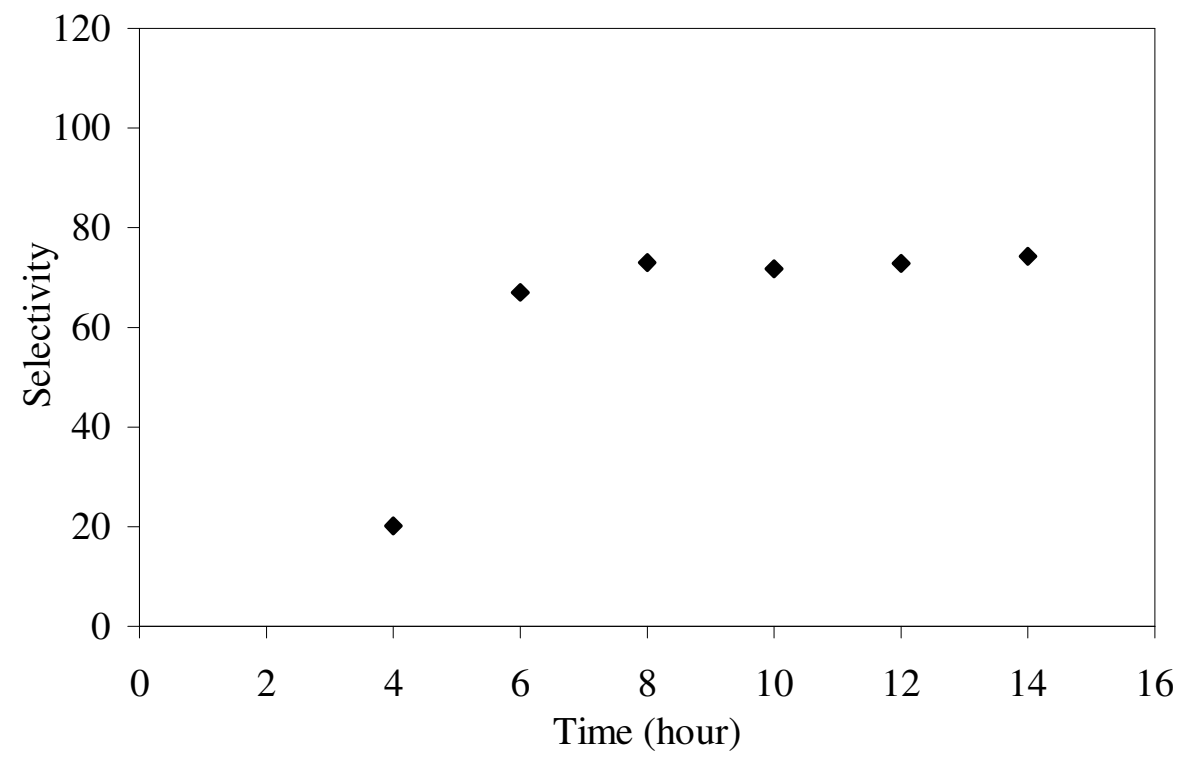

Figure 3.6 Change of selectivity with time for 100ppm methyl butyrate solution at $50^{\circ} \mathrm{C}, 8 \mathrm{mbar}$

After steady state condition had been achieved, at least 5 data were collected which took at least 10 hours and the following flux and selectivity data that are presented below are the averages of the steady state data.

\subsubsection{Effect of Feed Temperature and Pressure}

The increase in both total and organic fluxes as the feed temperature increases was an expected phenomenon. It is known that the properties of the compounds, both in the feed solution (diffusivity and viscosity) and in the 
membrane (permeability) are affected by the temperature increase in the feed solution. In addition, in pervaporation, the permeating molecules diffuse through the free volumes of the membrane. The thermal motion of the polymer chain in the amorphous regions randomly produces free volume. As the temperature increases, the frequency and amplitude of the polymer chain jumping increase (Mark, 1984). As a result the free volume in the membrane increases. Thus, when the temperature increases, the diffusion rate of individual permeating molecules increases, leading to a high permeation flux (Figure 3.7 and 3.8).

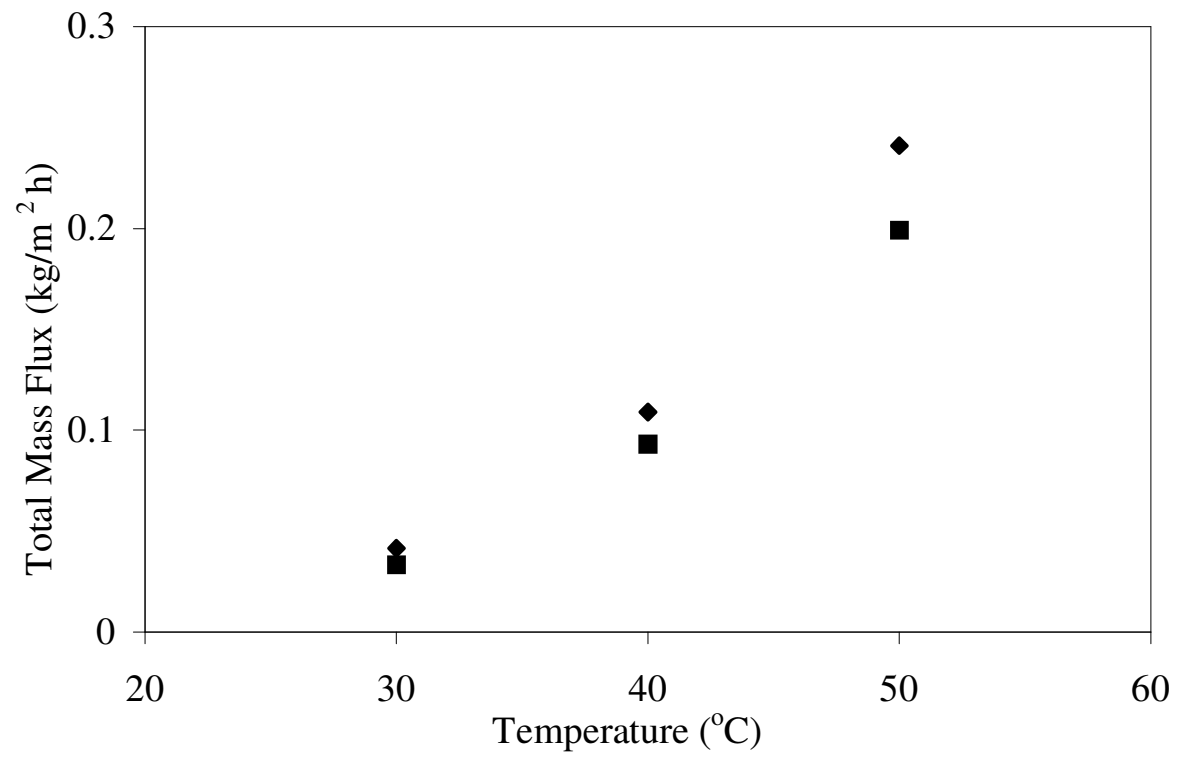

Figure 3.7 Effect of feed temperature on total mass flux at different downstream pressures for 100 ppm methyl butyrate solution

( $) 4$ mbar, ( $\square) 8$ mbar 


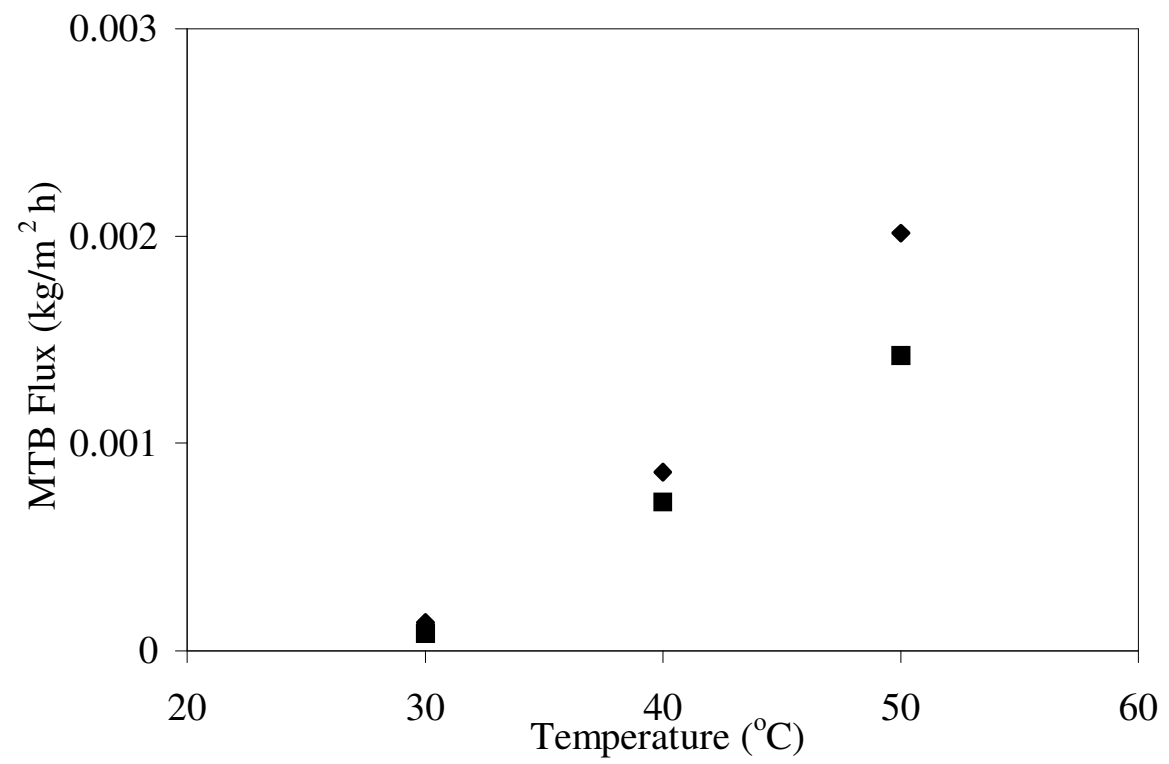

Figure 3.8 Effect of feed temperature on methyl butyrate flux at different downstream pressures for $100 \mathrm{ppm}$ methyl butyrate solution

(•) 4 mbar, (-) 8 mbar

In pervaporation another important parameter is the pressure difference across the membrane. Variations in permeate pressure directly affects the chemical potential gradient through the membrane, thus the fluxes are influenced by the downstream pressure. As the permeate pressure increases, the driving force for the permeation through the membrane decreases, resulting in a reduction in the permeation flux. Therefore, at lower downstream pressures, since the driving force for the permeation through the membrane increases, both total and component fluxes increase (Figure 3.7-3.9). In addition, it can be seen from the same figures that the permeate pressure is much more effective at higher feed temperatures. This may be contributed to the diffusivities of the 
permeating species. At higher feed temperatures both the free volume of the membrane and the diffusivities of the permeating species increases, subsequently the effect of downstream pressure becomes much more dominant.

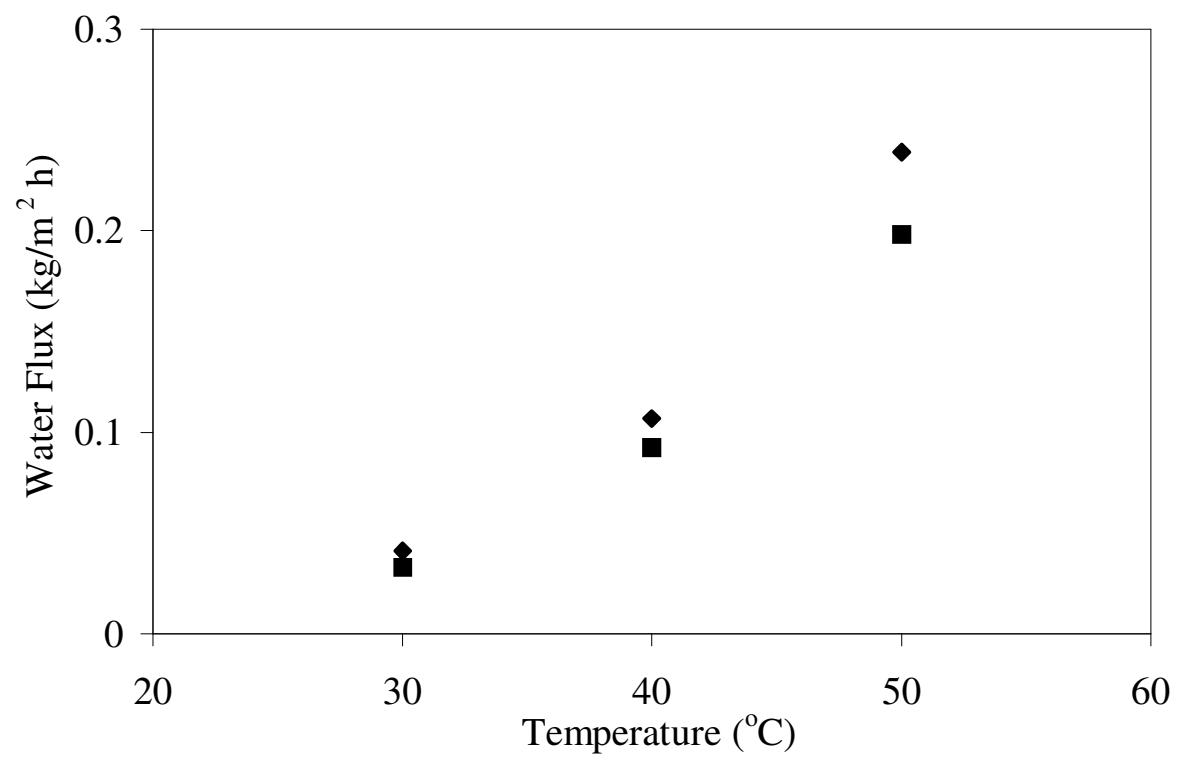

Figure 3.9 Effect of feed temperature on water flux at different downstream pressures for $100 \mathrm{ppm}$ methyl butyrate

( 4 ) mbar, ( $\mathbf{\square} 8$ mbar

Arrhenius plot of total mass flux is presented in Figure 3.10. The linear relationship between logarithm of fluxes and the reverse of temperature indicated that behavior of the membrane followed Arrhenius law. The temperature dependence of component fluxes were also explained by Arrhenius equation, the coefficient of determination $\left(\mathrm{r}^{2}\right)$ at least 0.93 . The 
activation energies for permeation of water and methyl butyrate (MTB), calculated from the slopes of individual Arrhenius plots (Equation 14), are shown in Table 3.2. The activation energy for change in overall flux is also presented in the same table. As can be seen from Table 3.2 the activation energy of MTB is higher than that of water, indicating that the permeation of water through the membrane is less temperature dependent than that of MTB. When the value of $E_{a}$ is high, the flux will be more sensitive to changes in temperature, therefore MTB was more responsive to temperature increase and generally showed a faster increase of flux.

The result of increase in both total and component fluxes at lower downstream pressure can also be concluded from Table 3.2. Since the activation energies are lower at lower permeate pressure (i.e. 4 mbar), the permeation of species through the membrane is much easier and thus resulting in higher corresponding mass fluxes. 


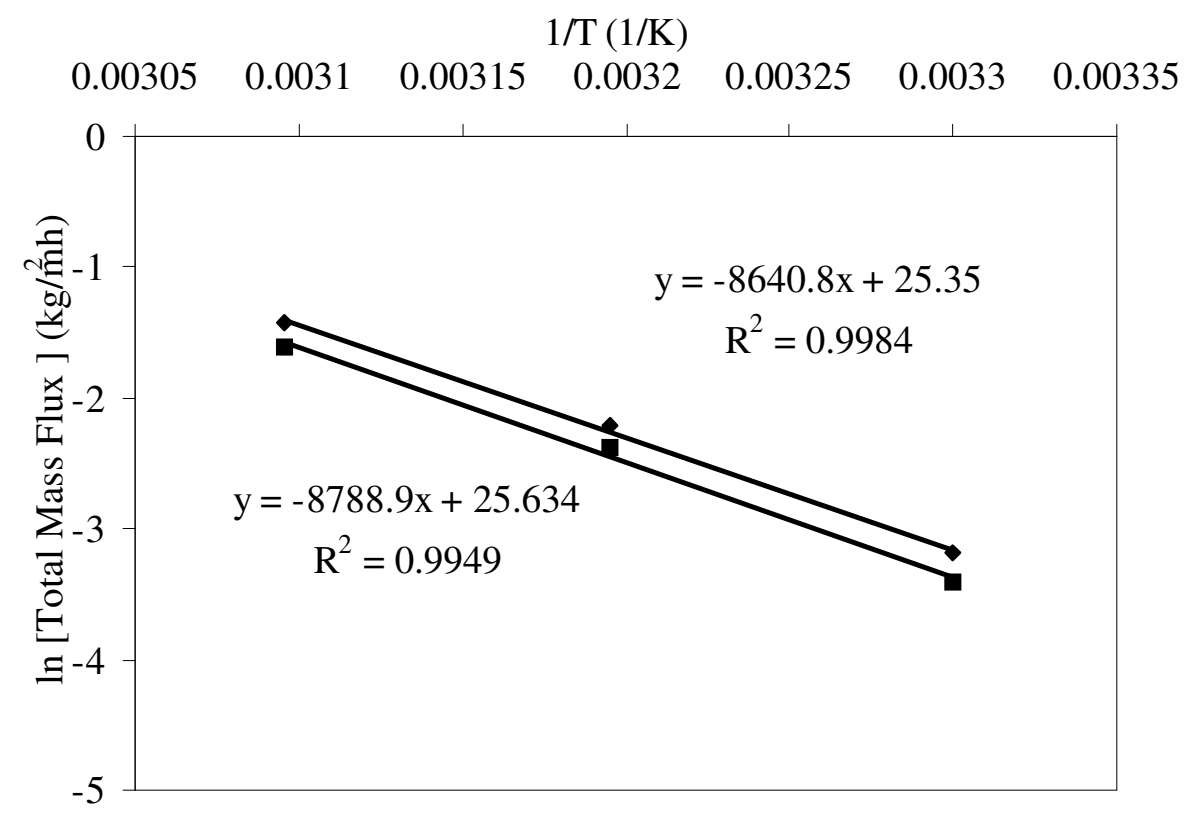

Figure 3.10 Arrhenius type relation on total mass flux (•) 4mbar, (ロ) 8mbar

Table 3.2 Activation energies $(\mathrm{kJ} / \mathrm{gmol})$ that are calculated from Arrhenius plots

\begin{tabular}{cccccccc}
\hline $\begin{array}{c}\text { Downstream } \\
\text { Pressure }\end{array}$ & Water Flux & \multicolumn{2}{c}{ Methyl Butyrate } & \multicolumn{2}{c}{ Overall Flux } \\
& $\mathrm{E}_{\mathrm{a}}$ & $\mathrm{r}^{2}$ & $\mathrm{E}_{\mathrm{a}}$ & $\mathrm{r}^{2}$ & $\mathrm{E}_{\mathrm{a}}$ & $\mathrm{r}^{2}$ \\
\hline 4 mbar & 71.7 & 0.9987 & 110.2 & 0.9632 & 71.8 & 0.9984 \\
& & & & & & \\
8 mbar & 73.0 & 0.9952 & 117.1 & 0.9266 & 73.1 & 0.9949 \\
& & & & & & \\
\hline
\end{tabular}


The effects of feed temperature and permeate pressure on selectivity of 100 ppm MTB solution can be seen in Figure 3.11. Generally, the selectivity of MTB increased as the feed temperature increased. As mentioned above, MTB flux is much more sensitive to temperature increase, thus leading to an increase in selectivity as the feed temperature increases from $30^{\circ} \mathrm{C}$ to $40^{\circ} \mathrm{C}$. On the other hand, although the organic flux increases with increase in temperature, the water flux also increases with the same portion at higher feed temperatures (i.e. 40 and $50^{\circ} \mathrm{C}$ ). The permeation of small sized water clusters becomes more easier when the free volume of the membrane increases. For these reasons, selectivity seems getting constant for higher feed temperatures. Moreover, the selectivity can increase or decrease with increase in permeate pressure, depending on the relative volatility of the permeating components (Huang, 1991). As it was stated since the driving force was higher at lower downstream pressures, the selectivities were higher consequently. 


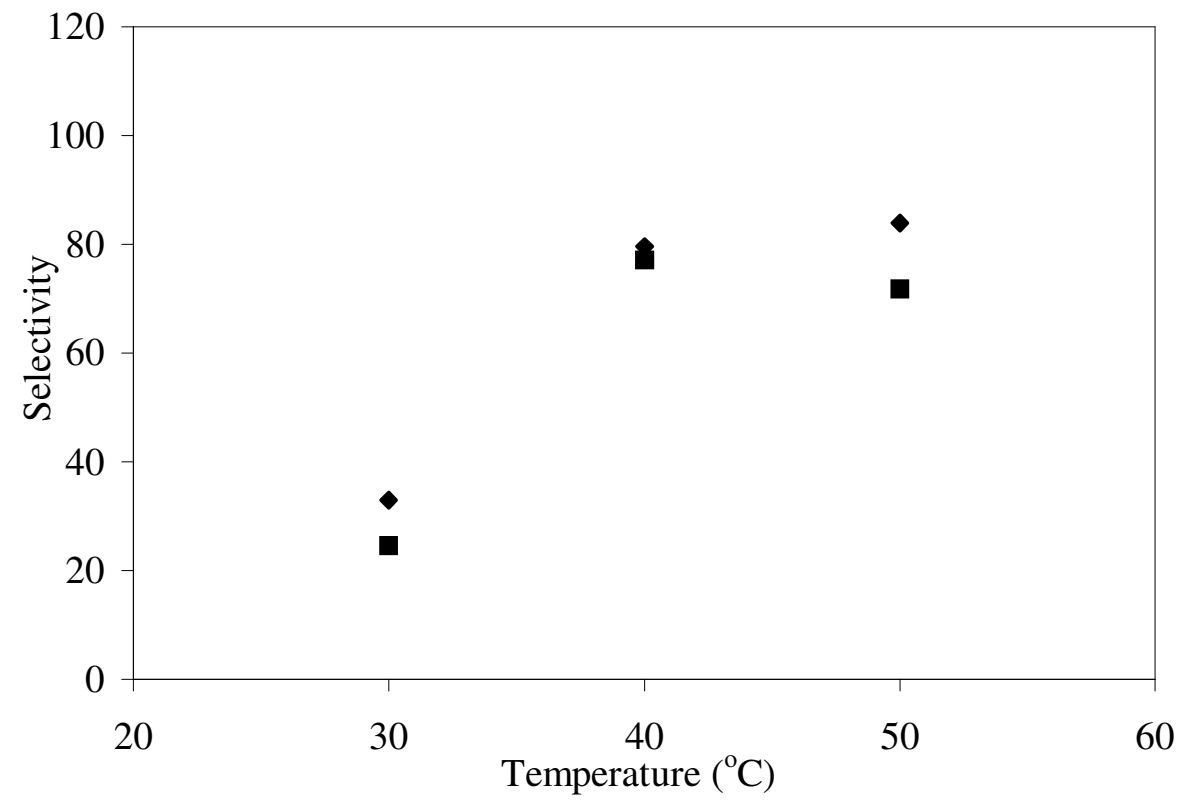

Figure 3.11 Effect of feed temperature on selectivity of 100 ppm methyl butyrate solution at different downstream pressures

(•) 4mbar, (匹) 8mbar

As can be concluded, as the flux increased, the selectivity also increased. The same trend has been also observed by other researchers (Karlsson et al., 1994; Rajagopalan and Cheryan, 1995). However, there are other studies in which the opposite trend was observed (Sampranpiboon et al., 2000; Korkut, 2001; Jiraratananon et al., 2002; Inal, 2003). 


\subsubsection{Effect of Feed Concentration in Binary Mixtures}

As cited before, a change in feed composition directly influences the sorption phenomena at the liquid-membrane interface. Figure 3.12, 3.13 and 3.14 show the effect of feed concentration on total, organic and water fluxes, respectively. It can be seen that when the concentration of organic molecules increases in the feed, the permeation flux of methyl butyrate (MTB) and ethyl butyrate (ETB) increases linearly, while water flux and total mass flux remains relatively constant. Due to high dilution of the feed solution, total and water fluxes may not be affected by the little changes in the feed concentration.

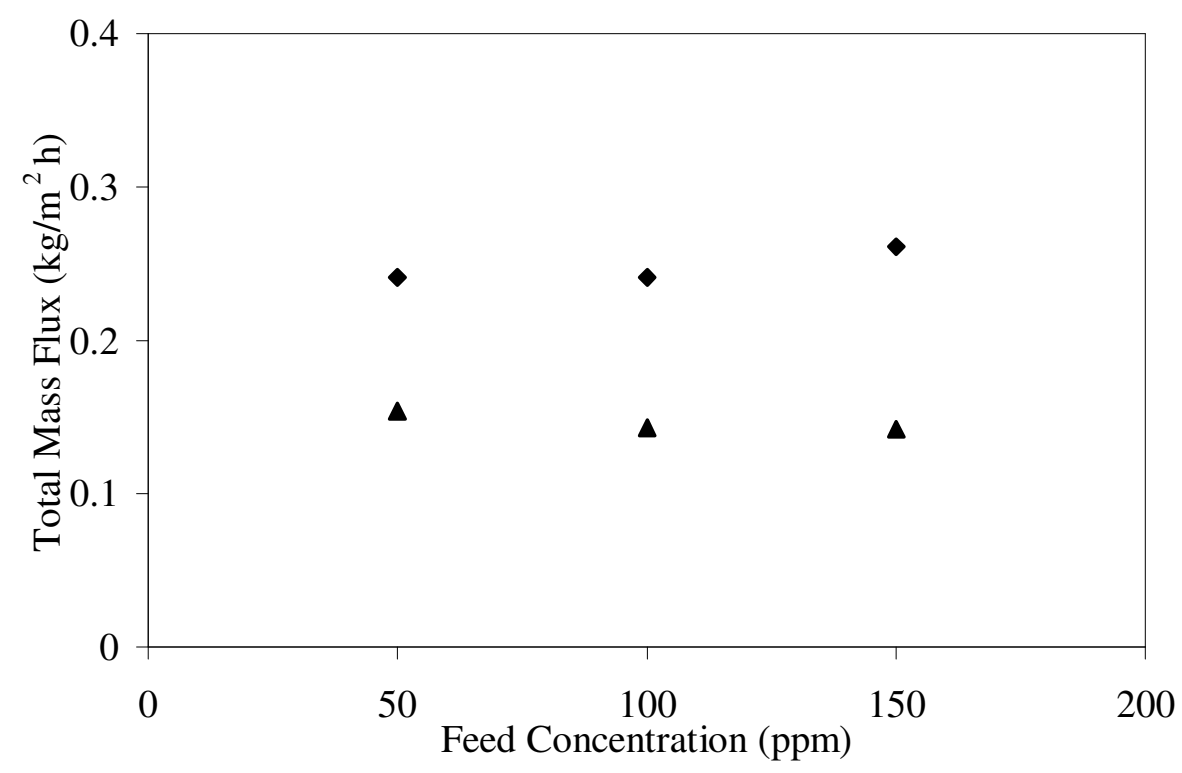

Figure 3.12 Effect of feed concentration on total mass flux at $50^{\circ} \mathrm{C}, 4 \mathrm{mbar}$ (•) methyl butyrate, $(\boldsymbol{\Delta})$ ethyl butyrate 


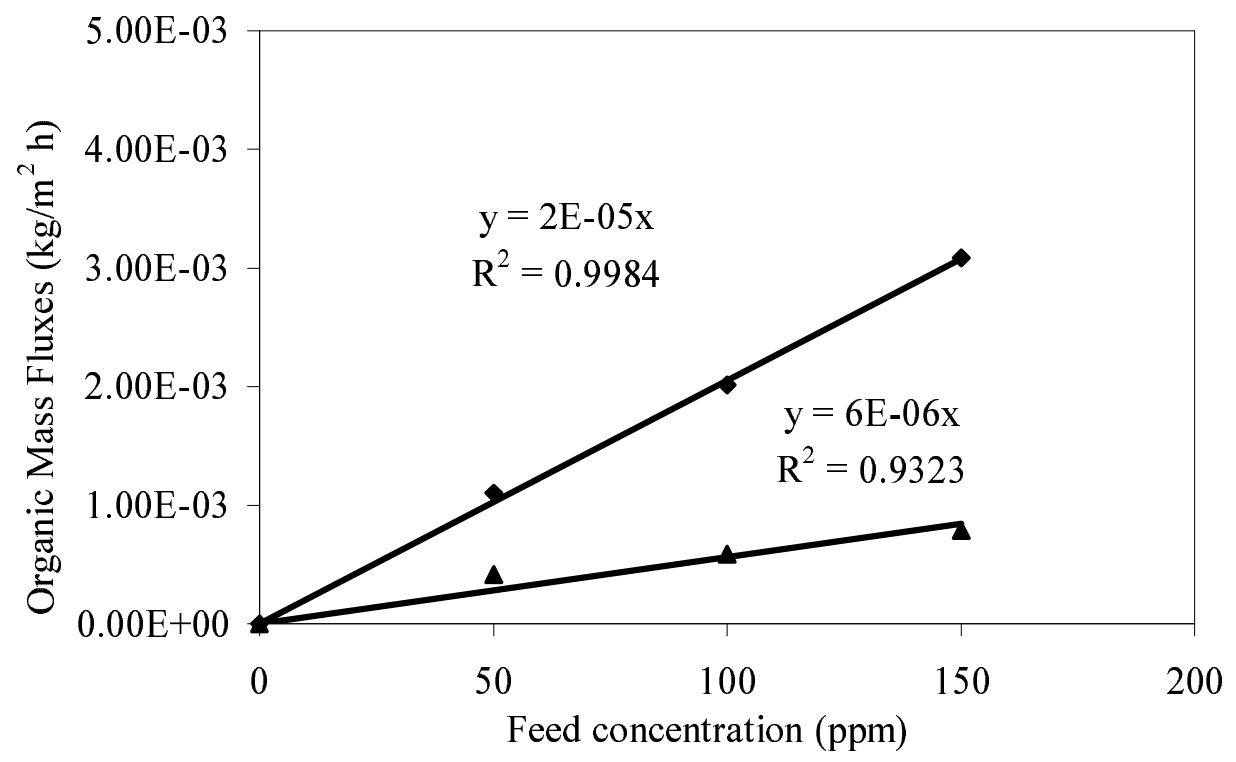

Figure 3.13 Effect of feed concentration on organic mass fluxes at $50^{\circ} \mathrm{C}, 4$ mbar

(•) methyl butyrate, ( $\mathbf{\Delta})$ ethyl butyrate 


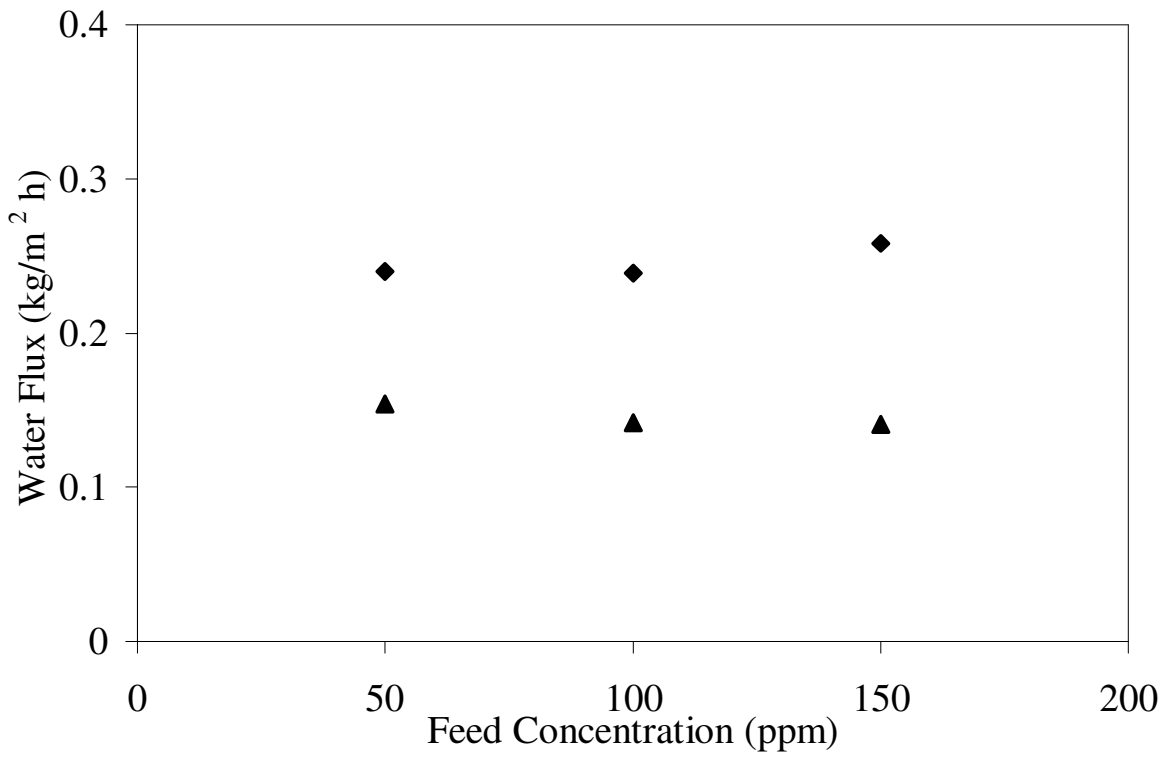

Figure 3.14 Effect of feed concentration on water fluxes of binary solutions at $50^{\circ} \mathrm{C}, 4$ mbar

( ) methyl butyrate solutions, ( $\boldsymbol{\Delta}$ ) ethyl butyrate solutions

Although, the increase in feed concentration causes linear increase in both MTB and ETB fluxes, the increase in permeate concentration is less than the increase in feed concentration, thus leading to a decrease in separation factor (Figure 3.15). The reason can be contributed to the reduction of activity coefficient of aroma compound in the feed solution as the concentration increases in it, resulting in increase in the sorption of the organic molecules in the membrane (Lamer et al., 1994) and the membrane becomes more swollen due to its high affinity towards organic molecules. As a result, small water clusters can permeate through the swollen area much more easily. 


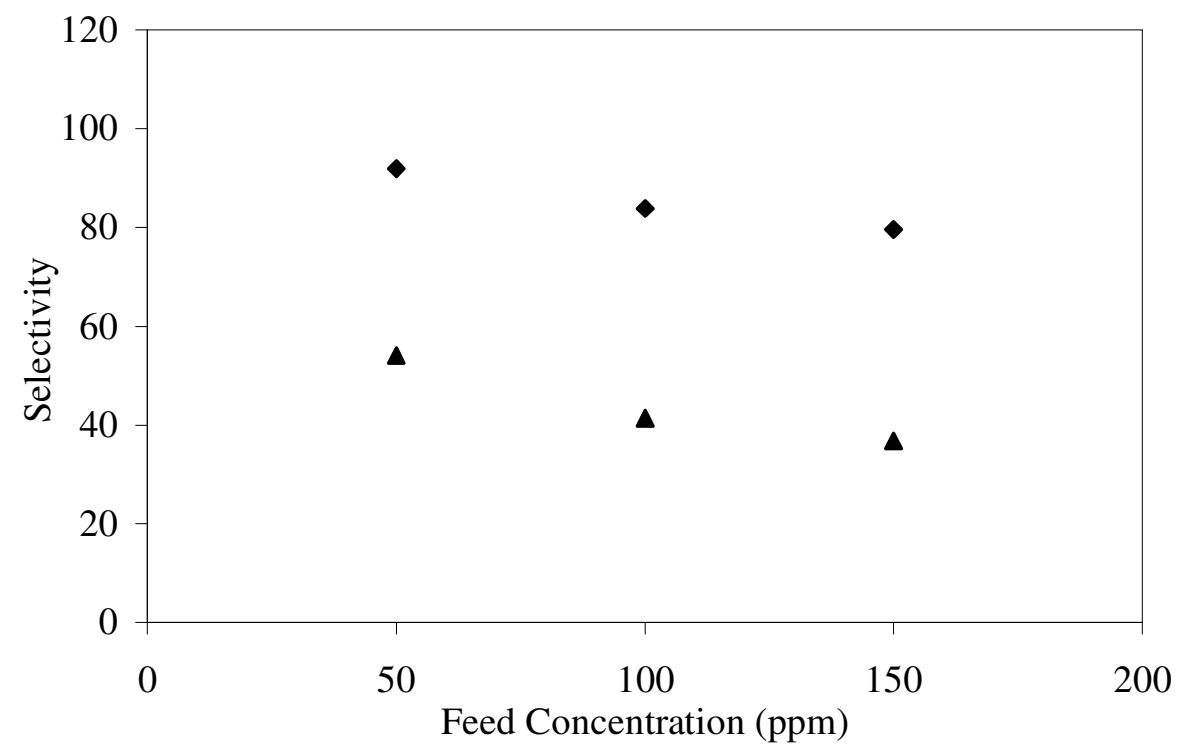

Figure 3.15 Effect of feed concentration on selectivities of binary solutions at $50^{\circ} \mathrm{C}, 4 \mathrm{mbar}$

(•) methyl butyrate, $(\boldsymbol{\Delta})$ ethyl butyrate

Among the two esters studied in separated binary mixtures, the MTB flux is higher than that of ETB (Figure 3.13) and the membrane is approximately two times more selective towards MTB than ETB (Figure 3.15). The permeability of molecules through a specific membrane depends on so many parameters and hence it is really difficult to explain the selectivity of a membrane towards a molecule by just considering one property of the molecule/membrane. The permeabilities of individual compounds in the membrane can be calculated from the slopes of Figure 3.13 by using Equation (7) as $4.8 \times 10^{-10}$ and $1.6 \times 10^{-10} \mathrm{~m}^{2} / \mathrm{sec}$ for MTB and ETB, respectively. The higher permeability of MTB can be explained in terms of molecular size. Since 
molecular weight of MTB is lower than ETB (Table 2.1), the molar volume is lower and consequently the diffusivity of MTB in water is higher than that of ETB, resulting in higher MTB flux with respect to ETB.

In addition, the higher selectivity of a membrane towards one component can also be explained by solubility parameters. Table 3.3 shows the total solubility parameters of MTB, ETB and related compounds. In liquids, it is known that, there exists strong forces between the molecules and the potential energy of the molecules which is called cohesive energy. The intermolecular forces contributing to the cohesive energy can be divided into 3; non-polar interactions, polar interaction and hydrogen bonding (Huang, 1991). The solubility parameters that are presented in Table 3.3 are generally the sum of these individual interactions. As can be seen from Table 3.3, the solubility parameters of MTB and ETB are not significantly different therefore it would be better to compare Hildebrand solubility parameters while explaining their preferential sorption by the membrane. 
Table 3.3 Solubility parameters and diffusivities of some compounds

\begin{tabular}{ccc}
\hline $\begin{array}{c}\text { Substances } \\
\end{array}$ & $\begin{array}{c}\text { **ansen Solubility } \\
\text { Parameters }(\mathbf{M P a})^{\mathbf{1 / 2}}\end{array}$ & $\begin{array}{c}\text { *Diffusivities in } \\
\text { water } \mathbf{~ a t ~} \mathbf{5 0} \mathbf{~}^{\circ} \mathbf{C} \\
\left(\mathbf{m}^{\mathbf{2}} \mathbf{/ s}\right)\end{array}$ \\
\hline Water & 47.9 & - \\
Methyl Butyrate & 18.2 & $1.62 \times 10^{-9}$ \\
Ethyl Butyrate & 17.4 & $1.47 \times 10^{-9}$ \\
PDMS & 16.6 & - \\
\hline
\end{tabular}

*Solubility parameters are taken from Polymer Handbook (Grulke, 1975) and Diffusivities are calculated by the help of Wilke-Chang equation (Geankoplis, 1993).

\subsubsection{Pervaporation Performance in MTB - ETB - Water Ternary Mixture}

It is a well known phenomenon that the presence of other molecules in the feed solution affects the fluxes and selectivities either negatively or positively. In Figure 3.16, the enrichment factors of organic compounds over water in binary and ternary mixtures can be compared. From the figure we can conclude that the enrichment factors have not been affected by the presence of other organic molecules. Moreover, in this figure it is much more obvious that, the selectivity of membrane towards MTB is 2 times higher than ETB. However, in order to be sure about influence of coupling affect, we should also 
check out the partial organic fluxes both in binary and ternary mixtures. If there were no significant interactions between the two permeating aroma compounds their individual permeation fluxes would be the same as those for the cases of binary mixture pervaporation involving a single aroma compound under the same operating conditions (Sampranpiboon et al., 2000). Figure 3.17 shows us that the MTB flux is retarded to its half by the presence of ETB in the feed solution, whereas ETB flux remains practically constant. This shows us that MTB is much more sensitive to changes in composition of feed solution than ETB.

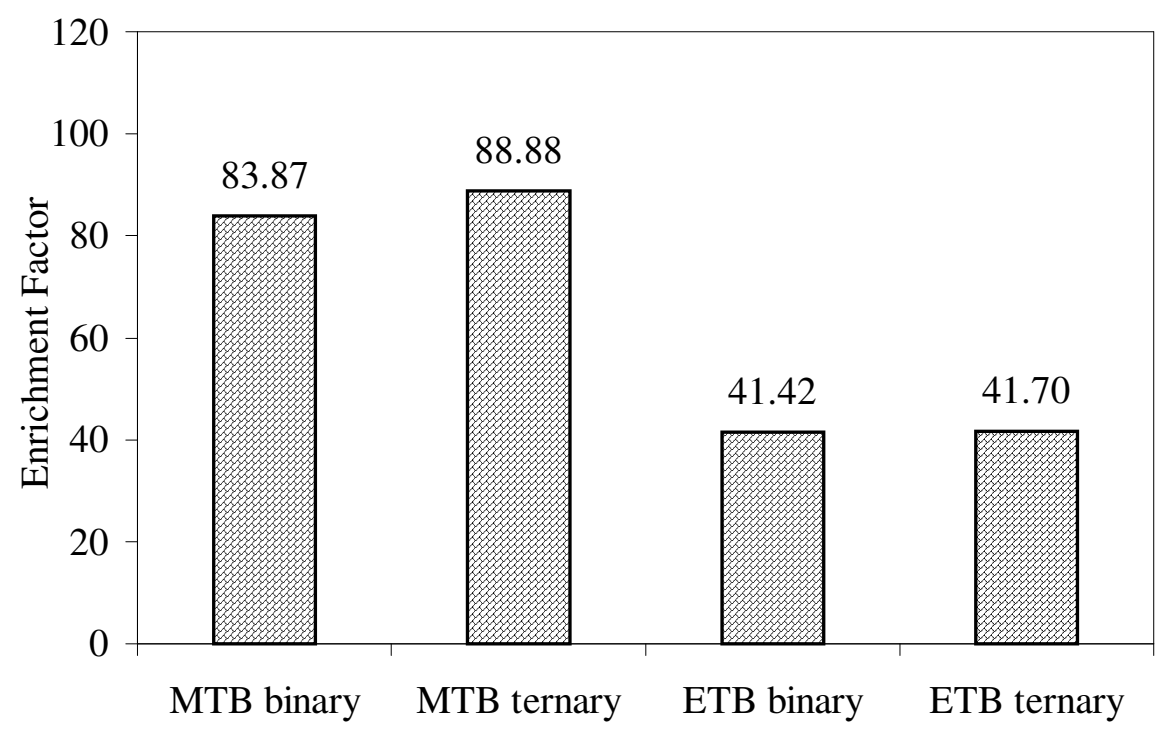

Figure 3.16 Comparison of enrichment factors in binary and ternary systems at $50{ }^{\circ} \mathrm{C}, 4$ mbar 


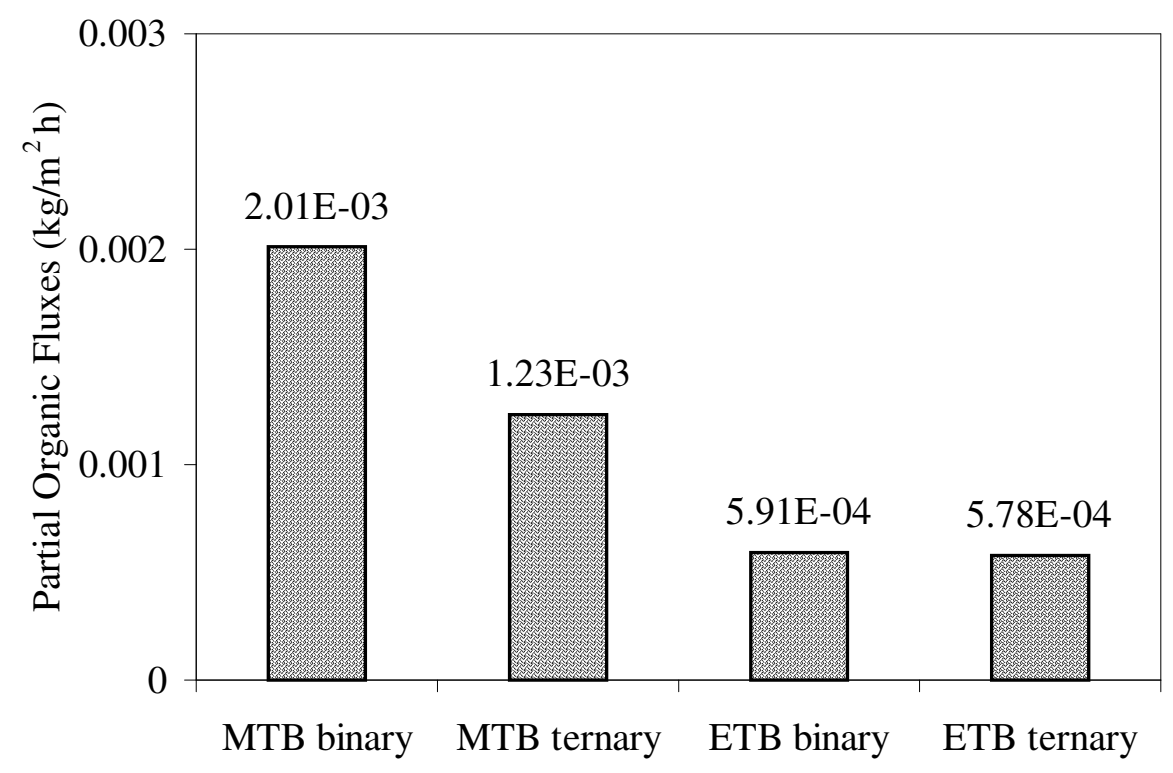

Figure 3.17 Comparison of partial organic fluxes in binary and ternary solutions at $50^{\circ} \mathrm{C}, 4$ mbar

\subsubsection{Pervaporation Performance in Strawberry Essence and Model Strawberry Solution}

In this part of the study, a strawberry essence was used in order to check the behavior of the membrane on a real solution instead of model solutions. First the aroma compounds in the essence were identified using GCMS. Unexpectedly, there were only two aroma compounds identified in the essence. Besides the aroma compounds ethyl butyrate (ETB) and methyl caproate (MTC), there were so many unknown substances detected. Although those unknown substances were found in the essence solution, the permeate did 
not contain any substances other than aroma compounds (ETB, MTC). Therefore, we have concluded that, those unknown substances may be the compounds having very high molecular weights such as oils which are added in order to solve and keep the aroma compounds inside the essence matrix. The enrichment factors of the aroma compounds for strawberry essence can be seen in Figure 3.18. It seems that the selectivity of the membrane towards ETB is much higher than MTC, however, while we are considering the selectivities we should always keep in mind the influence of impermeable components on the permeation of organic molecules.

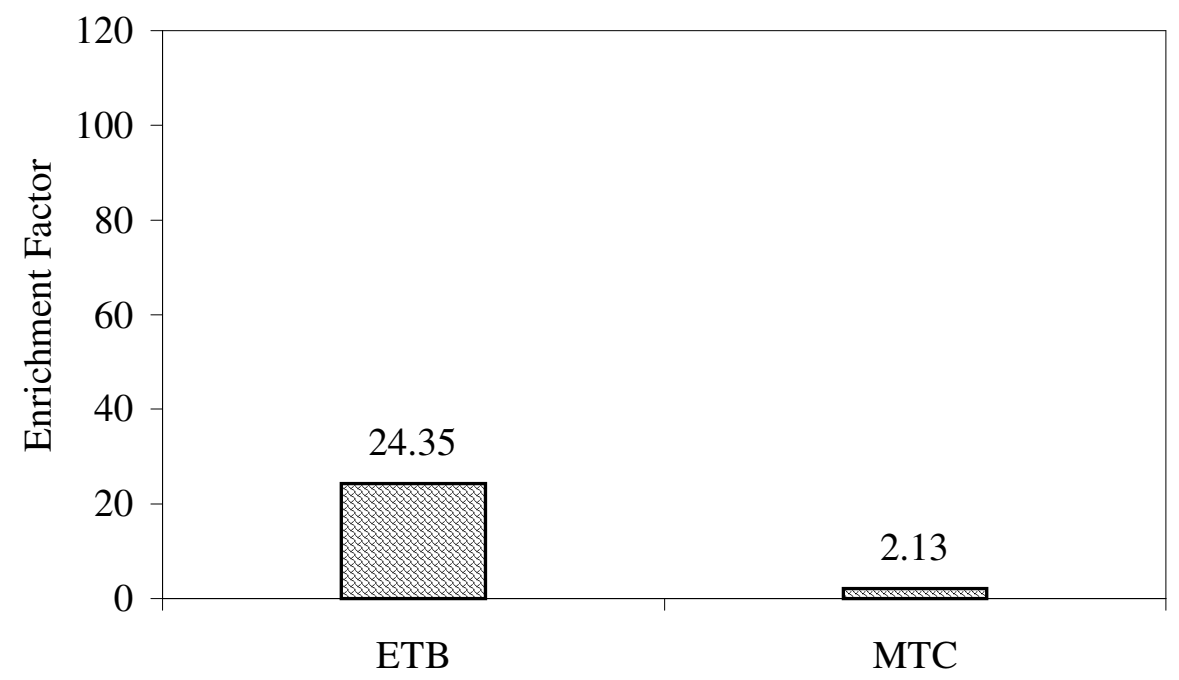

Figure 3.18 Enrichment factors of organic compounds for strawberry essence at $50^{\circ} \mathrm{C}, 4$ mbar $\mathrm{ETB}=$ ethyl butyrate, $\mathrm{MTC}=$ methyl caproate 
Final experiment had been performed with a model strawberry solution containing 6 aroma compounds (methyl butyrate, ethyl butyrate, butyl butyrate, methyl caproate, ethyl caproate and linalool).

Figure 3.19 shows the enrichment factors of the 6 aroma compounds. The interactions between the aroma compounds is a complex phenomena, nevertheless it can be concluded that the presence of other aroma compounds have affected the selectivities of MTB and ETB, negatively due to coupling effects. Flux coupling takes place when a permeant of low diffusivity ("slower" permeant) is dragged through the membrane polymer by a permeant of higher diffusivity ('faster" permeant), resulting in higher fluxes of the slower permeant than expected. The opposite might also happen, i.e., the slowing down of the diffusion of the faster permeant by the slower one (Schafer and Crespo, 2002). Moreover, low selectivity of the membrane towards BTB and ETC can be contributed to their higher molecular weights (Table 2.1) among the esters, studied. Furthermore, Linalool had also low enrichment factor as compared to esters. Generally the esters exhibit higher enrichment factors as compared to alcohols. This trend was also observed by other researchers (Bengsten et al., 1992; Borjesson et al., 1996). The total mass fluxes were 0.156 and $0.175 \mathrm{~kg} / \mathrm{m}^{2} \cdot \mathrm{h}$ for strawberry essence and model strawberry solution, respectively. 


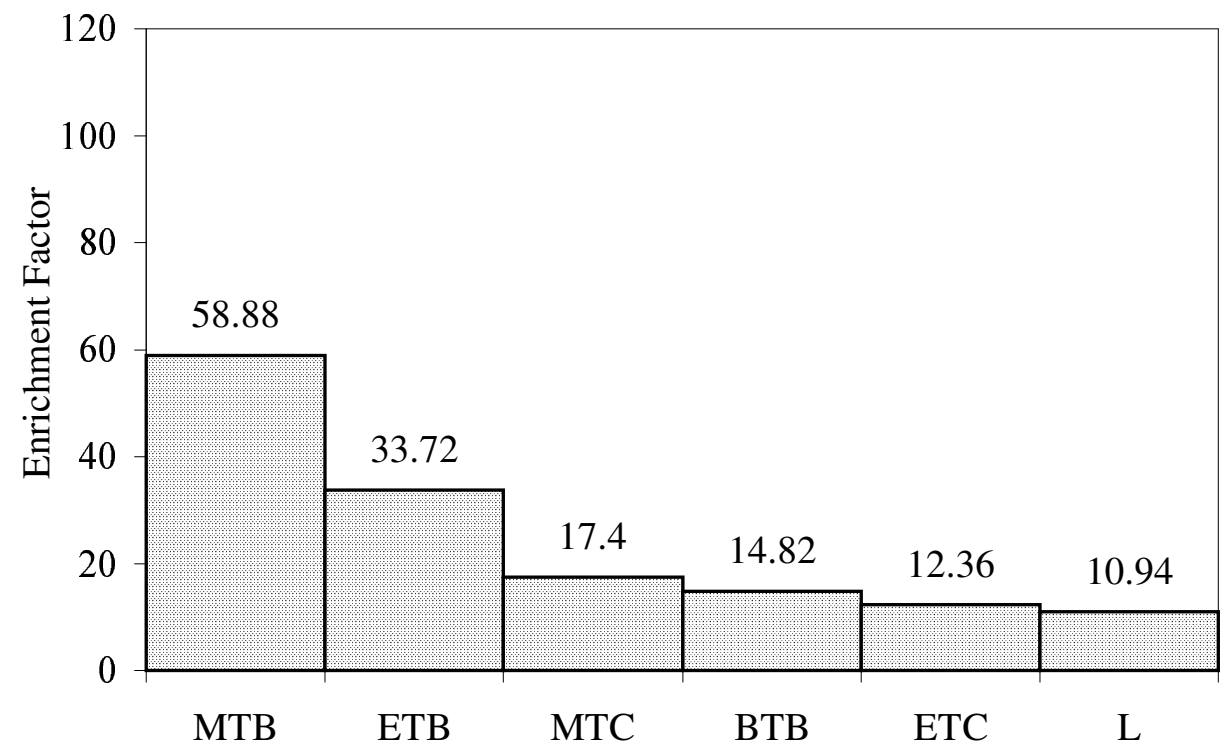

Figure 3.19 Enrichment factors of organic compounds for model strawberry solution at $50^{\circ} \mathrm{C}, 4$ mbar

$\mathrm{MTB}=$ methyl butyrate, $\mathrm{ETB}=$ ethyl butyrate, $\mathrm{MTC}=$ methyl caproate, $\mathrm{BTB}$ = butyl butyrate, $\mathrm{ETC}=$ ethyl caproate, $\mathrm{L}=$ linalool 


\section{CHAPTER 4}

\section{CONCLUSION \& RECOMMENDATIONS}

In the optimization of extraction conditions of SPME, it was found that the general behavior of aroma compounds was that, the peak area, which is related with the amount of aroma compound extracted, increased as the extraction temperature increased, but started to decrease after a point where the distribution constant decreased. Agitation speed increased the amount of analyte absorbed and showed a maximum at $50 \%$ of maximum agitation speed. Moreover, the optimum extraction time could be determined by defining the point where the compound reached equilibrium. No matrix effect had been observed and the optimum SPME extraction conditions for strawberry aroma compounds, was found as 30 minute at $40^{\circ} \mathrm{C}$ and $700 \mathrm{rpm}$ when $100 \mu \mathrm{m}$ PDMS fiber was used.

For pervaporation experiments, it can be concluded that as the feed temperature increased, total, organic and water fluxes increased linearly and followed an Arrhenius type relation. Selectivity also increased as the feed temperature increased, then it remained constant at 40 and $50^{\circ} \mathrm{C}$, where the increase in water flux was in the same portion with the organic flux.

At lower permeate pressures both fluxes and selectivities were higher. Moreover, as the feed concentration increased, the total mass flux and water flux did not change considerably, while the partial organic fluxes increased linearly. The selectivities decreased over the range of studied feed concentration. 
The selectivity of PERVAP 1070 was higher towards MTB in both binary and ternary solutions, and the presence of ETB adversely affected the partial organic flux of MTB in ternary solution. In addition, it was seen that the selectivities of MTB and ETB decreased in the presence of other strawberry aroma compounds due to coupling effects.

The strawberry essence, studied, contained two aroma compounds, namely ethyl butyrate and methyl caproate, and the presence of impermeable components might have affected the selectivities.

Pervaporation can be recommended for the enrichment of strawberry flavors. Further researches may be done with a real strawberry juice in order to determine the behaviors of the membrane and the pervaporation set-up under realistic circumstance. Different membranes can be tried and compared in terms of their fluxes and selectivities. 


\section{REFERENCES}

Arthur, C. L., Killam, L. M., Buchholz, K. D., and Pawliszyn, J. (1992). Automation and optimization of solid-phase microextraction, Anal. Chem., 64(17): 1960-1966.

Bartelt, R. J. (1997). Calibration of a commercial solid-phase microextraction device for measuring headspace concentrations of organic volatiles, Anal. Chem., 6(3): 364-372.

Baudot, A., and Marin, M. (1996). Dairy aroma compounds recovery by pervaporation, J. Membr. Sci., 120: 207-220.

Bengtsson, E., Tragardh, G., and Hallstrom, B. (1992). Concentration of apple juice aroma from evaporaotr condensate using pervaporation, Lebens. Wiss. Technol., 25: 29-34.

Blanch, G. P., Reglero, G., Herraiz, M., and Tabera, J. (1991). A comparison of different extraction methods for the volatile components of grape juice, $J$. Chrom. Sci., 29: 11-15.

Bomben, J. L., Kitson, J. A., and Morgan, A. I. Jr. (1973). Aroma recovery and retention in concentration and drying of foods, In Advances in Food Research, ed. C. O. Chichester, Academic Press, New York, USA, pp. 1-111. 
Borjesson, J., Karlsson, H. O. E., and Tragardh, G. (1996). Pervaporation of a model apple juice aroma solution: comparison of membrane performance, $J$. Membr. Sci., 119: 229-239.

Böddeker, K., and Bengtson G. (1991). Selective pervaporation of organic from water, In Pervaporation Membrane Separation Processes, ed. R. Y. M. Huang, Elsevier, Amsterdam, The Netherlands, pp. 437-460.

Brüschke, H. E. A. (2001). State-of-Art of pervaporation process in the chemical industry, In Membrane Technology in the Chemical Industry, ed. S. P. Nunes and K. V. Peinemann, Wiley-VCH, USA, pp. 127-172.

Brüschke, H. E. A. (1990). Removal of ethanol from aqueous streams by pervaporation, Desalination, 77: 323-329.

Bundschuh, E., Tylla, M., Baumann, G., and Griescher, K. (1986). Gewinnung von natürlichen aromen aus reststoffen der lebensmittelproduktion mit hilfe der $\mathrm{CO}_{2}$-hochdruckextraktion, Lebensmittel-Wissenschaft und Technologie, 19: 493-496.

Colombo, E. (1983). Progress in technologies of aroma recovery and purification, In Progress in Food Engineering, Proceedings of a European Symposium of the Food Working Party of the E.F.C.E., ed. C. Cantarelli and C. Peri, pp. 507-518.

Escoudier, J. L., Le Bouar, M., Moutounet, M., Jouret, C., and Barillere, J. M. (1988). Application and evaluation of pervaporation for production of low alchol wines, In Proceedings of the Third International Conference on 
Pervaporation Processes in the Chemical Industry, ed. R. Bakish, Bakish Materials Corporation, Englewood, NJ, USA, pp. 387-397.

Furton, K. G., Almirall, J. R., and Bruna J. (1995). A Simple, inexpensive, rapid, sensitive, and solventless method for the recovery of accelerants from fiber debris based on SPME, J. High Resol. Chrom., 18: 625-629.

Geankoplis, C. J. (1993). Transport Processes and Unit Operations, $3^{\text {rd }}$ ed., Prentice-Hall Inc., New Jersey, USA.

Ghodsizadeh, Y. (1986). Cryogenic aroma recovery, European patent, EP 0 201698 A1.

Giovanni, F. (1995). Fenaroli's Handbook of Food Flavor Ingredients, ed. G. A. Burdock, CRC Press, Boca Raton, FL, USA.

Gurulke, E. A. (1975). Solubility parameter values, In Polymer Handbook, ed. J. Brandrup and E. H. Immergut, John Wiley and Sons, New York, USA, pp: 526.

Hall, R. L. (1968). Food flavors: benefits and problems, Food Technol., 22: 1388-1392.

Hasting, A. P. M. (1978). A recent development in essence recovery, International Federation of Fruit Juice producers, Scientific Technical Commission, 15: 125-140. 
Hennepe, H. J. C. te, Bargeman, D., Mulder, M. V. H., and Smolders, C. A. (1987). Zeolite-filled silicone rubber membranes. Part1. Membranes preparation and pervaporation results, J. Membr. Sci., 35: 39-55.

Holt, R. U. (2001). Mechanisms effecting analysis of volatile flavor components by solid-phase microextraction and gas chromatography, $J$. Chromatogr. A, 937(1-2): 107-114.

Howel, J. A., Sanchez, V., and Field, R. W. (1993). Membranes in Bioprocessing, Chapman and Hall, Cambridge, UK, pp: 294-321.

Huang, R. Y. M. (1991). Pervaporation membrane separation processes, Elsevier Science Publishers, Amsterdam, The Netherlands.

Inal, M. (2003). Ethyl lactate production by hybrid processes: Determination of phase diagrams and evaluation of performance of ogranophilic pervaporation membranes, Master's thesis, Middle East Technical University, Department of Chemical Engineering, Ankara.

Jiraratananon, R., Sampranpiboon, P., Uttapap, D., and Huang, R. Y. M. (2002). Pervaporation separation and mass transport of ethyl butyrate solution by polyether block amide (PEBA) membranes, J. Membr. Sci., 210: 389-409.

Kanani, D. M., Nikhade, B. P., Balakrishnan, P., Singh, G., and Pangarkar, V. G. (2003). Recovery of Valuable Tea Aroma Components by Pervaporation, Ind. Eng. Chem. Res., 42: 6924-6932. 
Karlsson, H. O. E., and Tragardh, G. (1993). Aroma compound recovery with pervaporation-feed flow effects, J. Membr. Sci., 81: 163-171.

Karlsson, H. O. E., Loureiro, S., and Tragardh G. (1994). Aroma compound recovery with pervaporation-Temperature effects during pervaporation of a muscat wine, J Food Eng., 26: 177-191.

Kataoka, H., Lord, H. L., and Pawliszyn, J. (2000). Applications of solid-phase microextraction in food analysis, J. Chromatogr. A, 880(1-2): 35-62.

Kimmerle, K., and Gudernatsch W. (1991). Pilot Dealcoholizaiton of beer by pervaporation, In Proceedings of the Fifth International Conference on Pervaporation Processes in the Chemical Industry, ed. R. Bakish, Bakish Materials Corporation, Englewood, NJ, USA, pp. 291-307.

Kober, P. A. (1917). Pervaporation, Perstillation, and Percrystallisation, J. Amer. Chem. Soc., 39: 9444.

Kok, M. F., Yong, F. M., and Lim, G. (1987). Rapid extraction method for reproducible analysis of aroma volatiles, J. Agric. Food Chem., 35: 779-781.

Koops, G. H., and Smolders, C. A. (1991). Estimation and evaluation of polymeric materials for pervaporation membranes, In Pervaporation Membrane Separation Processes, ed. R. Y. M. Huang, Elsevier, Amsterdam, The Netherlands, pp. 253-278.

Korkut, S. (2001). Ethyl lactate production by hybrid processes: evaluation of performance of hydrophilic pervaporation membranes for ethyl lactate-water- 
ethanol mixtures, Master's Thesis, Middle East Technical University, Department of Chemical Engineering Department, Ankara.

Köseoglu, S. S., Hernandez, E., Shah, V., and Tuohey, D. (1995). Opportunities for pervaporation: processing edible oils and fats, In Proceedings of the Seventh International Conference on Pervaporation Processes in the Chemical Industry, ed. R. Bakish, Bakish Materials Corporation, Englewood, NJ, USA, pp. 263-270.

Lamer, T., Rohart, M. S., Voilley, A., and Baussart H. (1994). Influence of sorption and diffusion of aroma compounds in silicone rubber on their extraction by pervaporation, J. Membr. Sci., 90:2541-263.

Lipnizkki, F., Hausmanns, S., Ten, P., Field, R. W., and Laufenberg, G. (1999). Organophilic pervaporation: prospects and performance, Chem. Eng. J., 73: 113-129.

Lipnizki, F., Olsson, J., and Tragardh, (2002a). G. Scale-up of pervaporation for the recovery of natural aroma compounds in the food industry. Part 1: Simulation and performance, J. Food Eng., 54: 183-195.

Lipnizki., F., Olsson, J., and Tragardh, G. (2002b). Scale-up of pervaporation for the recovery of natural aroma compounds in the food industry. Part 2: Integration and optimization, J. Food Eng., 54: 197-205.

Louch, D., Motlagh, S., and Pawliszyn, J. (1992). Dynamics of organic compound extraction from water using liquid-coated fused silica fibers, Anal. Chem., 64: 1187-1199. 
Macku, C., and Jennings, W. G. (1987). Production of volatiles by ripening bananas, J. Agric. Food Chem., 35: 845-848.

Mark, J. E. (1984). Physical Properties of Polymer, ACS, Washington, DC, USA.

Miszczak, A., Forney, Ch.F., and Prange, R. K. (1995). Development of aroma volatiles and color during post harvest ripening of "Kent" strawberries, Amer. Soc. Hort. Sci J., 120: 650-655.

Néel, J. (1991). Introduction to pervaporation, In Pervaporation Membrane Separation Processes, ed. R. Y. M. Huang, Elsevier, Amsterdam, The Netherlands, pp: 1-109.

Olsson, J., and Tragardh, G. (1999). Influence of feed flow velocity on pervaporative aroma recovery from a model solution of apple juice aroma compounds, J. Food Eng., 39: 107-115.

Olsson, J., Tragardh, G., and Lipnizki, F. (2002). The influence of permeant and membrane properties on mass transfer in pervaporation of volatile organic compounds from dilute organic solutions, Sep. Sci. Tech., 37: 1199-1223.

Palmer, M. V., and Ting, S. S. T. (1995). Applications of supercritical fluid technology in food processing, Food Chem., 52: 345-352.

Pawliszyn, J. (1997). Solid Phase Microextraction Theory and Practice, Wiley-VCH, USA. 
Peng, M., and Liu, S. X. (2003). Recovery of Aroma compounds from dilute model blueberry solution by pervaporation, J. Food Sci., 68: 2706-2710.

Pereira, C. C., Rufino, J. M., Habert, A. C., Nobrega, R., Cabral, L. M. C., and Borges, C. P. (2002). Membrane for processing tropical fruit juice, Desalination 148: 57-60.

Poll, L. (1983). Influence of storage temperature on sensory evaluation and composition of volatiles of McIntosh apple juice, Lebensmittel-, Wissenschaft und Technologie, 16: 220-223.

Raasch, A., and Knorr, D. (1990). Supercritical extraction of flavour compounds from peel and pulp of passion fruit (Passiflora edulis Sims), Food Biotech., 4: 1-485.

Rajagopalan, N., and Cheryan, M. (1995). Pervaporation of grape juice aroma, J. Membr. Sci., 104: 243-250.

Reid, R. C., Prausnitz, J. M., and Poling B. E. (1987). Properties of Gaseous and Liquids, $4^{\text {th }}$ Ed., McGraw-Hill, New York, USA, pp: 52-55.

Rodriguez-Bencomo, J. J., Conde, J. E., Rodriguez-Delgado, M. A., GarciaMontelongo, F., and Perez-Trujillo, J. P. (2002). Determination of esters in dry and sweet white wines by headspace solid-phase microextraction and gas chromatography, J. Chromatog. A, 963(1-2): 213-223.

Sampranpiboon, P., Jiraratananon R., Uttapap, D., Feng, X., and Huang, R. Y.M. (2000). Separation of aroma compounds from aqueous solutions by 
pervaporation using polyoctylmethyl siloxane (POMS) and polydimethyl siloxane (PDMS) membranes, J. Membr. Sci., 174: 55-65.

Schafer, T., Bentson, G., Pingel, H., Boddeker, K. W., and Crespo J. P. S. G. (1999). Recovery of aroma compounds from a wine-must fermentation by ogranophilic pervaporation, Biotechnol. Bioeng., 62: 412-421.

Schafer, T., and Crespo, J. G. (1997). Recovery of aromas by pervaporation, ESMST XIVth Annual Summer School, Membrane integration in clean processes. Lisbon Instituto: Superior Tecnico, IST.

Schafer, T., and Crespo, J. G. (2002). Mass transport phenomena during the recovery of volatile compounds by pervaporation, In Transport Phenomena in Food Processing, ed. J. Welti-Chanes, J. F. Velez-Ruiz and G.V. BarbosaCanovas, CRC Press, Florida, USA, pp: 247-263.

Scherz, H., and Senser, F. (1994). Souci-Fachman-Kraut / Food Composition and Nutrition Tables, (5th. ed.) Medpharm Scientific Publisher, CRC Press Stuttgart: Boca Raton, (pp. )

Schieberle, P., and Hofmann, T. (1997). Evaluation of the character impact odorants in fresh strawberry juice by quantitative measurements and sensory studies on model mixtures, J. Agric. Food Chem., 45: 227-232.

Schultz, W. G., and Randall, J. M. (1970). Liquid carbon dioxide for selective aroma extraction, Food Tech., 24: 1282-1286. 
Shepherd, A., Habert, A. C., and Borges, C. P. (2002). Hollow fiber modules for orange juice aroma recovery using pervaporation, Desalination, 148: 111114.

Song, J., Fan, L., and Beaudry, R. M. (1998). Application of solid-phase microextraction and gas chromatography/time-of-flight mass spectrometry for rapid analysis of flavor volatiles in tomato and strawberry fruits, J. Agric. Food Chem., 46: 3721-3726.

Sonsuzer, S., Sahin, S., Yilmaz, L. (2004). Optimization of supercritical $\mathrm{CO}_{2}$ extraction of Tymbra spicata oil, J. Supercritical Fluids, 30:189-199.

Temelli, F., Chen, C. S., and Braddock, R. J. (1988). Supercritical fluid extraction in citrus oil processing, Food Tech., 42: 145-150.

Verheoeven, H., Beuerle, T., and Schwab, W. (1997). Solid-phase microextraction: artefact formation and its avoidance, Chromatographia, 46(12): $63-66$.

Zabetakis, I., and Holden, M. A. (1997). Strawberry flavor: analysis and biosynthesis, J. Sci. Food Agric., 74: 421-434. 


\section{APPENDIX A}

\section{PERVAPORATION DATA}

Table A.1 Pervaporation data for $100 \mathrm{ppm}$ MTB solution at $30^{\circ} \mathrm{C} 4 \mathrm{mbar}$

\begin{tabular}{ccc}
\hline Time(hour) & Flux $\left(\mathrm{kg} / \mathrm{m}^{2} \mathrm{~h}\right)$ & Selectivity \\
2 & 0.129 & - \\
4 & 0.041 & 20.63 \\
6 & 0.041 & 22.37 \\
8 & 0.041 & 27.97 \\
10 & 0.044 & 43.63 \\
12 & 0.040 & 37.84 \\
14 & 0.041 & 32.98 \\
& & \\
Avrg of st st & 0.041 & 32.95 \\
SE & $\pm 6.78 * 10^{-4}$ & \pm 3.71 \\
\hline
\end{tabular}


Table A.2 Pervaporation data for $100 \mathrm{ppm}$ MTB solution at $30^{\circ} \mathrm{C} 8 \mathrm{mbar}$

\begin{tabular}{ccc}
\hline Time(hour) & Flux $\left(\mathrm{kg} / \mathrm{m}^{2} \mathrm{~h}\right)$ & Selectivity \\
2 & 0.099 & - \\
4 & 0.034 & 10.76 \\
6 & 0.034 & 25.62 \\
8 & 0.031 & 20.04 \\
10 & 0.036 & 24.98 \\
12 & 0.034 & 27.65 \\
14 & 0.031 & 24.73 \\
& & \\
Avrg of st st & 0.033 & 24.60 \\
SE & $\pm 9.70 * 10^{-4}$ & \pm 1.25 \\
\hline
\end{tabular}


Table A.3 Pervaporation data for $100 \mathrm{ppm}$ MTB solution at $40^{\circ} \mathrm{C} 4 \mathrm{mbar}$

\begin{tabular}{ccc}
\hline Time(hour) & Flux $\left(\mathrm{kg} / \mathrm{m}^{2} \mathrm{~h}\right)$ & Selectivity \\
2 & 0.176 & - \\
4 & 0.109 & 68.60 \\
6 & 0.112 & 83.02 \\
8 & 0.110 & 78.18 \\
10 & 0.112 & 86.29 \\
12 & 0.104 & 73.43 \\
14 & 0.105 & 77.19 \\
& & \\
Avrg of st st & 0.109 & 79.62 \\
SE & $\pm 1.72 * 10^{-3}$ & \pm 2.26 \\
\hline
\end{tabular}


Table A.4 Pervaporation data for $100 \mathrm{ppm}$ MTB solution at $40^{\circ} \mathrm{C}, 8 \mathrm{mbar}$

\begin{tabular}{ccc}
\hline Time(hour) & Flux $\left(\mathrm{kg} / \mathrm{m}^{2} \mathrm{~h}\right)$ & Selectivity \\
2 & 0.128 & - \\
4 & 0.098 & 60.88 \\
6 & 0.094 & 70.91 \\
8 & 0.095 & 85.33 \\
10 & 0.096 & 83.78 \\
12 & 0.091 & 73.21 \\
14 & 0.091 & 74.53 \\
& & \\
Avrg of st st & 0.093 & 77.55 \\
SE & $\pm 1.029 * 10^{-3}$ & \pm 2.92 \\
\hline
\end{tabular}


Table A.5 Pervaporation data for $100 \mathrm{ppm}$ MTB solution at $50^{\circ} \mathrm{C} 4 \mathrm{mbar}$

\begin{tabular}{ccc}
\hline Time(hour) & Flux $\left(\mathrm{kg} / \mathrm{m}^{2} \mathrm{~h}\right)$ & Selectivity \\
2 & 0.249 & - \\
4 & 0.258 & 55.5 \\
6 & 0.248 & 71.89 \\
8 & 0.241 & 90.46 \\
10 & 0.235 & 83.83 \\
12 & 0.247 & 88.13 \\
14 & 0.235 & 85.01 \\
& & \\
Avrg of st st & 0.241 & 83.86 \\
SE & $\pm 2.8 * 10^{-3}$ & \pm 3.21 \\
\hline
\end{tabular}


Table A.6 Pervaporation data for $100 \mathrm{ppm}$ MTB solution at $50^{\circ} \mathrm{C}, 8 \mathrm{mbar}$

\begin{tabular}{ccc}
\hline Time(hour) & Flux $\left(\mathrm{kg} / \mathrm{m}^{2} \mathrm{~h}\right)$ & Selectivity \\
2 & 0.204 & - \\
4 & 0.200 & 40.12 \\
6 & 0.211 & 67.04 \\
8 & 0.196 & 72.99 \\
10 & 0.194 & 71.77 \\
12 & 0.193 & 72.87 \\
14 & 0.203 & 74.22 \\
& & \\
Avrg of st st & 0.199 & 71.78 \\
SE & $\pm 3.39 * 10^{-3}$ & \pm 1.25 \\
\hline
\end{tabular}


Table A.7 Pervaporation data for $50 \mathrm{ppm}$ MTB solution at $50^{\circ} \mathrm{C}, 4 \mathrm{mbar}$

\begin{tabular}{ccc}
\hline Time(hour) & Flux $\left(\mathrm{kg} / \mathrm{m}^{2} \mathrm{~h}\right)$ & Selectivity \\
2 & 0.84 & - \\
4 & 0.243 & 62.30 \\
6 & 0.248 & 91 \\
8 & 0.243 & 82 \\
10 & 0.245 & 94.67 \\
12 & 0.237 & 101.21 \\
14 & 0.233 & 91.21 \\
& & \\
Avrg of st st & 0.2412 & 92.018 \\
SE & $\pm 2.73 * 10^{-3}$ & \pm 3.11 \\
\hline
\end{tabular}


Table A.8 Pervaporation data for $150 \mathrm{ppm}$ MTB solution at $50^{\circ} \mathrm{C}, 4 \mathrm{mbar}$

\begin{tabular}{ccc}
\hline Time(hour) & Flux $\left(\mathrm{kg} / \mathrm{m}^{2} \mathrm{~h}\right)$ & Selectivity \\
2 & 0.304 & - \\
4 & 0.268 & 50.51 \\
6 & 0.261 & 63.72 \\
8 & 0.277 & 85.8 \\
10 & 0.261 & 85.95 \\
12 & 0.252 & 82.75 \\
14 & 0.254 & 79.2 \\
& & \\
Avrg of st st & 0.261 & 79.555 \\
SE & $\pm 4.39 * 10^{-3}$ & \pm 4.13 \\
\hline
\end{tabular}


Table A.9 Pervaporation data for $50 \mathrm{ppm}$ ETB solution at $50^{\circ} \mathrm{C}, 4 \mathrm{mbar}$

\begin{tabular}{ccc}
\hline Time(hour) & Flux $\left(\mathrm{kg} / \mathrm{m}^{2} \mathrm{~h}\right)$ & Selectivity \\
2 & 0.170 & - \\
4 & 0.166 & 36.74 \\
6 & 0.165 & 54.79 \\
8 & 0.150 & 51.61 \\
10 & 0.153 & 55.87 \\
12 & 0.152 & 53.67 \\
14 & 0.153 & 53.20 \\
& & \\
Avrg of st st & 0.1546 & 53.828 \\
SE & $\pm 2.76^{*} 10^{-3}$ & \pm 0.72 \\
\hline
\end{tabular}


Table A.10 Pervaporation data for $100 \mathrm{ppm}$ ETB solution at $50^{\circ} \mathrm{C}, 4 \mathrm{mbar}$

\begin{tabular}{ccc}
\hline Time(hour) & Flux $\left(\mathrm{kg} / \mathrm{m}^{2} \mathrm{~h}\right)$ & Selectivity \\
2 & 0.153 & - \\
4 & 0.144 & 23.44 \\
6 & 0.149 & 46.14 \\
8 & 0.143 & 39.07 \\
10 & 0.145 & 42.84 \\
12 & 0.139 & 37.61 \\
14 & 0.139 & 41.99 \\
& & \\
Avrg of st st & 0.143 & 41.53 \\
SE & $\pm 1.90 * 10^{-3}$ & \pm 1.49 \\
\hline
\end{tabular}


Table A.11 Pervaporation data for $150 \mathrm{ppm}$ ETB solution at $50^{\circ} \mathrm{C}, 4 \mathrm{mbar}$

\begin{tabular}{ccc}
\hline Time(hour) & Flux $\left(\mathrm{kg} / \mathrm{m}^{2} \mathrm{~h}\right)$ & Selectivity \\
2 & 0.163 & - \\
4 & 0.143 & 20.38 \\
6 & 0.138 & 37.72 \\
8 & 0.143 & 35.43 \\
10 & 0.146 & 41.21 \\
12 & 0.140 & 32.72 \\
14 & 0.145 & 37.22 \\
& & \\
Avrg of st st & 0.1424 & 36.86 \\
SE & $\pm 1.50 * 10^{-3}$ & \pm 1.4 \\
\hline
\end{tabular}


Table A.12 Pervaporation data for 100 ppm MTB and 100 ppm ETB solution at $50^{\circ} \mathrm{C}, 4 \mathrm{mbar}$

\begin{tabular}{cccc}
\hline Time(hour) & Flux $\left(\mathrm{kg} / \mathrm{m}^{2} \mathrm{~h}\right)$ & Enrich. MTB Enrich. ETB \\
2 & 0.182 & - & - \\
4 & 0.143 & 56.25 & 22.22 \\
6 & 0.140 & 86 & 44.24 \\
8 & 0.142 & 85.95 & 38.67 \\
10 & 0.139 & 90.67 & 39.42 \\
12 & 0.142 & 91.32 & 45.26 \\
14 & 0.138 & 90.48 & 41.13 \\
& & & \\
Avrg of st st & 0.140 & 88.88 & 41.70 \\
SE & $\pm 8.00 * 10^{-4}$ & \pm 1.19 & \pm 1.30 \\
\hline
\end{tabular}


Table A.13 Pervaporation data for strawberry essence at $50^{\circ} \mathrm{C}, 4 \mathrm{mbar}$

\begin{tabular}{cccc}
\hline Time(hour) & Flux $\left(\mathrm{kg} / \mathrm{m}^{2} \mathrm{~h}\right)$ & $\begin{array}{c}\text { Enrichment } \\
\text { ETB }\end{array}$ & $\begin{array}{c}\text { Enrichment } \\
\text { MTC }\end{array}$ \\
2 & 0.235 & - & - \\
4 & 0.156 & 10.66 & 1.01 \\
6 & 0.155 & 23.02 & 2.22 \\
8 & 0.16 & 25.13 & 2.18 \\
10 & 0.155 & 21.3 & 2.02 \\
12 & 0.156 & 26.82 & 2.15 \\
14 & 0.152 & 22.33 & 2.1 \\
16 & 0.157 & 27.51 & 2.08 \\
& & & \\
Avrg of st.st. & 0.156 & 24.35 & 2.13 \\
SE & $\pm 1.08 * 10^{-3}$ & \pm 1.03 & \pm 0.030 \\
\hline
\end{tabular}


Table A.14 Pervaporation data for strawberry model strawberry solution at $50^{\circ} \mathrm{C}, 4$ mbar (100ppm each compound)

\begin{tabular}{cccccccc}
\hline Time & Flux & Enrich. & Enrich. & Enrich. & Enrich. & Enrich. & Enrich. \\
(hour) & $\left(\mathrm{kg} / \mathrm{m}^{2} \mathrm{~h}\right)$ & MTB & ETB & MTC & BTB & ETC & L \\
2 & 0.210 & - & - & - & - & - & - \\
4 & 0.184 & 30.75 & 20.25 & 10.22 & 11.79 & 8.95 & 7.78 \\
6 & 0.177 & 50.85 & 31.20 & 15.38 & 16.56 & 10.24 & 10.84 \\
8 & 0.175 & 52.13 & 39.86 & 16.58 & 13.27 & 11.25 & 11.24 \\
10 & 0.173 & 55.61 & 32.43 & 19.64 & 15.49 & 13.65 & 9.28 \\
12 & 0.176 & 54.13 & 34.64 & 20.77 & 14.74 & 12.20 & 12.65 \\
14 & 0.172 & 51.66 & 30.45 & 14.63 & 14.03 & 14.45 & 10.70
\end{tabular}

\begin{tabular}{cccccccc}
$\begin{array}{c}\text { Avrg of } \\
\text { st.st. }\end{array}$ & 0.175 & 52.88 & 33.72 & 17.40 & 14.82 & 12.36 & 10.94 \\
SE & $\pm 9.28 * 10^{-4}$ & \pm 0.87 & \pm 1.69 & \pm 1.20 & \pm 0.57 & \pm 0.77 & \pm 0.54 \\
\hline
\end{tabular}




\section{APPENDIX B}

\section{GC ANALYSIS}

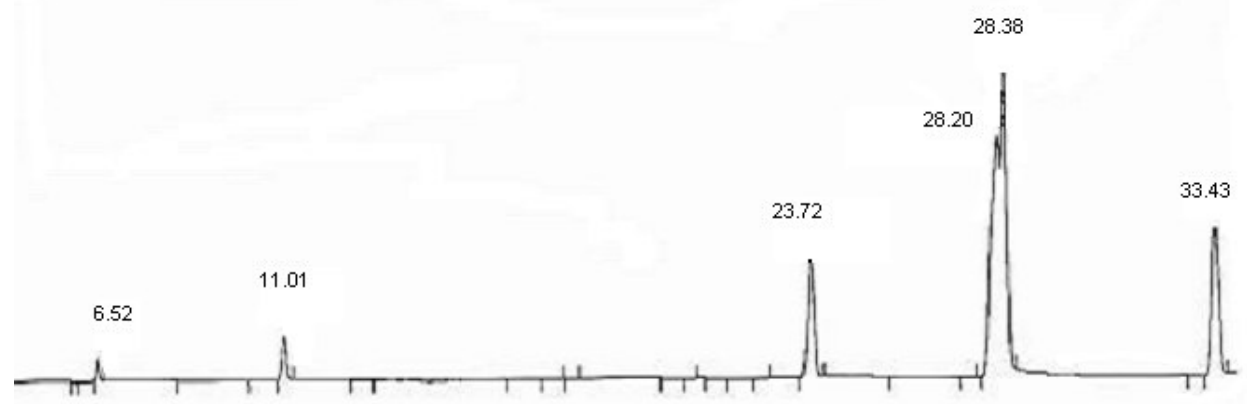

Figure B.1 Chromatogram of strawberry aroma compounds 